Aprendizado de máquina parcialmente supervisionado multidescrição para realimentação de relevância em recuperação de informação na $W E B$

Matheus Victor Brum Soares 



\section{Aprendizado de máquina parcialmente supervisionado multidescrição para realimentação de relevância em recuperação de informação na WEB}

Matheus Victor Brum Soares

Orientadora: $\operatorname{Prof}^{a} \operatorname{Dr}^{\mathrm{a}}$ Maria Carolina Monard

Dissertação apresentada ao Instituto de Ciências Matemáticas e de Computação - ICMC-USP, como parte dos requisitos para obtenção do título de Mestre em Ciências da Computação e Matemática Computacional. 



\section{Dedicatória}

Dedico este trabalho às pessoas que amo, em especial minha família. E dedico a todos que me ajudaram durante toda essa jornada até aqui. 


\section{Agradecimentos}

Agradeço a todos que ajudaram no desenvolvimento deste trabalho, em especial à minha orientadora $\operatorname{Prof}^{\mathrm{a}} \mathrm{Dr}^{\mathrm{a}}$ Maria Carolina Monard, e ao Prof Dr Ronaldo Cristiano Prati que foram as pessoas que mais me ajudaram durante todo meu projeto de Mestrado.

Agradeço também ao voluntários que ajudaram com sucesso a testar o sistema implementado neste trabalho: Adriano Soares, André Lorenço, Fábio Kunoh, Gustavo Frade, Hugo Cardoso, Humberto Amaral, Ígor Braga, Jackson Soares, Jorge Cutigi, Marcelo Barbosa, Mateus Miranda, Paula Perin, Roberto Ferrero, minha orientadora $\operatorname{Prof}^{\mathrm{a}} \operatorname{Dr}^{\mathrm{a}}$ Maria Carolina Monard, meu pai Lúcio Soares, meu irmão Fellipe Soares, entre outros que não se identificaram e/ou não realizaram o teste com exatidão. Também agradeço ao Rafael Giusti por auxiliar na edição de algumas imagens, e algumas dicas.

Trabalho realizado com auxílio do CNPq. 


\section{Resumo}

Atualmente, o meio mais comum de busca de informações é a WEB. Assim, é importante procurar métodos eficientes para recuperar essa informação. As máquinas de busca na $W E B$ usualmente utilizam palavras-chaves para expressar uma busca. Porém, não é trivial caracterizar a informação desejada. Usuários diferentes com necessidades diferentes podem estar interessados em informações relacionadas, mas distintas, ao realizar a mesma busca. O processo de realimentação de relevância torna possivel a participação ativa do usuário no processo de busca. A idéia geral desse processo consiste em, após o usuário realizar uma busca na WEB permitir que indique, dentre os sites encontrados, quais deles considera relevantes e não relevantes. A opinião do usuário pode então ser considerada para reordenar os dados, de forma que os sites relevantes para o usuário sejam retornados mais facilmente. Nesse contexto, e considerando que, na grande maioria dos casos, uma consulta retorna um número muito grande de sites $W E B$ que a satisfazem, das quais o usuário é responsável por indicar um pequeno número de sites relevantes e não relevantes, tem-se o cenário ideal para utilizar aprendizado parcialmente supervisionado, pois essa classe de algoritmos de aprendizado requer um número pequeno de exemplos rotulados e um grande número de exemplos não-rotulados. Assim, partindo da hipótese que a utilização de aprendizado parcialmente supervisionado é apropriada para induzir um classificador que pode ser utilizado como um filtro de realimentação de relevância para buscas na $W E B$, o objetivo deste trabalho consiste em explorar algoritmos de aprendizado parcialmente supervisionado, mais especificamente, aqueles que utilizam multidescrição de dados, para auxiliar na recuperação de sites na WEB. Para avaliar esta hipótese foi projetada e desenvolvida uma ferramenta denominada C-SEARCH que realiza esta reordenação dos sites a partir da indicação do usuário. Experimentos mostram que, em casos que buscas genéricas, que o resultado possui um bom diferencial entre sites relevantes e irrelevantes, o sistema consegue obter melhores resultados para o usuário. 


\section{Abstract}

As nowadays the $W E B$ is the most common source of information, it is very important to find reliable and efficient methods to retrieve this information. However, the WEB is a highly volatile and heterogeneous information source, thus keyword based querying may not be the best approach when few information is given. This is due to the fact that different users with different needs may want distinct information, although related to the same keyword query. The process of relevance feedback makes it possible for the user to interact actively with the search engine. The main idea is that after performing an initial search in the $W E B$, the process enables the user to indicate, among the retrieved sites, a small number of the ones considered relevant or irrelevant according with his/her required information. The user's preferences can then be used to rearrange sites returned in the initial search, so that relevant sites are ranked first. As in most cases a search returns a large amount of WEB sites which fits the keyword query, this is an ideal situation to use partially supervised machine learning algorithms. This kind of learning algorithms require a small number of labeled examples, and a large number of unlabeled examples. Thus, based on the assumption that the use of partially supervised learning is appropriate to induce a classifier that can be used as a filter for relevance feedback in $W E B$ information retrieval, the aim of this work is to explore the use of a partially supervised machine learning algorithm, more specifically, one that uses multi-description data, in order to assist the WEB search. To this end, a computational tool called C-SEARCH, which performs the reordering of the searched results using the user's feedback, has been implemented. Experimental results show that in cases where the keyword query is generic and there is a clear distinction between relevant and irrelevant sites, which is recognized by the user, the system can achieve good results. 


\section{Sumário}

Lista de Figuras . . . . . . . . . . . . . . . xv

Lista de Tabelas . . . . . . . . . . . . . . . . . . xvii

Lista de Algoritmos . . . . . . . . . . . . . . . xix

Lista de Abreviaturas . . . . . . . . . . . . . . . . . . xxi

1 Introdução 1

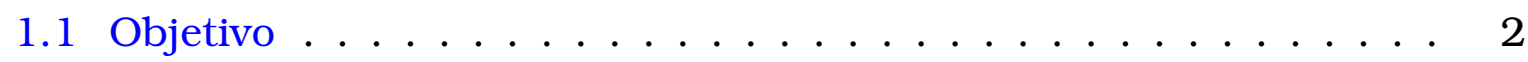

1.2 Organização...................... . . 3

2 Aprendizado Parcialmente Supervisionado 5

2.1 Fundamentos e Definições . . . . . . . . . . . . . . . 6

2.2 Multiplas Descrições de Dados . . . . . . . . . . . . . . 7

2.3 Algoritmo CO-TRAINING . . . . . . . . . . . . . . . 9

2.4 Considerações Finais $\ldots \ldots \ldots \ldots$

3 Recuperação de Informação 15

3.1 Pré-Processamento de WEB sites . . . . . . . . . . . . . 15

3.1 .1 Tokenização . . . . . . . . . . . . . . . . 16

3.1 .2 Remoção de Stopwords . . . . . . . . . . . . . . 17

3.1 .3 Stemming . . . . . . . . . . . . . . 17

3.2 Realimentação de Relevância . . . . . . . . . . . . . . . . . . . . 18

3.3 Recall e Precisão . . . . . . . . . . . . . . . . . . . . . . . . . . . 19

3.4 Considerações Finais . . . . . . . . . . . . . . . . . 20

4 Pretext II: Ferramenta para Pré-Processamento de Textos 23

4.1 Geração de Atributos . . . . . . . . . . . . . . . . . . 24

4.2 Medidas dos Atributos . . . . . . . . . . . . . 25

4.3 Modificações Realizadas . . . . . . . . . . . . . . . . . . 26

4.3.1 Tokenizador e Limpeza dos Dados . . . . . . . . . . . . . 26

4.3.2 Algoritmo do Porter para Português . . . . . . . . . . . . 28

4.3.3 N-grama e Outras Modificações . . . . . . . . . . . . 32 
4.4 Características da Nova Ferramenta . . . . . . . . . . . . 32

4.5 Considerações Finais . . . . . . . . . . . . . . 34

5 C-Search: Uma Ferramenta de Realimentação de Relevância 37

5.1 Visão Geral da Ferramenta . . . . . . . . . . . . . . . . . 37

5.2 Motor de Busca . . . . . . . . . . . . . . . . . . . 39

5.3 CO-TRAINING e PRETEXT II . . . . . . . . . . . . . . . . 39

5.4 Processo de Execução . . . . . . . . . . . . . . . . . . . . 40

5.4 .1 Perspectiva do Usuário . . . . . . . . . . . . . . . 40

5.4 .2 Funcionamento Interno . . . . . . . . . . . . . . 41

5.5 Exemplo de Execução . . . . . . . . . . . . . . . . . . . . . 45

5.6 Considerações Finais . . . . . . . . . . . . . . . . . . 45

6 Avaliação Experimental 49

6.1 Construção dos Testes com Voluntários . . . . . . . . . . . 50

6.2 Interpretação dos Gráficos Recall-Precisão . . . . . . . . . . . . 51

6.3 Descrição dos Resultados . . . . . . . . . . . . . . . . . . . 52

6.3.1 Resultados Positivos . . . . . . . . . . . . . . . . 53

6.3 .2 Resultados Neutros . . . . . . . . . . . . . . . . 57

6.3 .3 Resultados Negativos . . . . . . . . . . . . . 58

6.4 Considerações Finais . . . . . . . . . . . . . . . . 60

7 Conclusão $\quad 65$

$\begin{array}{ll}\text { Referências } & 69\end{array}$ 


\section{Lista de Figuras}

2.1 Duas descrições do conjunto de exemplos . . . . . . . . . . . 9

2.2 Conjunto de exemplos $L_{D_{1}}, L_{D_{2}}, U_{D_{1}}$ e $U_{D_{2}} \ldots \ldots \ldots \ldots$

2.3 Ilustração do algoritmo CO-TRAINING . . . . . . . . . . . 11

3.1 Exemplo de curvas recall-precisão. . . . . . . . . . . . . . . . 20

4.1 A curva de Zipf e os cortes de Luhn . . . . . . . . . . . . . 25

4.2 O novo funcionamento do PreTEXT II . . . . . . . . . . . . 33

5.1 Visão geral da ferramenta C-SEARCH . . . . . . . . . . . . . 38

5.2 O sistema C-SEARCH . . . . . . . . . . . . . . . . 42

5.3 O Rank 1 da realimentação do C-SEARCH . . . . . . . . . . . 46

5.4 O Rank 2 da realimentação do C-SEARCH . . . . . . . . . . . . 47

6.1 Gráficos recall-precisão da consulta sarmiento . . . . . . . . . 55

6.2 Gráficos recall-precisão da consulta maquinas finita . . . . . 56

6.3 Gráficos recall-precisão da consulta cotinga . . . . . . . . . . 58

6.4 Gráficos recall-precisão da consulta mercado de derivativos . 59

6.5 Gráficos recall-precisão da consulta Complexo MHC . . . . . . . 61

6.6 Gráficos recall-precisão da consulta títulos palmeiras . . . . 62 


\section{Lista de Tabelas}

2.1 Tabela atributo-valor ................. 6

3.1 Matriz de contingência . . . . . . . . . . . . . 19

4.1 Comparação de tokens distintos no PRETEXT e no PRETEXT II . . 27

4.2 Tempo de Execução do Algoritmo de stemming em Segundos . . . 30

4.3 Número de stems Gerados . . . . . . . . . . . . . . . . . . . . 30

4.4 Taxa de erro dos algoritmos C4.5 e SVM para o conjuntos de documentos da Folha de São Paulo . . . . . . . . . . . . . . . 31

4.5 Taxa de erro dos algoritmos C4.5 e SVM para o conjuntos de documentos do jornal da USP . . . . . . . . . . . . 31

4.6 Funcionalidades da nova versão do PRETEXT . . . . . . . . . . . . 34

6.1 Consultas e números total e parcial de sites relevantes marcados pelo usuário por consulta. . . . . . . . . . . . . . . . . 53 


\section{Lista de Algoritmos}

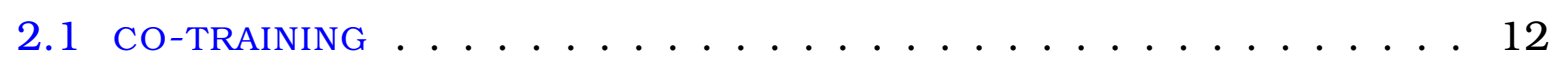




\section{Lista de Abreviaturas}

AM Aprendizado de Máquina

APS Aprendizado Parcialmente Supervisionado

IA Inteligência Artificial

RI Recuperação de Informação

RR Realimentação de Relevância 


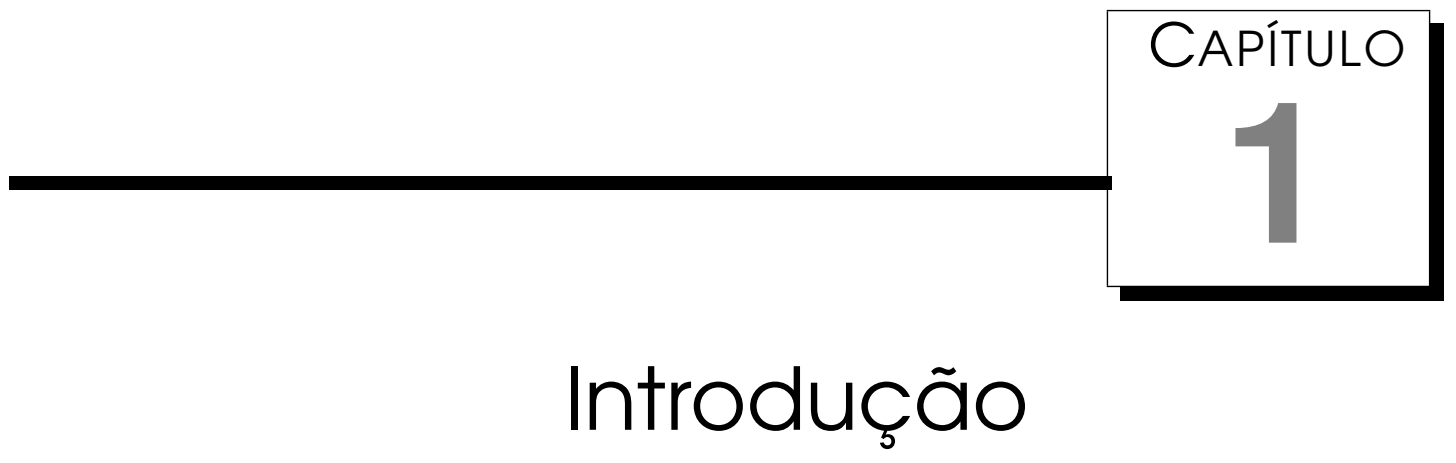

om todas as facilidades que a $W E B$ oferece, e o grande volume de informações de assuntos diversos que nela se encontram, a WEB tem se tornado o meio dominante de busca por informação. As pessoas estão cada vez mais procurando informações em livros, jornais, revistas e outras fontes, armazenadas digitalmente, utilizando a WEB como fonte de busca. A busca na WEB tem sua origem no campo da Recuperação de Informação (RI). Nesse contexto, os documentos a serem recuperados são os WEB sites. Todavia, recuperar a informação desejada pelo usuário é uma tarefa que apresenta várias dificuldades, pois, para obter documentos de seu interesse, o usuário deverá traduzir seu critério de busca em uma consulta apropriada.

Considere, por exemplo, um usuário com a seguinte necessidade de recuperar informações em documentos WEB:

"Encontre documentos contendo informações sobre as músicas da cantora Adriana Calcanhoto de forma que: (1) Esteja dividida por álbum, (2) contenha fotos dos encartes e (3) tenham sido lançadas entre 1992 e 1999."

Claramente, a descrição acima não pode ser usada para encontrar informações por meio das interfaces das máquinas de busca na WEB. A forma mais comum de se criar uma consulta é a partir de palavras-chave, como "Adriana Calcanhoto discografia".

Todavia, isso não é o suficiente para satisfazer as necessidades do usuário em um sistema de RI. Dessa maneira, é muito provável que a presença de documentos não relevantes entre os documentos retornados seja alta. Em outras palavras, o conjunto de respostas a uma consulta contém a maioria dos 
documentos relevantes ao usuário (alta cobertura ${ }^{1}$ ), mas contém também um grande número de documentos irrelevantes (baixa precisão). Nesse cenário, os principais objetivos dos sistemas de RI são recuperar o maior número possível de documentos relevantes (alta cobertura) e o menor número possível de documentos não relevantes (alta precisão).

Uma maneira de contribuir para que esses objetivos sejam alcançados é processar os resultados de uma consulta de maneira que os documentos irrelevantes sejam filtrados. Algumas das abordagens propostas utilizam algoritmos de aprendizado de máquina supervisionado para a construção desses filtros (Deng et al., 2004). Em linhas gerais, a idéia consiste em construir um categorizador que classifique os documentos como relevantes ou não de acordo com a consulta. Entretanto, essa abordagem requer que um grande conjunto de documentos, a serem utilizados como entrada (conjunto de treinamento) para o algoritmo de aprendizado, sejam previamente rotulados como relevantes ou não. Para ajudar nesse processo, neste trabalho é proposto o uso de Aprendizado Parcialmente Supervisionado (APS) ${ }^{2}$, mais especificamente, aqueles algoritmos que utilizam descrições múltiplas (multidescrição) do conjunto de dados para a construção de filtros de realimentação de relevância para a recuperação de informação. Algoritmos de aprendizado parcialmente supervisionado são particularmente úteis nesse processo, pois requerem menos exemplos rotulados. A multidescrição dos dados auxilia no processo de categorização dos dados, pois cada descrição é processada individualmente e somente os exemplos classificados com alto grau de confiança em todas as múltiplas descrições são classificados.

O processo de realimentação de relevância nada mais é que a classificação manual de poucos exemplos relevantes e irrelevantes pelo usuário, e o processamento desses exemplos para a recuperação de informação mais pertinente ao usuário. A partir dos poucos dados manualmente classificados, uma nova consulta é realizada levando em conta a relevância dos dados para o usuário. Unindo esses poucos exemplos rotulados manualmente, com a grande quantidade de exemplos não rotulados existentes na $W E B$, cria-se um cenário ideal para a utilização de algoritmos de aprendizado parcialmente supervisionado para auxiliar na construção de filtros que permitam recuperar maior número de documentos relevantes e poucos documentos não relevantes.

\subsection{Objetivo}

Partindo da hipótese que a utilização de aprendizado parcialmente supervisionado multidescrição é apropriada para a construção de filtros de buscas

\footnotetext{
${ }^{1}$ Cobertura, do inglês recall

${ }^{2}$ Também denominado de Aprendizado Semissupervisionado
} 
na $W E B$, o objetivo deste trabalho é explorar algoritmos de aprendizado de máquina parcialmente supervisionado multidescrição para auxiliar na recuperação de documentos na WEB. A proposta consiste em utilizar essa classe de algoritmos de aprendizado para construir semiautomaticamente filtros de realimentação de relevância que possam remover documentos irrelevantes recuperados a partir de uma consulta (busca) do usuário.

Algoritmos de aprendizado de máquina parcialmente supervisionado são especialmente adequados para a construção desses filtros, pois requerem um pequeno número de exemplos rotulados, as quais devem ser indicados pelo usuário, para a indução do categorizador a ser utilizado como filtro. Além disso, esses algoritmos podem fazer uso de uma grande quantidade de exemplos não rotulados, disponíveis na $W E B$, com o intuito de melhorar o processo de aprendizado.

Com o objetivo de avaliar a nossa proposta quanto ao uso de algoritmos de aprendizado parcialmente supervisionado multidescrição para construir filtros de realimentação de relevância, foi projetado e implementado o CSEARCH, uma ferramenta que reordena o ranking dos sites retornados na busca, a partir da indicação do usuário de um número reduzido de sites relevantes e irrelevantes. A proposta foi avaliada por um grupo de voluntários.

Os resultados experimentais mostraram bons resultados no caso de consultas nas quais os sites relevante e irrelevantes tem informações marcantes que os diferenciem, e o pré-processamento utilizado para transformar a informação textual (não estruturada) contida nos sites, o qual não considera o aspecto semântico dessa informação, para o formato estruturado requerido pelo algoritmo de aprendizado, mantém essas características necessárias para diferenciar sites relevantes de irrelevantes considerando as poucas preferências indicadas pelo usuário.

\subsection{Organização}

Este trabalho está organizado da seguinte maneira:

Capítulo 2: os fundamentos e técnicas de aprendizado de máquina parcialmente supervisionado multidescrição são apresentados neste capítulo. São também descritos alguns algoritmos dessa família presentes na literatura.

Capítulo 3: neste capítulo são apresentados brevemente os conceitos gerais de recuperação de informação no contexto de busca na $W E B$, bem como algumas etapas relacionadas ao processo de RI. Conceitos sobre o processo de realimentação de relevância também estão presentes neste capítulo. 
Capitulo 4: o pré-processamento para transformar informações não estruturadas em um formato estruturado é muito importante no contexto deste trabalho. Neste capítulo é apresentada a ferramenta de pré-processamento de textos PRETEXT II utilizada para esse fim. Essa ferramenta é o resultado de um processo de remodelagem e reimplementação da ferramenta PRETEXT implementada há mais de cinco anos. Neste capítulo são destacadas as novas funcionalidades e remodelagem realizadas nesta ferramenta e que deram origem a nova ferramenta PRETEXT II.

Capítulo 5: neste capítulo é apresentado o projeto e a implementação do CSEARCH, uma ferramenta de realimentação de relevância para reordenação dos rankings de uma busca. É mostrada uma visão geral da ferramenta bem como cada um dos seus componentes. O processo de execução do C-SEARCH considerado na perspectiva do usuário bem como no seu funcionamento interno também é apresentado e exemplificado.

Capitulo 6: neste capítulo é descrita a avaliação experimental do C-SEARCH, a qual foi realizada usando as medidas de recall (cobertura) e precisão e as curvas recall-precisão correspondentes, considerando os resultados das consultas realizadas por diferentes usuários-voluntários que participaram da experiência.

Capitulo 7: neste capítulo é apresentado a conclusão deste trabalho, assim como trabalhos futuros. 


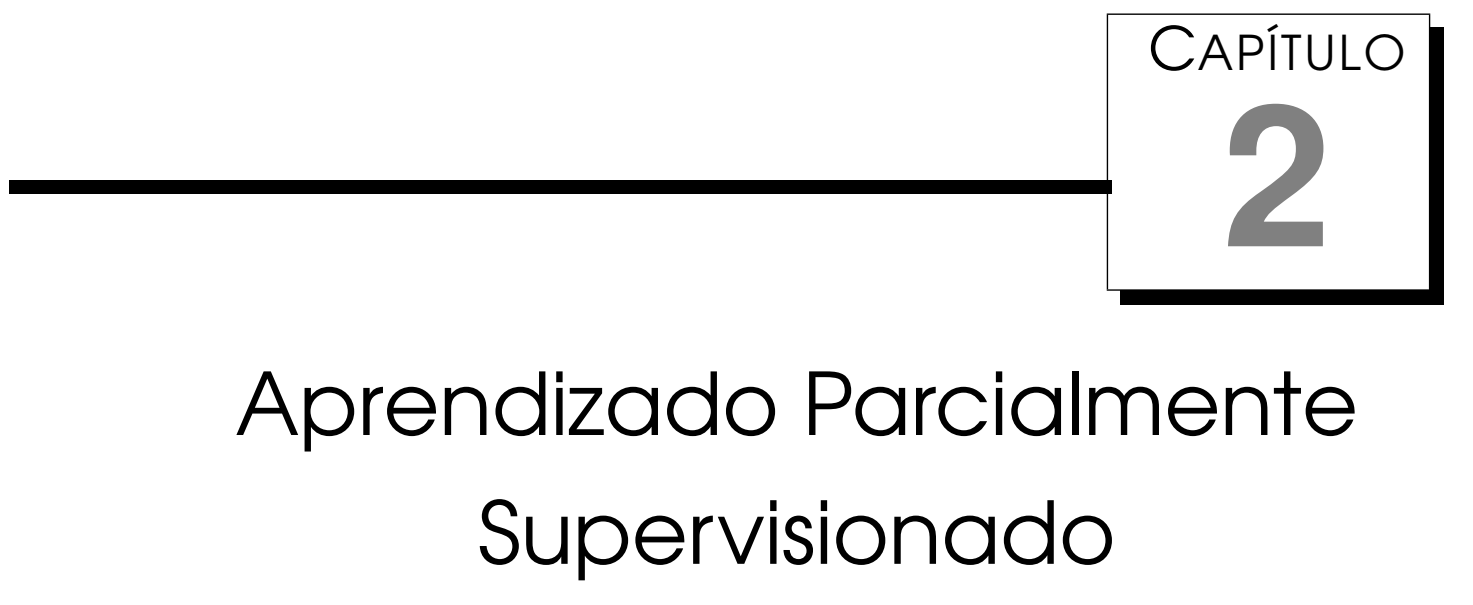

$\mathrm{O}$

Aprendizado de Máquina (AM) é uma subárea da Inteligência Artificial (IA) que pesquisa métodos computacionais relacionados à aquisição de novos conhecimentos, novas habilidades e novas formas de organizar o conhecimento já existente (Mitchell, 1997). Existem diversas formas de classificar os vários métodos de AM, dentre eles está a classificação considerando o nível de supervisão do conjunto de dados (exemplos) de treinamento, denominada modo de aprendizado. Os conjuntos de dados que apresentam valores para um atributo especial chamado classe (ou rótulo), são supervisionados, enquanto que conjuntos de dados que não possuem esse atributo são chamados não supervisionados.

Em conjuntos de dados com o atributo classe é possível realizar o aprendizado supervisionado, no qual se busca aprender uma função de mapeamento a partir dos dados de treinamento para prever a classe de um novo exemplo. Porém, para um bom aprendizado, é necessário que a maioria dos exemplos do conjunto de dados de treinamento possuam o valor da classe. Entretanto, conseguir um número expressivo de dados rotulados é uma tarefa muitas vezes cara e pode até ser inviável. Por outro lado, com conjuntos de dados sem o atributo classe somente é possível utilizar aprendizado não supervisionado, no qual o algoritmo tentará descobrir semelhança entre os dados de treinamento para adquirir alguma informação sobre eles.

Existe também um terceiro tipo de conjunto de dados no quais poucos de seus exemplos apresentam o valor da classe. Para esse tipo de dados pode-se utilizar o aprendizado parcialmente supervisionado. O APS apóia-se no apren- 
dizado supervisionado e não-supervisionado. A idéia é utilizar um pequeno número de exemplos rotulados, os quais são geralmente caros e difíceis de se obter, e um grande número de exemplos não rotulados, os quais encontramse facilmente disponíveis, com o objetivo de rotular mais desses exemplos e, assim, melhorar o desempenho de algoritmos de aprendizado supervisionado minimizando o erro de classificação de novos exemplos (Nigam et al., 2000). Essa forma de aprendizado constitui o foco deste trabalho e é descrita neste capítulo.

\section{1 Fundamentos e Definições}

A grande maioria dos algoritmos de AM, seja supervisionado, não supervisionado ou parcialmente supervisionado, utilizam como entrada uma representação de dados chamada de tabela atributo-valor, no qual cada linha representa um exemplo e as colunas representam valores dos atributos. $\mathrm{Na}$ Tabela 2.1 é apresentado o formato geral de uma tabela atributo-valor com $N$ exemplos $\mathbf{E}_{i}, i=1, \ldots, N$, na forma $E=\left\{\left(\mathbf{E}_{1}, y_{1}\right), \ldots,\left(\mathbf{E}_{N}, y_{N}\right)\right\}$. Os $\mathbf{E}_{i}$ são vetores na forma $\left(x_{i 1}, x_{i 2}, \ldots, x_{i M}\right)$ cujos componentes são valores discretos ou contínuos relacionados com o conjunto de atributos $X=\left\{X_{1}, X_{2}, \ldots, X_{M}\right\}$. Ou seja, $x_{i j}$ denota o valor do atributo $X_{j}$ do exemplo $\mathbf{E}_{i}$. O $y_{i}$ é a classe do exemplo dado por uma função $f$ desconhecida, $f\left(\mathbf{E}_{i}\right)=y_{i}$.

\begin{tabular}{c|ccccc|c}
\cline { 2 - 6 } & $X_{1}$ & $X_{2}$ & $X_{3}$ & $\ldots$ & $X_{M}$ & Classe $(Y)$ \\
\hline \hline $\mathbf{E}_{1}$ & $x_{11}$ & $x_{12}$ & $x_{13}$ & $\ldots$ & $x_{1 M}$ & $y_{1}$ \\
$\mathbf{E}_{2}$ & $x_{21}$ & $x_{22}$ & $x_{23}$ & $\ldots$ & $x_{2 M}$ & $y_{2}$ \\
$\mathbf{E}_{3}$ & $x_{31}$ & $x_{32}$ & $x_{33}$ & $\ldots$ & $x_{3 M}$ & $y_{3}$ \\
$\vdots$ & $\vdots$ & $\vdots$ & $\vdots$ & $\ddots$ & $\vdots$ & $\vdots$ \\
$\mathbf{E}_{N}$ & $x_{N 1}$ & $x_{N 2}$ & $x_{N 3}$ & $\ldots$ & $x_{N M}$ & $y_{N}$ \\
\hline \hline
\end{tabular}

Tabela 2.1: Tabela atributo-valor

Para o aprendizado parcialmente supervisionado, o valor da classe da maioria dos exemplos é desconhecida. Nesse caso, o conjunto de dados $E$ é dividido em duas partes:

1. os exemplos $L=\left\{\left(\mathbf{E}_{i}^{l}, y_{i}\right) \mid i=1 \ldots p\right\}$, para o subconjunto de exemplos nas quais os valores da classe $Y=\left\{y_{1}, \ldots, y_{p}\right\}$ são conhecidos ${ }^{1}$; e

2. os exemplos $U=\left\{\mathbf{E}_{p+j}^{u} \mid j=1 \ldots q\right\}$ para o subconjunto de exemplos sem o valor da classe.

É importante observar que em APS $q \gg p$. Esse é o cenário padrão de aprendizado parcialmente supervisionado (Chapelle et al., 2006).

\footnotetext{
${ }^{1}$ Os diferentes valores que o atributo classe pode assumir são denominados classes.
} 
Um subconjunto $L$ muito pequeno de exemplos rotulados pode ser insuficiente para criar um classificador preciso, dessa forma, os exemplos sem rótulo $U$ são utilizados para auxiliar o aprendizado. Porém, mesmo que seja muito pequeno, o subconjunto $L$ deve, obrigatoriamente, conter exemplos rotulados com todos os valores possiveis do atributo classe no conjunto de dados $E$.

Uma das técnicas mais usadas para o APS é o SELF-TRAINING. O algoritmo consiste em induzir um classificador com os poucos exemplos rotulados $L$ e utilizar esse classificador para rotular os exemplos em $U$, adicionando ao conjunto $L$ somente os exemplos classificados com maior grau de confiança. Usando esse novo conjunto de exemplos rotulados, um novo classificador é induzido e o processo se repete até que todos os exemplos de treinamento sejam rotulados. O SELF-TRAINING tem sido utilizado em diversas aplicações. Em (Rosenberg et al., 2005) o SELF-TRAINING é utilizado para sistemas de detecção de objetos a partir de imagens. Em (Riloff et al., 2003) essa técnica é utilizada para detectar sentenças objetivas e subjetivas nas frases.

Os algoritmos de aprendizado parcialmente supervisionado podem ser divididos em: descrição (visão) única, como o SELF-TRAining, e múltipla descrição (Muslea, 2002). Os algoritmos de múltipla descrição normalmente são variações do algoritmo CO-TRAINing (Blum \& Mitchell, 1998), que será detalhado na seção 2.3 .

\subsection{Multiplas Descrições de Dados}

Dentre os algoritmos de aprendizado parcialmente supervisionado existe uma família de algoritmos que utiliza duas ou mais descrições (visões) dos da$\operatorname{dos}^{2}$. Esses algoritmos são chamados de algoritmos de aprendizado parcialmente supervisionado multidescrição. A utilização de descrições redundantes para o mesmo conjunto de dados é motivada pelo fato que, frequentemente, existem conjuntos de informações diferentes que se referem ao mesmo objeto, e cada conjunto de informação é capaz de descrever de maneira independente o objeto de interesse.

Para exemplificar, pode-se utilizar uma analogia com relação aos nossos sentidos. Dado um conjunto de frutas contendo laranja, maçã, banana, limão, melancia e caju, cada descrição dos dados poderia estar baseada nos sentidos olfato, paladar, tato e visão. Cada uma dessas descrições é suficiente para identificar cada uma dessas frutas. Porém, com a utilização de múltiplas descrições o grau de confiança na identificação pode ser aumentado. Considerando agora somente a laranja e o limão do exemplo anterior, utilizar a descrição provida pelo tato pode não ter um resultado muito preciso na identi-

\footnotetext{
${ }^{2}$ Visão e descrição são termos utilizados indistintamente neste trabalho.
} 
ficação, porém, utilizando mais uma descrição, como o olfato, a possibilidade de acerto aumentaria consideravelmente.

De modo mais formal, em um problema de aprendizado multidescrição, com duas descrições $D_{1}$ e $D_{2}$ por exemplo, um exemplo rotulado $\mathbf{E}_{i}$ é uma tripla $\left(\mathbf{E}_{i}^{1}, \mathbf{E}_{i}^{2}, y_{i}\right)$, onde $y_{i}$ é o rótulo da classe, e $\mathbf{E}_{i}^{1}$ e $\mathbf{E}_{i}^{2}$ são, respectivamente, a descrição do exemplo $\mathbf{E}_{i}$ nas descrições $D_{1}$ e $D_{2}$. Analogamente, um exemplo não rotulado é denotado por $\left(\mathbf{E}_{i}^{1}, \mathbf{E}_{i}^{2}\right.$, ?). Essa definição é facilmente estendida para qualquer número de visões.

Habitualmente, assume-se que cada descrição dos dados deveria ser suficiente para o aprendizado, caso houvesse um conjunto grande o suficiente de exemplos rotulados $L$. Porém, não é esse o cenário do aprendizado parcialmente supervisionado multidescrição, no qual o número de exemplos rotulados é escasso. Dessa forma, o objetivo é utilizar todas as descrições em conjunto para identificar a classe dos exemplos não rotulados $U$ com uma maior confiança. A presença de duas ou mais descrições dos dados sugere estratégias nas quais cada indutor faça a predição individualmente do exemplo se baseando em uma das visões, e aqueles exemplos preditos com maior confiança são também adicionados ao conjunto de exemplos de treinamento do outro indutor (Muslea et al., 2002).

Essa estratégia é utilizada em um dos principais algoritmos de APS, originalmente proposto por Blum \& Mitchell (1998), denominado CO-TRAINING. Esse algoritmo utiliza um método bastante interessante para rotular exemplos quando o número original de exemplos rotulados é pequeno. O método utilizado por CO-TRAINING consiste da indução de dois classificadores, cada um deles induzido utilizando uma descrição diferente dos exemplos de treinamento, os quais cooperam entre si. Cada um desses classificadores somente rotula algum exemplo de seu conjunto de exemplos não rotulados se tiver um alto grau de certeza da classificação desse exemplo. Esses novos exemplos rotulados são então adicionados ao conjunto original de exemplos rotulados de ambos indutores, e o processo é repetido até não ser possível rotular exemplos com alto grau de certeza. Assim, sempre que um desses dois classificadores rotular um exemplo, ele colabora na melhoria da precisão do outro classificador, por estar incrementando o número de exemplos do conjunto de treinamento. Após a execução de CO-TRAINING, tem-se um conjunto com maior número de exemplos rotulados, o qual pode ser utilizado como conjunto de treinamento por qualquer algoritmo de aprendizado supervisionado para induzir um classificador.

O aprendizado multidescrição é amplamente utilizado em aplicações como classificação de sites de Internet (Blum \& Mitchell, 1998), reconhecimento de entidades nominais (Collins \& Singer, 1999), indução de wrappers (Muslea, 
2002), classificação de e-mails (Kiritchenko \& Matwin, 2001), classificação de diálogos (Maeireizo et al., 2004) e classificação de textos (Matsubara et al., 2005).

\subsection{Algoritmo CO-TRAINING}

Para facilitar a compreensão deste algoritmo, considere que o conjunto de atributos $E$ que descreve os exemplos, pode ser dividido em dois subconjuntos $E_{D_{1}}$ e $E_{D_{2}}$ de atributos independentes, os quais representam as descrições dos exemplos, tal que $E=E_{D_{1}} \cup E_{D_{2}}$ e $E_{D_{1}} \cap E_{D_{2}}=\varnothing$ como ilustra a Figura 2.1, na qual, por simplicidade, é considerado que $E_{D_{1}}=\left\{X_{1}, X_{2}, \ldots, X_{j}\right\}$ e $E_{D_{2}}=$ $\left\{X_{j+1}, X_{j+2}, \ldots, X_{M}\right\}$. Como mencionado, exemplos com valor de $Y$ igual a "?" representam exemplos não rotulados.

\begin{tabular}{c|cccccccc|c}
\cline { 2 - 10 } & $X_{1}$ & $X_{2}$ & $X_{3}$ & $X_{4}$ & $\ldots$ & $X_{j}$ & $\ldots$ & $X_{M}$ & $\mathrm{Y}$ \\
\hline \hline$E_{1}$ & $x_{11}$ & $x_{12}$ & $x_{13}$ & $x_{14}$ & $\ldots$ & $x_{1 j}$ & $\ldots$ & $x_{1 M}$ & $y_{1}$ \\
$E_{2}$ & $x_{21}$ & $x_{22}$ & $x_{23}$ & $x_{24}$ & $\ldots$ & $x_{2 j}$ & $\ldots$ & $x_{2 M}$ & $?$ \\
$E_{3}$ & $x_{31}$ & $x_{32}$ & $x_{33}$ & $x_{34}$ & $\ldots$ & $x_{3 j}$ & $\ldots$ & $x_{3 M}$ & $?$ \\
$E_{4}$ & $x_{41}$ & $x_{42}$ & $x_{43}$ & $x_{4}$ & $\ldots$ & $x_{4 j}$ & $\ldots$ & $x_{4 M}$ & $y_{4}$ \\
$E_{5}$ & $x_{51}$ & $x_{52}$ & $x_{53}$ & $x_{4}$ & $\ldots$ & $x_{5 j}$ & $\ldots$ & $x_{5 M}$ & $y_{5}$ \\
$E_{6}$ & $x_{61}$ & $x_{62}$ & $x_{63}$ & $x_{64}$ & $\ldots$ & $x_{6 j}$ & $\ldots$ & $x_{6 M}$ & $?$ \\
$\vdots$ & $\vdots$ & $\vdots$ & $\vdots$ & $\vdots$ & $\ddots$ & $\vdots$ & $\ddots$ & $\vdots$ & $\vdots$ \\
$E_{i}$ & $x_{i 1}$ & $x_{i 2}$ & $x_{i 3}$ & $x_{i 4}$ & $\ldots$ & $x_{i j}$ & $\ldots$ & $x_{i M}$ & $?$ \\
$\vdots$ & $\vdots$ & $\vdots$ & $\vdots$ & $\vdots$ & $\ddots$ & $\vdots$ & $\ddots$ & $\vdots$ & $\vdots$ \\
$E_{N}$ & $x_{N 1}$ & $x_{N 2}$ & $x_{N 3}$ & $x_{N 4}$ & $\ldots$ & $x_{N j}$ & $\ldots$ & $x_{N M}$ & $?$ \\
\hline \hline
\end{tabular}

\begin{tabular}{c|cccc|c}
\cline { 2 - 5 } & $X_{1}$ & $X_{2}$ & $\ldots$ & $X_{j}$ & $\mathrm{Y}$ \\
\hline \hline$E_{1}$ & $x_{11}$ & $x_{12}$ & $\ldots$ & $x_{1 j}$ & $y_{1}$ \\
$E_{2}$ & $x_{21}$ & $x_{22}$ & $\ldots$ & $x_{2 j}$ & $?$ \\
$E_{3}$ & $x_{31}$ & $x_{32}$ & $\ldots$ & $x_{3 j}$ & $?$ \\
$E_{4}$ & $x_{41}$ & $c_{42}$ & & $x_{4 j}$ & $y_{4}$ \\
$E_{5}$ & $x_{51}$ & ${ }_{52}$ & $\ldots$ & $x_{5 j}$ & $y_{5}$ \\
$E_{6}$ & $x_{61}$ & $x_{62}$ & $\ldots$ & $x_{6 j}$ & $?$ \\
$\vdots$ & $\vdots$ & $\vdots$ & $\ddots$ & $\vdots$ & $\vdots$ \\
$E_{i}$ & $x_{i 1}$ & $x_{i 2}$ & $\ldots$ & $x_{i j}$ & $?$ \\
$\vdots$ & $\vdots$ & $\vdots$ & $\ddots$ & $\vdots$ & $\vdots$ \\
$E_{N}$ & $x_{N 1}$ & $x_{N 2}$ & $\ldots$ & $x_{N j}$ & $?$ \\
\hline \hline
\end{tabular}

\begin{tabular}{c|cccc|c}
\cline { 2 - 6 } & $X_{(j+1)}$ & $X_{(j+2)}$ & $\ldots$ & $X_{M}$ & $\mathrm{Y}$ \\
\hline \hline$E_{1}$ & $x_{1(j+1)}$ & $x_{1(j+2)}$ & $\ldots$ & $x_{1 M}$ & $y_{1}$ \\
$E_{2}$ & $x_{2(j+1)}$ & $x_{2(j+2)}$ & $\ldots$ & $x_{2 M}$ & $?$ \\
$E_{3}$ & $x_{3(j+1)}$ & $x_{3(j+2)}$ & $\ldots$ & $x_{3 M}$ & $?$ \\
$E_{4}$ & $x_{4(j+1)}$ & $x_{4(j+2)}$ & $\ldots$ & $x_{4 M}$ & $y_{4}$ \\
$E_{5}$ & $x_{5(j+1)}$ & $x_{5(j+2)}$ & $\ldots$ & $x_{5 M}$ & $y_{5}$ \\
$E_{6}$ & $x_{6(j+1)}$ & $x_{6(j+2)}$ & $\ldots$ & $x_{6 M}$ & $?$ \\
$\vdots$ & $\vdots$ & $\vdots$ & $\ddots$ & $\vdots$ & $\vdots$ \\
$E_{i}$ & $x_{i(j+1)}$ & $x_{i(j+2)}$ & $\ldots$ & $x_{i M}$ & $?$ \\
$\vdots$ & $\vdots$ & $\vdots$ & $\ddots$ & $\vdots$ & $\vdots$ \\
$E_{N}$ & $x_{N(j+1)}$ & $x_{N(j+2)}$ & $\ldots$ & $x_{N M}$ & $?$ \\
\hline \hline
\end{tabular}

Figura 2.1: Duas descrições do conjunto de exemplos

Além da separação em duas descrições, o conjunto $E=\left\{\mathbf{E}_{1}, \mathbf{E}_{2}, \ldots, \mathbf{E}_{N}\right\}$ de 
exemplos deve ser dividido em dois subconjuntos $L$ e $U$, i.e. o conjunto de exemplos rotulados (Labelled) e não rotulados (Unlabelled), respectivamente, como visto na Seção 2.1. O subconjunto $L \subset E$, que contém exemplos que possuem o valor do atributo classe conhecido é, por sua vez, dividido em duas descrições $L_{D_{1}}$ e $L_{D_{2}}$ tal que $L=L_{D_{1}} \cup L_{D_{2}}$ e $L_{D_{1}} \cap L_{D_{2}}=\varnothing$. Da mesma forma, o subconjunto $U \subset E$, que contém exemplos que não possuem o valor do atributo classe, é também dividido em duas descrições $U_{D_{1}}$ e $U_{D_{2}}$, tal que $U=U_{D_{1}} \cup U_{D_{2}}$ e $U_{D_{1}} \cap U_{D_{2}}=\varnothing$. Na Figura 2.2 encontram-se ilustrados esses quatro conjuntos de exemplos.

\begin{tabular}{c|cccccccc|c}
\cline { 2 - 9 } & $X_{1}$ & $X_{2}$ & $X_{3}$ & $X_{4}$ & $\ldots$ & $X_{j}$ & $\ldots$ & $X_{M}$ & $\mathrm{Y}$ \\
\hline \hline$E_{1}$ & $x_{11}$ & $x_{12}$ & $x_{13}$ & $x_{14}$ & $\ldots$ & $x_{1 j}$ & $\ldots$ & $x_{1 M}$ & $y_{1}$ \\
$E_{2}$ & $x_{21}$ & $x_{22}$ & $x_{23}$ & $x_{24}$ & $\ldots$ & $x_{2 j}$ & $\ldots$ & $x_{2 M}$ & $?$ \\
$E_{3}$ & $x_{31}$ & $x_{32}$ & $x_{33}$ & $x_{34}$ & $\ldots$ & $x_{3 j}$ & $\ldots$ & $x_{3 M}$ & $?$ \\
$E_{4}$ & $x_{41}$ & $x_{42}$ & $x_{43}$ & $x_{44}$ & $\ldots$ & $x_{4 j}$ & $\ldots$ & $x_{4 M}$ & $y_{4}$ \\
$E_{5}$ & $x_{51}$ & $x_{52}$ & $x_{53}$ & $x_{54}$ & $\ldots$ & $x_{5 j}$ & $\ldots$ & $x_{5 M}$ & $y_{5}$ \\
$E_{6}$ & $x_{61}$ & $x_{62}$ & $x_{63}$ & $x_{64}$ & $\ldots$ & $x_{6 j}$ & $\ldots$ & $x_{6 M}$ & $?$ \\
$\vdots$ & $\vdots$ & $\vdots$ & $\vdots$ & $\vdots$ & $\vdots$ & $\vdots$ & $\vdots$ & $\vdots$ & $\vdots$ \\
$E_{i}$ & $x_{i 1}$ & $x_{i 2}$ & $x_{i 3}$ & $x_{i 4}$ & $\ldots$ & $x_{i j}$ & $\ldots$ & $x_{i M}$ & $?$ \\
$\vdots$ & $\vdots$ & $\vdots$ & $\vdots$ & $\vdots$ & $\vdots$ & $\vdots$ & $\vdots$ & $\vdots$ & $\vdots$ \\
$E_{N}$ & $x_{N 1}$ & $x_{N 2}$ & $x_{N 3}$ & $x_{N 4}$ & $\ldots$ & $x_{N j}$ & $\ldots$ & $x_{N M}$ & $y_{N}$ \\
\hline \hline
\end{tabular}

\begin{tabular}{c|cccc|c}
\cline { 2 - 6 } & $X_{1}$ & $X_{2}$ & $\ldots$ & $X_{j}$ & $\mathrm{Y}$ \\
\hline \hline$E_{1}$ & $x_{11}$ & $x_{12}$ & $\ldots$ & $x_{1 j}$ & $y_{1}$ \\
$E_{4}$ & $x_{41}$ & $x_{2}$ & $\ldots$ & $x_{4 j}$ & $y_{4}$ \\
$E_{5}$ & $x_{51}$ & $x_{2}$ & $\ldots$ & $x_{5 j}$ & $y_{5}$ \\
$\vdots$ & $\vdots$ & $\vdots$ & $\vdots$ & $\vdots$ & $\vdots$ \\
$E_{N}$ & $x_{N 1}$ & $x_{N 2}$ & $\ldots$ & $x_{N j}$ & $y_{N}$ \\
\hline \hline
\end{tabular}

\begin{tabular}{c|cccc|c}
\cline { 2 - 5 } & $X_{(j+1)}$ & $X_{(j+2)}$ & $\cdots$ & $X_{M}$ & $\mathrm{Y}$ \\
\hline \hline$E_{1}$ & $x_{1(j+1)}$ & $x_{1(j+2)}$ & $\ldots$ & $x_{1 M}$ & $y_{1}$ \\
$E_{4}$ & $x_{4(j+1)}$ & $4_{4(j+2)}$ & $\ldots$ & $x_{4 M}$ & $y_{4}$ \\
$E_{5}$ & $x_{5(j+1)}$ & $x_{5(j+2)}$ & $\ddots$ & $x_{5 M}$ & $y_{5}$ \\
$\vdots$ & $\vdots$ & $\vdots$ & $\vdots$ & $\vdots$ & $\vdots$ \\
$E_{N}$ & $x_{N(j+1)}$ & $x_{N(j+2)}$ & $\ldots$ & $x_{N M}$ & $y_{N}$ \\
\hline \hline
\end{tabular}

\begin{tabular}{c|cccc|c}
\cline { 2 - 6 } & $X_{1}$ & $X_{2}$ & $\ldots$ & $X_{j}$ & $\mathrm{Y}$ \\
\hline \hline$E_{2}$ & $x_{21}$ & $x_{22}$ & $\ldots$ & $x_{2 j}$ & $?$ \\
$E_{3}$ & $x_{31}$ & $x_{32}$ & $\ldots$ & $x_{3 j}$ & $?$ \\
$E_{6}$ & $x_{61}$ & 62 & $\ldots$ & $x_{6 j}$ & $?$ \\
$\vdots$ & $\vdots$ & $\vdots$ & $\vdots$ & $\vdots$ & $\vdots$ \\
$E_{i}$ & $x_{i 1}$ & $x_{i 2}$ & $\cdots$ & $x_{i j}$ & $?$ \\
$\vdots$ & $\vdots$ & $\vdots$ & $\vdots$ & $\vdots$ & $\vdots$ \\
$E_{N}$ & $x_{N 1}$ & $x_{N 2}$ & $\ldots$ & $x_{N j}$ & $y_{N}$ \\
\hline \hline
\end{tabular}

\begin{tabular}{c|cccc|c}
\cline { 2 - 6 } & $X_{(j+1)}$ & $X_{(j+2)}$ & $\cdots$ & $X_{M}$ & $\mathrm{Y}$ \\
\hline \hline$E_{2}$ & $x_{2(j+1)}$ & $x_{2(j+2)}$ & $\ldots$ & $x_{2 M}$ & $?$ \\
$E_{3}$ & $x_{3(j+1)}$ & $x_{3(j+2)}$ & $\ldots$ & $x_{3 M}$ & $?$ \\
$E_{6}$ & $x_{6(j+1)}$ & $x_{6(j-2)}$ & $\ldots$ & $x_{6 M}$ & $?$ \\
$\vdots$ & $\vdots$ & $\vdots$ & $\vdots$ & $\vdots$ & $\vdots$ \\
$E_{i}$ & $x_{i(j+1)}$ & $x_{i(j+2)}$ & $\cdots$ & $x_{i M}$ & $?$ \\
$\vdots$ & $\vdots$ & $\vdots$ & $\vdots$ & $\vdots$ & $\vdots$ \\
$E_{N}$ & $x_{N(j+1)}$ & $x_{N(j+2)}$ & $\ldots$ & $x_{N M}$ & $y_{N}$ \\
\hline \hline
\end{tabular}

Figura 2.2: Conjunto de exemplos $L_{D_{1}}, L_{D_{2}}, U_{D_{1}}$ e $U_{D_{2}}$ (Matsubara, 2004)

Os dados de entrada do algoritmo CO-TRAINING consistem desses quatro 
subconjuntos de exemplos $L_{D_{1}}, L_{D_{2}}, U_{D_{1}}$ e $U_{D_{2}}$. No primeiro passo do algoritmo, o qual encontra-se descrito em alto nível na Figura 2.3, são criados dois subconjuntos $U_{D_{1}}^{\prime}$ e $U_{D_{2}}^{\prime}$, tal que $U^{\prime}=U_{D_{1}}^{\prime} \cup U_{D_{2}}^{\prime}$ e $U_{D_{1}}^{\prime} \cap U_{D_{2}}^{\prime}=\varnothing$, sendo $U^{\prime}$ um subconjunto de, geralmente, poucos exemplos de $U$, ou seja, esses dois subconjuntos de exemplos não rotulados $U_{D_{1}}^{\prime}$ e $U_{D_{2}}^{\prime}$ são subconjuntos de $U_{D_{1}} \mathrm{e}$ $U_{D_{2}}$, respectivamente. Os exemplos que compõem $U_{D_{1}}^{\prime}$ e $U_{D_{2}}^{\prime}$ são removidos de $U_{D_{1}}$ e $U_{D_{2}}$ a fim de verificar as condições $U_{D_{1}}^{\prime} \cap U_{D_{1}}=\varnothing$ e $U_{D_{2}}^{\prime} \cap U_{D_{2}}=\varnothing$.

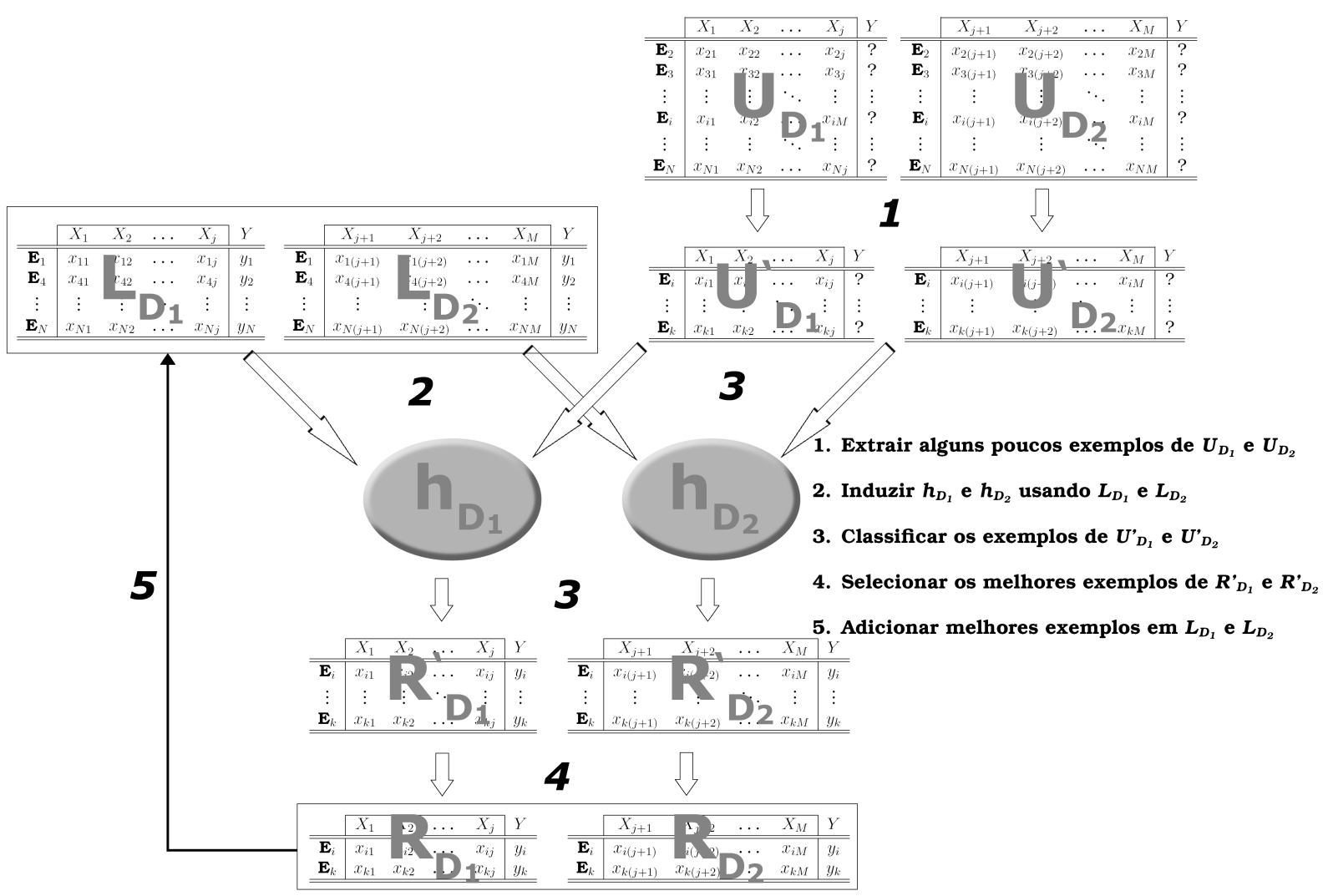

Figura 2.3: Ilustração do algoritmo CO-TRAINING

No segundo passo são induzidos, usando como algoritmo base o Naive Bayes $^{3}$ (Mitchell, 1997) e os conjuntos de exemplos rotulados $L_{D_{1}}$ e $L_{D_{2}}$, dois classificadores $h_{D_{1}}$ e $h_{D_{2}}$, os quais são utilizados para rotular todos os exemplos não rotulados de $U_{D_{1}}^{\prime}$ e $U_{D_{2}}^{\prime}$ (passo 3). No fim desse processo, $R_{D_{1}}^{\prime}$ e $R_{D_{2}}^{\prime}$ contém, respectivamente, o conjunto de exemplos rotulados pelos classificadores $h_{D_{1}}$ e $h_{D_{2}}$. O quarto passo consiste da seleção dos "melhores" exemplos rotulados $\left(\mathbf{x}_{i}, y_{i}\right)$ a partir de $R_{D_{1}}^{\prime}$ e $R_{D_{2}}^{\prime}$, os quais $\left(\mathbf{x}_{i}^{D_{1}}, y_{i}\right)$ e $\left(\mathbf{x}_{i}^{D_{2}}, y_{i}\right)$ são inseridos em $R_{D_{1}}$ e $R_{D_{2}}$ respectivamente, e adicionados em $L_{D_{1}}$ e $L_{D_{2}}$ respectivamente e, também, excluidos de $U_{D_{1}}^{\prime}$ e $U_{D_{2}}^{\prime}$ respectivamente. Desse modo, o número de exemplos rotulados nos conjuntos $L_{D_{1}}$ e $L_{D_{2}}$ pode ser incrementado a cada iteração. Finalmente, o processo é repetido, até que não existam mais exemplos em $U_{D_{1}}$ (ou em $U_{D_{2}}$ ) a serem rotulados, ou o máximo número de iterações $k$ seja

\footnotetext{
${ }^{3}$ Gualquer algoritmo que retorne um valor de confiança (score) na classificação pode ser utilizado como algoritmo base do CO-TRAINING.
} 
atingido. O número máximo de iterações $k$ é utilizado para quando o conjunto de dados é muito grande e a execução poderia ser demasiadamente demorada, portanto é estipulado uma quantidade máxima de vezes que o algoritmo será executado. O Algoritmo 2.1 descreve mais formalmente o CO-TRAINING.

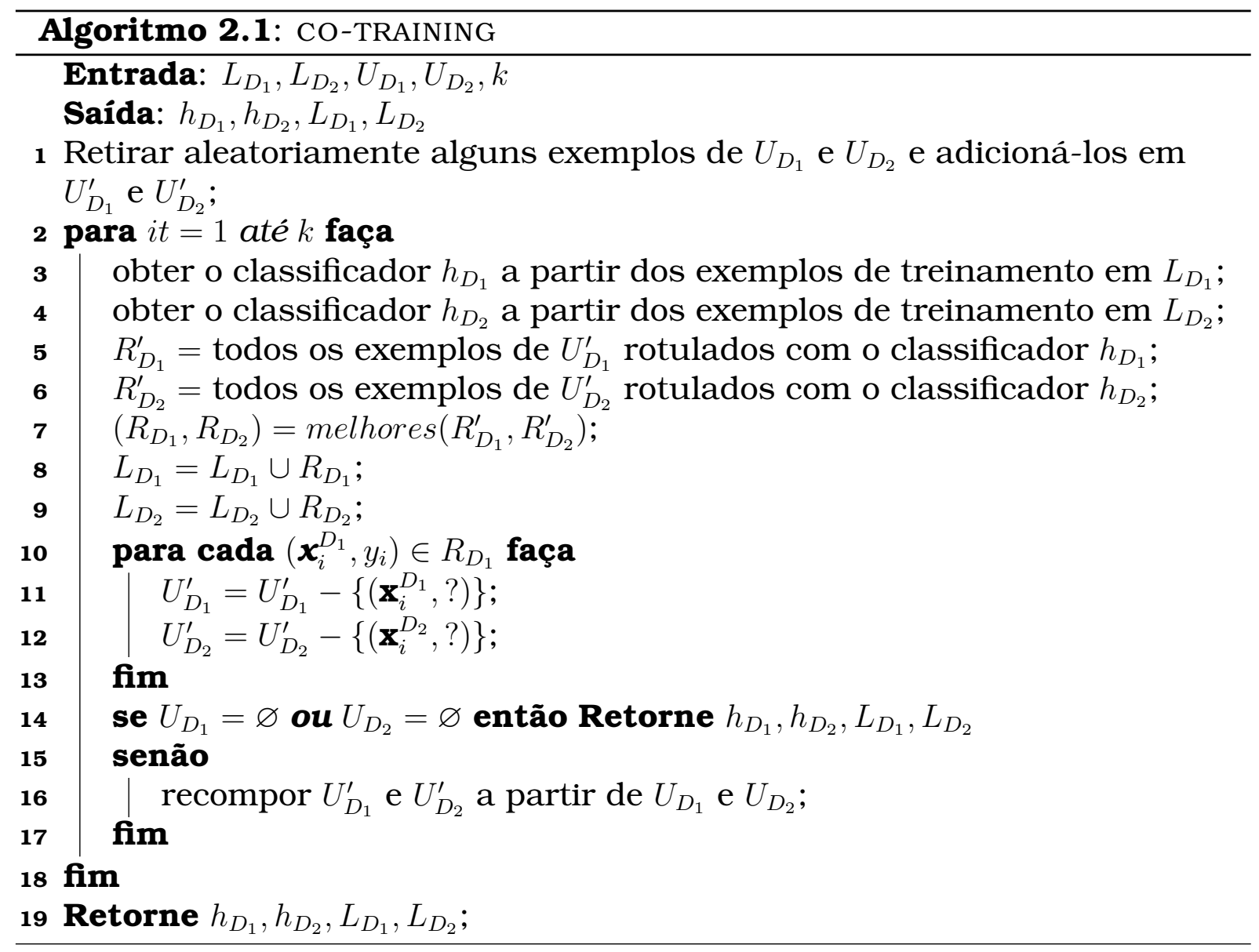

A função melhores $/ 2^{4}$ seleciona exemplos classificados com maior confiança em cada iteração pelos indutores $h_{D_{1}}$ e $h_{D_{2}}$ para serem adicionados no conjunto de treinamento. Na proposta original de CO-TRAINING (Blum \& Mitchell, 1998), são utilizados exemplos com duas classes, e os autores sugerem rotular os $p$ exemplos positivos e os $n$ exemplos negativos rotulados com maior confiança independentemente por $h_{D_{1}}$ e $h_{D_{2}}$ para incrementar os conjuntos $L_{D_{1}}$ e $L_{D_{2}}$ de exemplos rotulados. Ou seja, em cada iteração a funçao melhores $/ 2$ original do CO-TRAINING rotula $2 p+2 n$ exemplos.

Pode ser observado que a idéia principal do CO-TRAINING é que os exemplos rotulados com maior confiança pelo classificador $h_{D_{1}}$ irão, a cada iteração, melhorar a precisão do classificador $h_{D_{2}}$, e vice versa. Entretanto, se houver uma classificação errônea com alta confiança de um exemplo, ele poderá degradar o modelo a partir da próxima iteração. Para suprir esse defeito foram criadas variações deste algoritmo, como o CO-EM (Nigam et al., 2000; Jones, 2005), o CO-TESTING (Muslea et al., 2000) e o CO-EMT (Muslea et al., 2002).

\footnotetext{
${ }^{4}$ Notação que indica o nome da função e o número de argumentos
} 


\subsection{Considerações Finais}

Como mencionado, algumas suposições são feitas para a utilização de algoritmos de aprendizado parcialmente supervisionado multidescrição, tais como: as descrições dos dados devem ser compativeis e independentes, ou seja, em todas as descrições os exemplos possuem a mesma classe e cada descrição é suficientemente boa para gerar um classificador preciso. Todavia, essas suposições usualmente não se aplicam para problemas do mundo real. Dessa forma, é importante pesquisar soluções que possibilitem trabalhar com essas limitações relacionadas à incompatibilidade e correlação das descrições. 


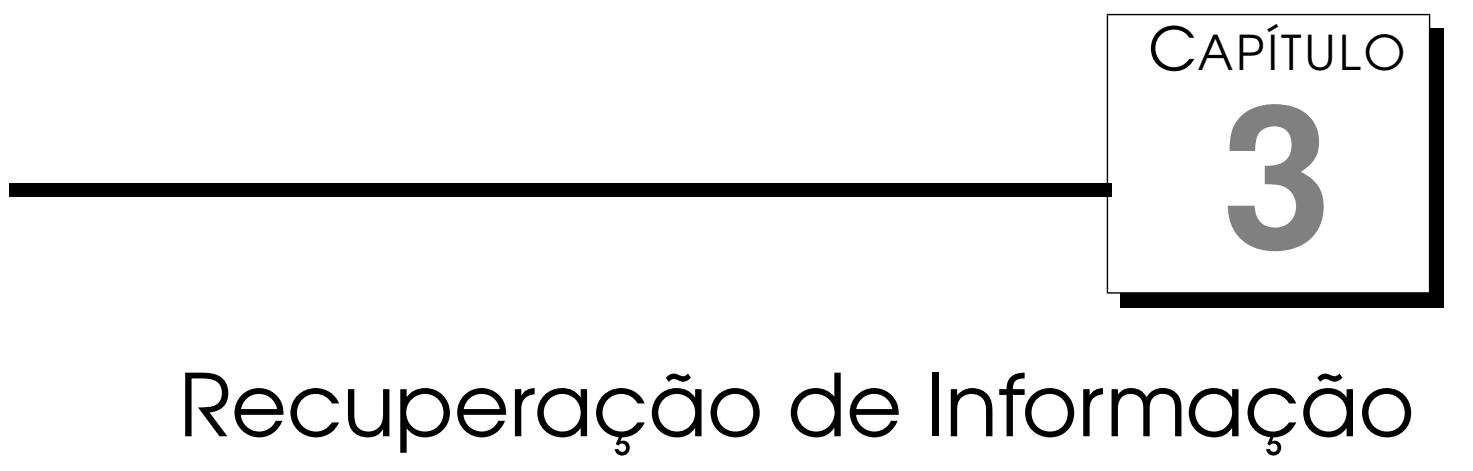

$\mathcal{A}$

Recuperação de Informação é uma área que lida com o armazenamento de documentos e a recuperação automática de informação associada a eles (Baeza-Yates \& Ribeiro-Neto, 1999). O principal objetivo de um sistema de RI é recuperar informação (contida nos documentos) que possa ser útil ou relevante para o usuário. Recuperar informação em um conjunto de documentos nada mais é que encontrar um subconjunto de documentos que satisfazem uma consulta do usuário. Infelizmente, caracterizar a informação desejada pelo usuário não é uma tarefa simples. Em sua forma mais comum, uma consulta é um conjunto de palavras-chave. A consulta por palavraschave consiste em estabelecer um conjunto de uma ou mais palavras que expressem a idéia do usuário com relação à informação desejada, e será recuperado um conjunto de documentos que contem um ou mais desses termos.

O que torna a recuperação de informação na WEB diferente de uma recuperação de informação em um banco de dados, por exemplo, é o formato não estruturado dos WEB sites, que se assemelham a documentos textuais. Dessa forma, torna-se necessária a utilização de uma representação estruturada dos dados, tal como uma tabela atributo-valor, a qual pode ser obtida por meio do pré-processamento de WEB sites.

\section{1 Pré-Processamento de WEB sites}

Uma das maneiras de transformar WEB sites em dados estruturados é transformá-los em uma representação atributo-valor utilizando a abordagem bag of words, na qual a frequência das palavras (termos), independentes de seu contexto ou significado, é considerada. Utilizando esses termos como 
nome de atributos, é gerada uma tabela cujas linhas correspondem à frequência, ou outra medida relacionada, respectivamente, com cada termo que aparece no $W E B$ site.

Além de textos, WEB sites também possuem marcações, chamadas de Tags HTML $^{1}$, que não fazem parte do conteúdo. Tais marcações devem ser identificadas e tratadas de forma adequada.

Uma tabela atributo-valor gerada utilizando-se a abordagem bag of words tem algumas peculiaridades. Geralmente tem-se o problema da "Maldição da Dimensionalidade" ${ }^{2}$, pois a tabela apresenta um grande número de atributos (termos) devido ao grande número de palavras - vocabulário - utilizadas no conjunto de $W E B$ sites, mas cada $W E B$ site utiliza relativamente poucos atributos (o texto de cada WEB site geralmente consiste de um subconjunto pequeno de todas as palavras existentes), gerando assim uma tabela muito esparsa. Dessa forma, alguns métodos de redução de atributos, descritos a seguir, são utilizados a fim de condensar a informação pertinente para a recuperação de informação.

\subsubsection{Tokenização}

O primeiro passo para examinar o texto não estruturado de um $W E B$ site é identificar as características importantes. Para isso, primeiramente quebra-se o fluxo contínuo de caracteres em palavras ou, mais precisamente, tokens. Esse processo é trivial para uma pessoa que tenha conhecimento da estrutura da linguagem. Porém, para um programa de computador, isso pode ser mais complicado. Para tanto, é necessário a remoção de alguns caracteres indesejados, como sinais de pontuação, separação silábica, marcações especiais e números, os quais, isoladamente, trazem pouca informação.

Esse processo apresenta algumas dificuldades, inerentes da forma como os tokens devem ser extraídos do texto (dos Santos, 2002; Manning \& Schütze, 1999). Algumas vezes um espaço em branco não é suficiente para auxiliar no reconhecimento de um token, visto que em um texto usualmente existem sinais de pontuação, como vírgula, ou ponto final, que não fazem parte de um determinado token. Dessa forma, se for considerado somente um espaço em branco para a divisão de tokens, podem existir tokens que deveriam ser semelhantes, porém, eles são agrupados de maneiras distintas. Existe também a ambiguidade do ponto final, que não permite determinar quando esse ponto representa uma divisão entre sentenças e quando representa uma abreviação. Dentre os símbolos não alfanuméricos, existem aqueles que têm uma relevân-

\footnotetext{
${ }^{1}$ Tag HTML: texto usado para identificar a aparência, formato, comportamento, e/ou tipo de elementos em uma site HTML

${ }^{2}$ Maldição da Dimensionalidade, do inglês curse of dimensionality
} 
cia para o aprendizado, e aqueles que simplesmente podem ser ignorados. E até a existência de letras maiúsculas e minúsculas pode dificultar o processo de tokenização, pois uma mesma palavra ocorrendo no início de uma frase (usualmente escrita com maiúscula) pode ser agrupada em um token diferente da mesma palavra ocorrendo no meio da frase. Esses aspectos devem ser cuidadosamente considerados, pois uma extração eficiente de tokens gera melhores resultados, i.e. diminuição do número de atributos finais (termos), na abordagem bag of words.

\section{1.2 Remoção de Stopwords}

Várias palavras, em qualquer língua, são muito comuns e não são significativas para o aprendizado quando consideradas isoladamente. Essas palavras incluem pronomes, artigos, preposições, advérbios, conjunções, e outras. Com essas palavras, é gerada uma stoplist, na qual inúmeras stopwords podem ser armazenadas para que sejam desconsideradas ao processar o texto. Dessa forma, a remoção de stopwords minimiza consideravelmente a quantidade total de tokens usados para representar os documentos.

\subsubsection{Stemming}

Um dos métodos amplamente utilizado e difundido que pode ser utilizado a fim de reduzir a quantidade de tokens necessários para representar uma coleção de documentos, é a transformação de cada termo para o radical que o originou, por meio de algoritmos de stemming. Basicamente, algoritmos de stemming consistem em uma normalização linguística, na qual as formas variantes de um termo são reduzidas a uma forma comum denominada stem. A consequência da aplicação de algoritmos de stemming consiste na remoção de prefixos ou sufixos de um termo. Por exemplo, os tokens observar, observadores, observasse, observou e observe podem ser transformados para um mesmo stem observ.

Percebe-se que algoritmos de stemming são fortemente dependentes do idioma no qual os documentos estão escritos. Um dos algoritmos de stemming mais conhecidos é o algoritmo do Porter, que remove sufixos de termos em inglês (Porter, 1980, 2006). O algoritmo tem sido amplamente usado, referenciado e adaptado nas últimas três décadas. Diversas implementações do algoritmo estão disponibilizadas na $W E B$, entre elas o site oficial ${ }^{3}$ escrita e mantida pelo autor para a distribuição do seu algoritmo. Existe também uma linguagem de programação especialmente criada para geração de stem em vários idiomas, chamada Snowball (Porter, 2001).

\footnotetext{
$3_{\text {http: //www.tartarus.org/ martin/PorterStemmer }}$
} 


\subsection{Realimentação de Relevância}

Em muitos casos, consultas elaboradas para sistemas de RI podem estar incompletas ou ambíguas, o que implica na recuperação de documentos não relevantes. É importante observar que mesmo com todas as técnicas e esforços para recuperação eficiente de informação, somente quem pode dizer se o resultado de uma consulta é ou não útil é o usuário. Dessa forma, para aumentar a efetividade da recuperação foi proposto o processo de Realimentação de Relevância (RR) (Ruthven \& Lalmas, 2003), que consiste em o usuário identificar (rotular) de acordo com suas necessidades alguns documentos relevantes e irrelevantes dentre os retornados, e o sistema utiliza esses exemplos rotulados para gerar uma segunda consulta.

Um sistema de realimentação de relevância funciona de forma iterativa. Inicialmente, um sistema de RI recupera um grupo de documentos referentes a uma certa consulta, o usuário seleciona alguns poucos documentos relevantes e irrelevantes entre os retornados, o sistema de realimentação de relevância constrói uma nova consulta baseada nestes documentos, e o sistema de RI recupera um novo conjunto de documentos. Nesse processo, o sistema de realimentação de relevância irá recuperar mais documentos semelhantes aos documentos relevantes, e ordenar documentos mais relevantes antes de documentos menos relevantes. Se a consulta ainda não for satisfatória para o usuário, o processo pode se repetir quantas vezes se fizer necessário.

Existem inúmeras técnicas de realimentação de relevância, o método de Rocchio utiliza a consulta inicial $q$, adiciona a média dos termos dos documentos relevantes $d_{j}^{r}$ e subtrai a média dos termos dos documentos irrelevantes $d_{j}^{i}$ para criar uma nova consulta $q_{1}$, como mostra a Equação 3.1.

$$
q_{1}=q+\frac{\sum_{j=1}^{n_{1}} d_{j}^{r}}{n_{1}}-\frac{\sum_{j=1}^{n_{2}} d_{j}^{i}}{n_{2}}
$$

Por exemplo, realizando uma consulta sobre "música" ( $q=$ música) suponha que o usuário queira informações referentes à música popular brasileira $\left(\sum_{j=1}^{n_{1}} d_{j}^{r}=\right.$ popular, brasileira, $\left.M P B\right)$, mas não tem interesse sobre músicas estrangeiras $\left(\sum_{j=1}^{n_{2}} d_{j}^{i}=\right.$ pop music). Dessa maneira, desconsiderando a média, $q_{1}$ poderia ser igual a $q_{1}=$ música + popular + brasileira + MPB - "pop music".

Existem também técnicas de pseudorrealimentação de relevância, nas quais o usuário não interage ativamente na seleção de documentos relevantes, mas essa informação é adquirida de forma automática, por exemplo, examinando os WEB sites que foram clicados após a consulta (Deng et al., 2004). Neste trabalho o foco está nos métodos utilizando aprendizado de máquina. Tendo alguns poucos documentos rotulados como relevantes ou irrelevantes, podemos nos enquadrar no cenário de aprendizado parcialmente supervisionado, 
e considerar o problema de realimentação de relevância como um problema de classificação com poucos exemplos rotulados e um número expressivo de exemplos não rotulados.

A realimentação de relevância não é uma funcionalidade facilmente encontrada em máquinas de busca na $W E B$. Um possivel motivo seria que usuários na WEB estão interessados em sistemas que retornem sites relevantes de imediato. Outro motivo seria o desempenho computacional do método, visto que uma máquina de busca na $W E B$ retorna milhões de documentos em poucos milésimos de segundo, e uma segunda consulta com métodos de realimentação de relevância pode diminuir a velocidade de recuperação. Por isso, o método deve ser eficiente para que possa ser utilizado.

\subsection{Recall e Precisão}

Para avaliar um sistema de RI foram propostas inúmeras medidas, as quais podem ser derivadas da matriz de contingência, ilustrada na Tabela 3.1, no qual $A$ é o conjunto de documentos relevantes e $B$ o conjunto de documentos recuperados.

\begin{tabular}{c|c|c|c} 
& Relevantes & Não-Relevantes & \\
\hline Recuperados & $A \cap B$ & $\bar{A} \cap B$ & $B$ \\
\hline Não Recuperados & $A \cap \bar{B}$ & $\bar{A} \cap \bar{B}$ & $\bar{B}$ \\
\hline & $A$ & $\bar{A}$ & $N$
\end{tabular}

Tabela 3.1: Matriz de contingência

Dentre essas medidas, as mais conhecidas e utilizadas amplamente pela comunidade são a recall e a precisão. Recall, também denominado cobertura $^{4}$, refere-se à quantidade de documentos relevantes recuperados dentre todos os documentos relevantes do conjunto de documentos, definida pela Equação 3.2. Precisão refere-se ao número de documentos relevantes dentre os que foram recuperados, definida pela Equação 3.3.

$$
\begin{gathered}
\text { Recall }=\frac{|A \cap B|}{|A|} \\
\text { Precisão }=\frac{|A \cap B|}{|B|}
\end{gathered}
$$

A partir do recall e da precisão pode ser traçada uma curva recall-precisão que representa o comportamento de sistemas de RI com relação às consultas realizadas - Figura 3.1. Dessa forma, é possivel comparar a eficiência do

\footnotetext{
${ }^{4}$ Neste trabalho será utilizado o termo recall por ser amplamente utilizado na literatura.
} 
sistema para diferentes consultas, e, também, comparar diferentes sistemas de RI.

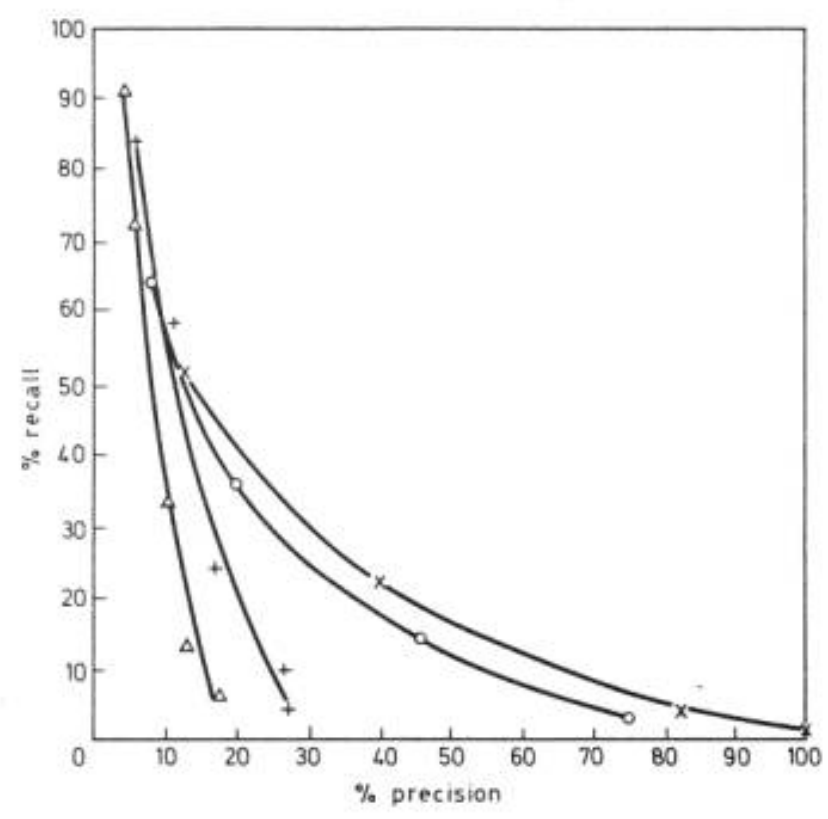

Figura 3.1: Exemplo de curvas recall-precisão.

Existem também outras medidas menos utilizadas como fallout, que indica a quantidade de documentos não relevantes recuperados dentre todos documentos não relevantes do conjunto de documentos, definida pela Equação 3.4, e a medida $F$, que é a média harmônica entre precisão e recall, definida pela Equação 3.5.

$$
\begin{aligned}
& \text { Fallout }=\frac{|\bar{A} \cap B|}{|\bar{A}|} \\
& F=\frac{2}{\frac{1}{\text { Precisão }}+\frac{1}{\text { Recall }}}
\end{aligned}
$$

\subsection{Considerações Finais}

As máquinas de busca na WEB têm seus alicerces na recuperação de informação. Dentre elas, Google (http://www.google.com/), e Yahoo (http: //www.yahoo.com/) estão entre as mais utilizadas, e conseguem recuperar milhões de sites em poucos milésimos de segundo. Porém, não possuem sistemas de realimentação de relevância, o que faz com que exista um número muito grande de $W E B$ sites não relevantes dentre os recuperados, e o uso de filtros de realimentação de relevância poderiam possibilitar uma busca mais individual a cada usuário gerando melhores resultados. 
Nesse capítulo foi feito uma breve revisão sobre a área de RI com um foco maior em RI para a $W E B$, pois o objetivo de nosso trabalho é pesquisar métodos de realimentação de relevância utilizando aprendizado parcialmente supervisionado multidescrição. 


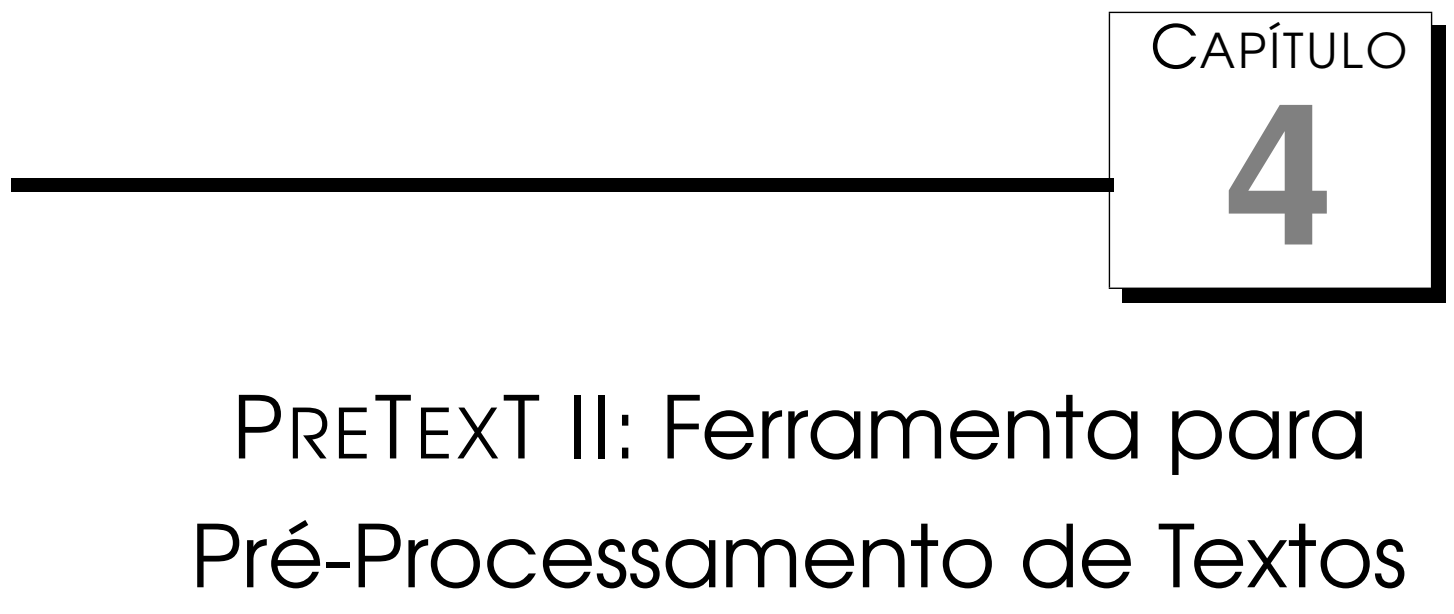

$O$

PRETEXT, proposto por Matsubara et al. (2003), é uma ferramenta computacional que realiza o pré-processamento de textos utilizando a abordagem bag of words e gera uma tabela atributo-valor. A ferramenta foi desenvolvida utilizando o paradigma de orientação a objetos, na linguagem de programação Perl (Schwartz et al., 1997). Desde sua criação, o PRETEXT vem sendo utilizado em diversos trabalhos envolvendo mineração de textos (Weiss et al., 2005; Hotho et al., 2005; Rezende et al., 2003) dentro e fora do ICMCUSP. Essa ferramenta é importante no contexto deste trabalho, pois ela é utilizada para processar os textos dos sites $W E B$ retornados nas consultas dos usuários, as quais devem ser processadas para serem utilizadas por algoritmos de aprendizado parcialmente supervisionado multidescrição. Porém, a ferramenta apresentava algumas deficiências, várias delas apontadas pelos usuários, bem como a falta de algumas funcionalidades para processar WEB sites. Assim, devido a importância dessa ferramenta no desenvolvimento deste trabalho, o PRETEXT passou por um processo de remodelagem e reimplementação e foi criado o PRETExT II (Soares et al., 2008c), uma ferramenta com mais funcionalidades (Soares et al., 2008a), e melhor desempenho computacional (Soares et al., 2008b, 2009).

Neste capítulo são descritas as funcionalidades da ferramenta PRETEXT, e as melhorias, novas funcionalidades e remodelagem realizadas na nova ferramenta PRETEXT II. 


\subsection{Geração de Atributos}

O PRETEXT (Matsubara et al., 2003) implementa as funcionalidades de tokenização, remoção de stopwords e stemming descritas na Seção 3.1, e também várias outras descritas brevemente a seguir.

Taxonomias: Para certos domínios da aplicação, alguns tokens diferentes podem fazer mais sentido se analisados em um nível de abstração mais elevado. Por exemplo, maçã, manga, e uva podem ter um sentido mais geral se forem todos considerados como fruta. Esse tipo de generalização de termos pode auxiliar o processo de aprendizado. A taxonomia é a classificação de objetos baseado em similaridades entre eles. Essa etapa, caso utilizada, deve ser assistida por um especialista no domínio.

Cortes de Palavras Baseado em Frequência: Outra forma de reduzir o número de atributos a ser considerado na tabela atributo-valor é encontrar os tokens mais representativos dentre os existentes. A Lei de Zipf (Zipf, 1949) pode ser usada para encontrar termos considerados pouco representativos em uma determinada coleção de documentos. Luhn usou essa lei como uma hipótese para especificar dois pontos de corte para excluir tokens não relevantes (Luhn, 1958) em uma coleção de documentos. Os termos que excedem o corte superior são os mais frequentes e são considerados comuns por aparecer em qualquer tipo de documento, como as preposições, conjunções e artigos. Já os termos abaixo do corte inferior são considerados raros e, portanto, não contribuem significativamente na discriminação dos documentos. Na Figura 4.1 é mostrada a curva da Lei de Zipf (I) e os cortes de Luhn aplicados a Lei de Zipf (II). Nessa figura, o eixo cartesiano $f$ representa a frequência das palavras e o eixo cartesiano $r, r=1,2,3, \ldots$, as palavras correspondentes, ordenadas segundo essa frequência. Por exemplo, para $r=1, f_{1}$ representa o token de maior frequência; para $r=2, f_{2}$ representa o token com segunda maior frequência, e assim por diante.

$N$-grama: A ocorrência de palavras em sequência pode conter mais informação do que palavras isoladas. Desse modo, criando-se atributos pela união de duas ou mais palavras consecutivas, pode-se gerar atributos com um maior poder de predição. O $n$-grama ${ }^{1}$ é exatamente essa junção de palavras, no qual $n$ representa o número de palavras que foram unidas para a geração de um atributo. Existem vários $n$-grama que são gerados por simples acaso, porém, aqueles que apresentam uma frequência maior podem ser úteis para o aprendizado. Por exemplo, considerar as palavras

\footnotetext{
${ }^{1} \hat{E}$ importante ressaltar que a palavra grama deve ser usada sempre no singular.
} 


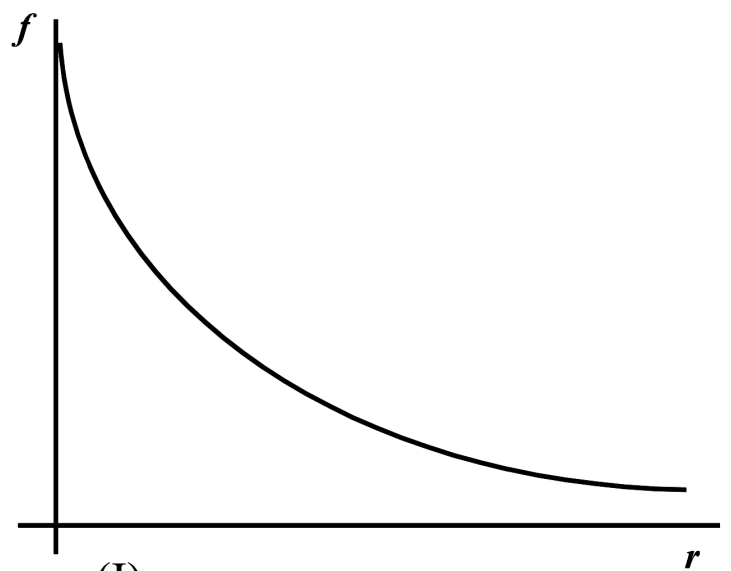

(I) Curva de Zipf

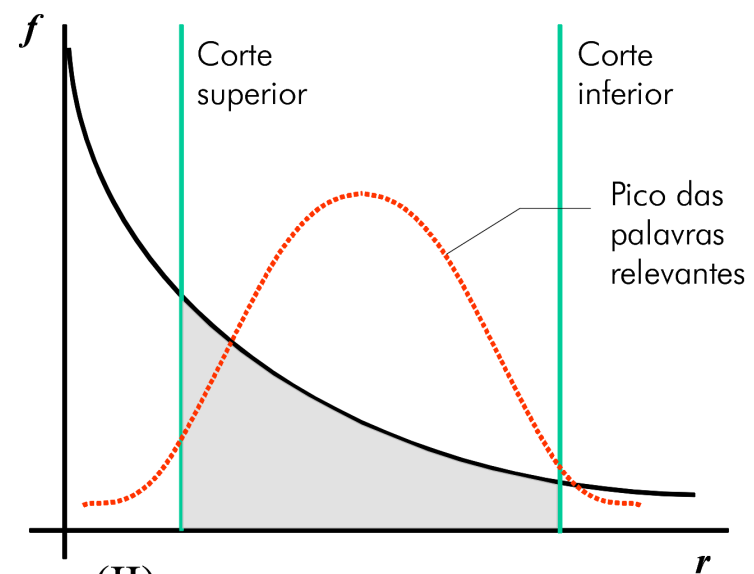

(II) Curva de Zipf e Cortes Luhn

Figura 4.1: A curva de Zipf e os cortes de Luhn

São e Paulo individualmente pode agregar pouco conhecimento, pois São pode referir-se ao verbo ser e Paulo é um nome próprio relativamente comum no Brasil. Entretanto, o termo composto São Paulo pode agregar muito mais informação se o texto se refere à cidade ou estado de São Paulo.

\subsection{Medidas dos Atributos}

Além dessas funcionalidades para auxiliar na redução do número de atributos visando melhorar a relevância da informação para a classificação do texto, a ferramenta PRETEXT implementa as medidas mais comuns da literatura para calcular o valor dos atributos na tabela atributo-valor (Sebastiani, 2002).

Boolean: Essa medida atribui o valor um (verdadeiro) ao atributo se ele existe no documento e zero (falso) caso contrário.

Term Frequency: Essa medida, conhecida também como $t f$, consiste na contagem de aparições de um determinado atributo (termo) em um documento, atribuindo-se essa contagem ao valor do atributo (frequência absoluta).

Term Frequency Linear: Para indicar a frequência com que um termo aparece na coleção de documentos, um fator de ponderação pode ser utilizado para que os termos que aparecem na maioria dos documentos tenham um peso de representação menor. A tf-linear (Matsubara et al., 2003) definida pelas Equações 4.1 e 4.2, utiliza um fator linear de ponderação. Esse fator é dado por um menos a frequência relativa do número de documentos em que o termo aparece no número total de documentos. 


$$
\begin{gathered}
a_{i j}=t \text { flinear }\left(t_{j}, d_{i}\right)=\operatorname{freq}\left(t_{j}, d_{i}\right) \times \operatorname{linear}\left(t_{j}\right) \\
\operatorname{linear}\left(t_{j}\right)=1-\frac{d\left(t_{j}\right)}{N}
\end{gathered}
$$

Term Frequency - Inverse Document Frequency: A tf-idf também é uma medida que pondera a frequência dos termos na coleção de documentos, de tal maneira que termos que aparecem na maioria dos documentos tenham um peso de representação menor (Jones, 1972; Robertson, 2004). Nesse caso, o fator de ponderação $i d f$ é inversamente proporcional ao logaritmo do número de documentos em que o termo aparece no número total $N$ de documentos - Equações 4.3 e 4.4.

$$
\begin{gathered}
a_{i j}=t f i d f\left(t_{j}, d_{i}\right)=\operatorname{freq}\left(t_{j}, d_{i}\right) \times i d f\left(t_{j}\right) \\
i d f\left(t_{j}\right)=\log \frac{N}{d\left(t_{j}\right)}
\end{gathered}
$$

Além das medidas citadas, o PRETEXT possui funcionalidades de suavização caso algum valor de atributo seja zero por conta de seu fator de ponderação e normalização dos dados, tal que documentos pequenos e grandes tenham o mesmo poder representativo.

A seguir são descritas as modificações mais importantes realizadas no PRETEXT, bem como as caracteristicas da nova ferramenta, denominado PRETEXT II, resultante dessas modificações e da introdução de novas funcionalidades.

\subsection{Modificações Realizadas}

Com a reimplementação do PRETEXT II diversas funções foram aperfeiçoadas para que a ferramenta fosse mais flexível e rápida. A seguir são descritas algumas das principais modificações que fizeram do PRETEXT II uma ferramenta que pode atender a um número maior de usuários com interesses diversos. Também são descritos alguns experimentos que comprovam as melhorias incorporadas na ferramenta.

\subsection{Tokenizador e Limpeza dos Dados}

Ao tokenizador da ferramenta PRETEXT II foram adicionados alguns novos tratamentos para que fossem identificados, limpos e agrupados mais tokens 
(termos) semelhantes (Soares et al., 2008a). A identificação de separadores de frases foi implementada facilitando a futura tarefa de geração de $n$-grama. Com a adição dessa funcionalidade não são mais agrupados tokens que são, por exemplo, separados por um ponto final.

Para permitir ao usuário um maior controle sobre a ferramenta, foi adicionada a funcionalidade de remoção de símbolos definidos pelo usuário. $\mathrm{O}$ usuário pode determinar tanto os símbolos que devem ser removidos quanto os que devem ser considerados como divisores de frases. Existem opções, também, de limpeza de números, tags HTML entre outros. Além disso, antes e depois da aplicação do algoritmo de stemming, é feita uma limpeza de espaços e divisores de frases múltiplos, deixando o resultado final o mais limpo e compacto possível.

Uma modificação importante realizada foi a alteração da forma como era chamada a função responsável pela "limpeza" do texto. No PRETEXT, essa remoção era feita considerando uma linha por vez de cada texto. No PRETExT II, essa limpeza é feita uma única vez por documento. Isso evita carregar desnecessariamente a função inúmeras vezes na memória, melhorando o desempenho computacional.

Com o objetivo de comparar a redução do número de atributos do PRETEXT para o PRETEXT II, foi contabilizado o número de tokens distintos considerados por ambas as ferramentas, antes do algoritmo de stemming (Pré-stemming) e no final do processo (Final), considerando o mesmo número inicial de tokens (Início). Na Tabela 4.1 é mostrado o número de tokens diferentes das duas versões da ferramenta.

\begin{tabular}{c||cccc}
\hline \hline & & CD1 & CD2 & CD3 \\
\hline \multirow{3}{*}{ PRETEXT } & Início & 127.829 & 201.533 & 308.465 \\
& Pré-stemming & 55.977 & 79.783 & 110.353 \\
& Final & 31.649 & 44.938 & 62.480 \\
\hline \multirow{3}{*}{ PRETEXT II } & Início & 127.829 & 201.533 & 308.465 \\
& Pré-stemming & 54.041 & 76.116 & 103.976 \\
& Final & 29.329 & 40.925 & 55.789 \\
\hline \hline
\end{tabular}

Tabela 4.1: Comparação de tokens distintos no PRETEXT e no PRETEXT II (Soares et al., 2008a)

Pode ser observado que após a limpeza e o stemming o PRETExT II apresenta uma maior redução do número de atributos em todos os conjuntos de documentos. Cada conjunto de documentos (CD) utilizado nesse experimento consiste de um subconjunto de arquivos textos retirados do corpus do NILC/São Carlos ${ }^{2}$ que contém artigos do jornal Folha de São Paulo de 1994. Ele é composto de 3.341 documentos totalizando 155 MB e está dividido em 22

\footnotetext{
${ }^{2}$ Núcleo Interinstitucional de Linguística Computacional - NILC - http: / /www. nilc. icme . usp.br
} 
classes. A construção de cada um dos três conjuntos de documentos foi realizada retirando de maneira aleatória 150, 300 e 600 documentos respectivamente do conjunto de 3.341 documentos do NILC.

\subsubsection{Algoritmo do Porter para Português}

As modificações realizadas no algoritmo de stemming para português apresentaram uma das mais importantes melhorias no PRETEXT II (Soares et al., 2008b, 2009). Dentre as modificações mais relevantes, destacamos o tratamento de verbos irregulares em português, o qual foi substancialmente melhorado. No PRETEXT, o tratamento de verbos irregulares era caro, pois esse tratamento era feito de forma que cada palavra era analisada individualmente com relação a cada verbo, considerando um verbo de cada vez, para cada um dos 12 verbos irregulares mais comuns da língua portuguesa. No PRETEXT II, foi construído um dicionário de verbos irregulares (por meio de uma tabela hash do Perl que é uma estrutura muito eficiente), de tal maneira que uma simples consulta ao dicionário é feita para esse tratamento. Além disso, a lista de verbos irregulares foi ampliada, contendo agora todas as conjugações dos verbos dar, dizer, estar, fazer, haver, ir, poder, saber, ser, ter, ver, vir, rir, pôr, ler, crer, caber, querer e trazer.

Foi também adicionada a remoção de pronomes oblíquos e plurais antes do processo principal de stemming. Na nova versão, algumas regras foram adicionadas para a remoção dos pronomes oblíquos "me", "te" e "vos", e o tratamento do plural "ções".

Alem disso, foram também melhoradas várias outras regras do algoritmo de stemming para português. Uma descrição detalhada dessas melhorias encontra-se em Soares et al. (2008b, 2009).

Essas modificações no algoritmo de stemming do PRETEXT permitiram diminuir muito o tempo de execução do algoritmo sem afetar a qualidade dos stems gerados, como mostram os resultados da avaliação experimental realizada.

Foram utilizados dois conjuntos de documentos retirados de corpus do NILC/São Carlos. O primeiro conjunto de documentos contém artigos do jornal Folha de São Paulo de 1994, e o segundo artigos do Jornal da USP. No conjunto da Folha de São Paulo, foram utilizados 7 cadernos, com aproximadamente 365 documentos cada. Ou seja, o número de documentos em cada caderno (classe) é praticamente o mesmo ( $\sim 14,4 \%$ ). No conjunto do Jornal da USP, foram utilizados 6 cadernos. Nesse conjunto de documentos o número de documentos em cada caderno é diferente, apresentando alto desbalanceamento entre as classes. O número de documentos do maior caderno é 227 $(34,7 \%)$, enquanto que o do menor caderno é 55 documentos $(8,4 \%)$. 
O algoritmo de stemming do PRETEXT II foi comparado com:

- a versão implementada no PRETEXT do algoritmo de Porter em português (Matsubara et al., 2003); e

- as duas implementação do algoritmo proposto em Orengo \& Huyck (2001), implementados em Perl e disponiveis na internet Lingua::PT::Stemmer ${ }^{3}$ e Lingua::Stem::Pt ${ }^{4}$.

O algoritmo de stemming proposto por Orengo \& Huyck (2001) foi desenvolvido especificamente para o português. Esse algoritmo consiste em um conjunto de 8 passos, executados de acordo com uma ordem pré-definida pelo algoritmo, de tal maneira que os sufixos mais extensos devem ser removidos primeiro (por exemplo, o sufixo de plural es seria removido antes de do sufixo s). Esse algoritmo foi desenvolvido com base nos sufixos mais comuns encontrados no português.

Para comparar o desempenho das quatro implementações de stemming foram medidos:

- o tempo de execução;

- o número de stems gerados; e

- a taxa de erro dos classificadores gerados utilizando os algoritmos de aprendizado C4.5 (Quinlan, 1993) e SVM (Hastie \& Tibshirani, 1998; Keerthi et al., 2001).

Inicialmente, o módulo de limpeza do PRETEXT II foi utilizado para realizar a limpeza dos dois conjuntos de documentos, os quais foram após submetidos a cada um dos algoritmos. Ou seja, o conjunto de documentos processados é idêntico em todos os casos. Na Tabela 4.2 é mostrado o tempo de execução, medido em segundos, obtido com cada um dos algoritmos de stemming. As colunas $P_{F S P}$ e $P_{J U S P}$ mostram a proporção do tempo de execução dos algoritmos considerando o algoritmo do PRETEXT como referência utilizando, respectivamente, o conjunto de documentos da Folha de São Paulo (FSP) e do Jornal da USP (JUSP).

Como pode ser observado, o algoritmo de stemming do PRETEXT II realiza o processo de stemming em um tempo computacional muito menor que os outros algoritmos. No caso do conjunto de documentos da FSP, esse tempo é de somente $15 \%$ do tempo utilizado pelo PRETEXT, e de $16 \%$ para o conjunto de documentos JUSP. Entretanto, o tempo utilizado pelas duas versões do algoritmo proposto por Orengo \& Huyck (2001) é mais de 5 vezes maior que

\footnotetext{
${ }^{3}$ http: / / cpan.uwinnipeg.ca/htdocs/Lingua-PT-Stemmer/Lingua/PT/Stemmer.html

${ }^{4}$ http: / / cpan.uwinnipeg.ca/htdocs/Lingua-Stem/Lingua/Stem/Pt.html
} 


\begin{tabular}{c||c|c||c|c}
\hline \hline & Folha de & & Jornal da & \\
& São Paulo & $P_{F S P}$ & USP & $P_{J U S P}$ \\
\hline PRETEXT II & 471 & 0,15 & 19 & 0,16 \\
\hline PRETEXT & 3.195 & 1,00 & 117 & 1,00 \\
\hline Lingua::PT::Stemmer & 16.225 & 5,08 & 594 & 5,08 \\
\hline Lingua::Stem::Pt & 16.341 & 5,11 & 627 & 5,36 \\
\hline \hline
\end{tabular}

Tabela 4.2: Tempo de Execução do Algoritmo de stemming em Segundos (Soares et al., 2008b).

o algoritmo do PRETEXT. Quando comparado diretamente com o algoritmo do PRETEXT II, o tempo de execução de ambas versões é mais de 30 vezes maior que o novo algoritmo de stemming do PRETEXT II.

Na Tabela 4.3 é mostrado o número de stems gerados por cada algoritmo. Como anteriormente, as colunas $S_{F S P}$ e $S_{J U S P}$ mostram a proporção do número de stems gerados pelos algoritmos considerando o algoritmo do PRETEXT como referência.

\begin{tabular}{c||c|c||c|c}
\hline \hline & Folha de & & Jornal da & \\
& São Paulo & $S_{F S P}$ & USP & $S_{J U S P}$ \\
\hline PRETEXT II & 95.589 & 0,98 & 17.611 & 0,96 \\
\hline PRETEXT & 97.400 & 1,00 & 18.179 & 1,00 \\
\hline Lingua::PT::Stemmer & 90.501 & 0,92 & 16.751 & 0,92 \\
\hline Lingua::Stem::Pt & 90.501 & 0,92 & 16.751 & 0,92 \\
\hline \hline
\end{tabular}

Tabela 4.3: Número de stems Gerados (Soares et al., 2008b).

Pode ser observado que o número de stems gerados tanto pelo algoritmo da ferramenta PRETEXT II quanto pelas duas implementações do algoritmo proposto por Orengo \& Huyck (2001), é menor que o gerado pelo algoritmo do PRETEXT. Porém, o número de stems gerados pelo algoritmo proposto por Orengo \& Huyck (2001) é significantemente menor, confirmando os resultados e conclusões publicados pelos autores.

Finalmente, com o objetivo de verificar a qualidade dos stems gerados para construir modelos de classificação, foram gerados os classificadores correspondentes aos dois conjuntos de documentos utilizando a ferramenta DISCOVER (Prati, 2003) com o algoritmo C4.5 (Quinlan, 1993), executado com parâmetros default, e a ferramenta Weka (Witten \& Frank, 2005) com o algoritmo SVM (Hastie \& Tibshirani, 1998; Keerthi et al., 2001), utilizando o método SMO com kernel polinomial e parâmetros default. A taxa de erro dos classificadores foi estimada utilizado 10-fold stratified cross validation. Foram feitos cortes apropriados por frequência do atributo (cortes de Luhn) em ambos os conjuntos de dados. O conjunto da Folha de São Paulo teve o corte de mínimo 15 e máximo 1500, e o conjunto do jornal da USP teve o corte de mínimo 50 e máximo 500. 
Para o conjunto de documentos da Folha de São Paulo, ambos algoritmos obtiveram bons resultados utilizando as tabelas atributo-valor geradas por cada um dos quatro algoritmos de stemming, como mostrado na Tabela 4.4. Os resultados obtidos com C4.5 mostram que há uma diferença mínima para mais do algoritmo do PRETEXT II com relação aos algoritmos de Orengo \& Huyck (2001). No entanto, houve uma pequena melhora com relação ao algoritmo do PRETEXT. Já para SVM, o cenário é diferente. O erro do novo algoritmo de stemming do PRETEXT II e dos que implementaram Orengo \& Huyck (2001) são iguais, enquanto que o algoritmo do PRETEXT apresenta melhores resultados. Entretanto, não há diferença significativa nesses resultados.

\begin{tabular}{|c||c|c|}
\cline { 2 - 3 } \multicolumn{1}{c||}{} & C4.5 & SVM \\
\hline \hline PRETEXT II & 7,31 & 0,83 \\
\hline PRETEXT & 8,29 & 0,67 \\
\hline Lingua::PT::Stemmer & 7,19 & 0,83 \\
\hline Lingua::Stem::Pt & 7,19 & 0,83 \\
\hline \hline
\end{tabular}

Tabela 4.4: Taxa de erro dos algoritmos C4.5 e SVM para o conjuntos de documentos da Folha de São Paulo processados com cada algoritmo de stemming (Soares et al., 2008b).

Para o conjunto de documentos do Jornal USP, os algoritmos de aprendizado tiveram resultados insatisfatórios e, algumas vezes, o erro foi maior que o erro majoritário $(65,29 \%$ ), como mostrado na Tabela 4.5. Com o C4.5, somente a base de dados gerada usando o algoritmo de stemming do PRETExT II obteve um erro menor que o erro majoritário, porém muito próximo a ele. Todas as outras bases tiveram erros maiores do que o erro majoritário. Já para o algoritmo SVM, o erro dos classificadores é menor que o erro majoritário. Entretanto, esses erros são muito altos, o que mostra que não há uma boa divisão entre as classes. Como mencionado anteriormente, esse conjunto de documentos apresenta um forte desbalanceamento entre as classes, o que também pode contribuir para o fraco desempenho dos classificadores gerados.

\begin{tabular}{|c||c|c|}
\cline { 2 - 3 } \multicolumn{1}{c||}{} & C4.5 & SVM \\
\hline \hline PRETEXT II & 64,70 & 48,62 \\
\hline PRETEXT & 67,58 & 48,17 \\
\hline Lingua::PT::Stemmer & 66,52 & 48,78 \\
\hline Lingua::Stem::Pt & 67,13 & 48,78 \\
\hline \hline
\end{tabular}

Tabela 4.5: Taxa de erro dos algoritmos C4.5 e SVM para o conjuntos de documentos do jornal da USP processados com cada algoritmo de stemming (Soares et al., 2008b).

A partir de todos os resultados obtidos na comparação das implementações dos algoritmos de stemming, pode-se verificar a grande melhoria do algoritmo de stemming do PRETEXT II em termos de desempenho computacional. Assim, 
no que se refere à velocidade de processamento, o algoritmo de stemming do PRETEXT II conseguiu resultados muito melhores que todos os outros algoritmos. Considerando os demais parâmetros avaliados, não foram encontrados diferenças significativas.

\subsubsection{N-grama e Outras Modificações}

Outra melhoria introduzida no PRETEXT II está relacionada com a geração de n-grama. Na geração de $n$-grama, o PRETEXT construía um, dois e trêsgramas simultaneamente, armazenando todos os $n$-grama na memória antes da criação dos arquivos de saída. Essa operação demandava muita memória, ocupando muito rapidamente toda a memória disponível. O PRETEXT II executa os $n$-grama de maneira independente e separada para cada valor de $n$, e gera os arquivos de saída antes de considerar o próximo valor de $n$. É importante ressaltar que, diferentemente do PRETEXT, no PRETEXT II não existe um valor fixo predeterminado de $n$, o qual pode assumir qualquer valor. Isso possibilita a geração de atributos com qualquer número de $n$-grama.

Outra mudança significativa leva em conta como é feita a divisão das frases. No PRETEXT, a criação dos $n$-grama era feita com todos os tokens existentes em um parágrafo, delimitado apenas por uma nova linha. Já o PRETEXT II, com as separações de frases já identificadas pelo tokenizador, não gera $n$-grama com tokens de frases diferentes. Essa simples abordagem reduz significativamente o número de $n$-grama distintos.

Foi também introduzida no PRETEXT II a facilidade para corte por frequência de documentos, ou seja, para eliminar tokens que estão presentes em menos, ou mais documentos que o limite determinado pelo usuário. Foi implementada também a funcionalidade de criar tabelas atributo-valor transpostas. Deve ser resaltado que após a remodelagem realizada, outras funções de stemming, medidas e normalizações podem ser facilmente incorporadas ao PRETEXT II.

\subsection{Características da Nova Ferramenta}

Após a introdução das melhorias descritas e a remodelagem, a ferramenta PRETEXT II possui as características que estão ilustradas na Figura 4.2 e explicadas brevemente a seguir.

- O módulo Start.pl lê o arquivo de configuração config.xml e, com base nos parâmetros especificados nesse arquivo, gerencia os demais módulos. 


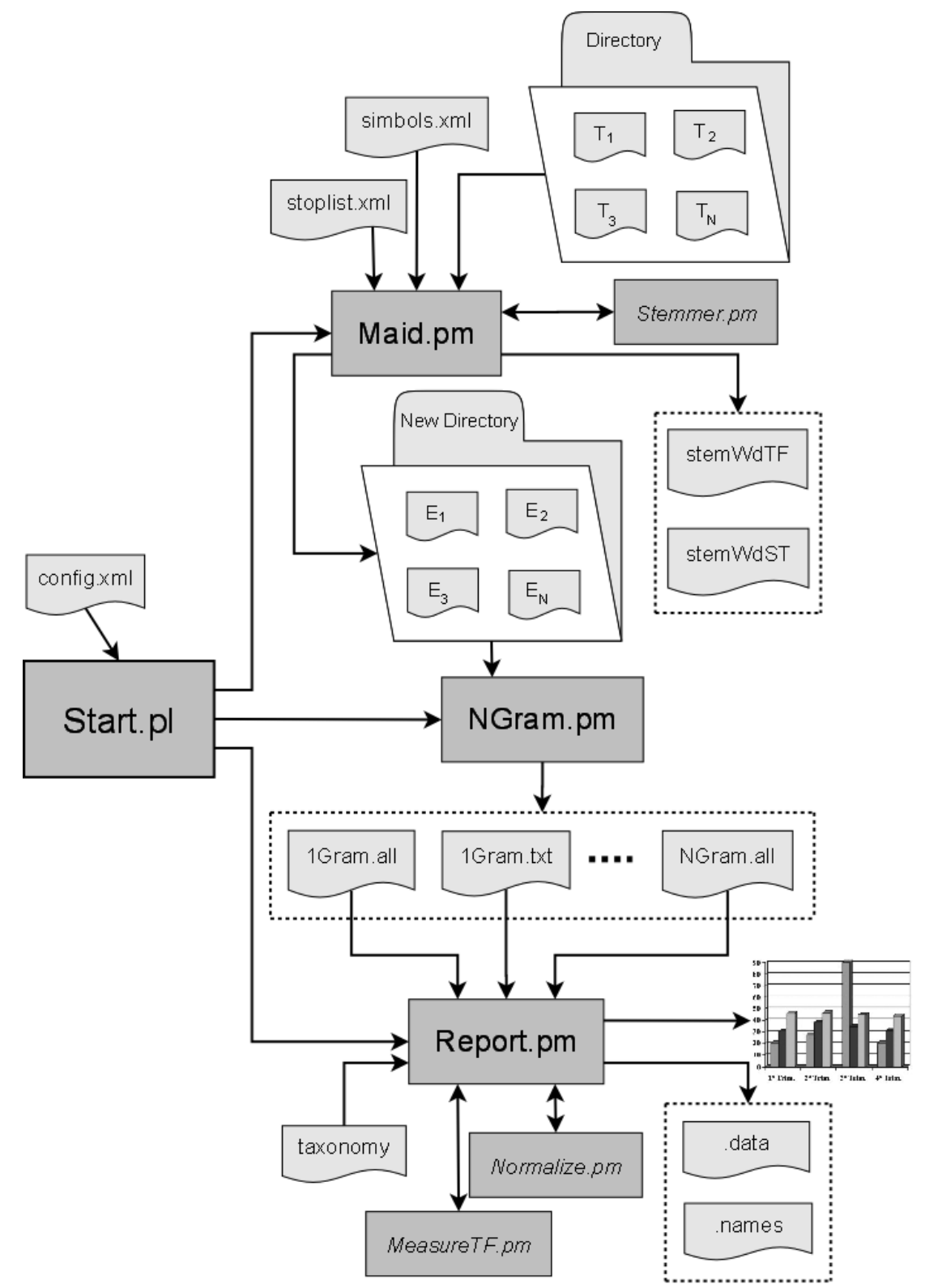

Figura 4.2: O novo funcionamento do PRETEXT II

- O módulo Maid.pm é responsável pela limpeza do conjunto de documentos iniciais $\left\{T_{1}, T_{2}, \ldots, T_{N}\right\}$, remoção das stopwords contidas no arquivo stoplist.xml e remoção de símbolos não relevantes a partir do arquivo simbol.xml. A geração dos stems é realizada por uma das classes que herdam da classe abstrata Stemmer.pm e contém o algoritmo de stemming para a linguagem solicitada. No PRETEXT II, estão disponiveis algoritmos de stemming para as línguas portuguesa, espanhola e inglesa. Como resultado, são gerados os arquivos stemWdTF.all (stems ordenados por frequência) e stemWdST.all (stems ordenados por ordem alfabética), os quais contem a contagem de stems e os tokens que foram transformados em cada stem, além de um conjunto de arquivos "limpos" $\left\{E_{1}, E_{2}, \ldots, E_{N}\right\}$, que são utilizados como entrada para o módulo NGram.pm. 
- O módulo NGram.pm é responsável pela geração dos n-grama e tem como saída os arquivos NGram.txt (contagem de $n$-grama em cada documento) e NGram.all (contagem de $n$-grama total do conjunto de documentos), com $n=1,2,3, \ldots$.

- O módulo Report.pm recebe como entrada os arquivos .txt e .all, faz o processamento das taxonomias contidas no arquivo taxonomy caso exista e calcula as medidas e normalizações solicitadas pelo usuário. O cálculo dessas medidas e normalizações é realizado pelas classes que herdam das classes abstratas MeasureTF.pm e Normalize.pm, produzindo como resultado uma tabela atributo-valor no formato do DSX do DISCOVER (Prati, 2003; Batista, 2003), arquivos .data e .names respectivamente, e alguns gráficos.

Realizando o pré-processamento de textos utilizando a nova versão da ferramenta PRETEXT é possível calcular uma grande quantidade de informação referente aos documentos processados, tais como os arquivos limpos, e todos os arquivos de saída com informações sobre tokens, stems e $n$-grama, assim como a tabela atributo-valor no formato requisitado pelo usuário. $\mathrm{Na}$ Tabela 4.6 são mostradas as principais funcionalidades de cada módulo.

\begin{tabular}{|l|l|l|}
\hline Maid.pm & NGram.pm & Report.pm \\
\hline \hline limpeza dos documentos & $\begin{array}{l}n \text {-grama para qualquer } \\
\text { valor de } n\end{array}$ & gráficos \\
\hline remoção de tags HTML & & cortes por frequência \\
\hline tratamento de símbolos & & cortes por documentos \\
\hline stoplist XML & taxonomia \\
\hline $\begin{array}{l}\text { stemming para portu- } \\
\text { guês, inglês e espanhol }\end{array}$ & $\begin{array}{l}\text { normalizações por linha } \\
\text { e coluna: quadrática e li- } \\
\text { near* }\end{array}$ \\
\hline $\begin{array}{l}\text { criação dos arquivos } \\
\text { "limpos" }\end{array}$ & $\begin{array}{l}\text { medidas: tf-idf, tf, tf- } \\
\text { linear e boolean" }\end{array}$ \\
\hline & $\begin{array}{l}\text { tabela atributo-valor } \\
\text { transposta }\end{array}$ \\
\hline
\end{tabular}

Tabela 4.6: Funcionalidades da nova versão do PRETEXT

*Essas funcionalidades podem ser facilmente estendidas.

\subsection{Considerações Finais}

Neste capítulo foi apresentada a nova ferramenta PRETEXT II, que obteve uma grande melhoria em seu desempenho computacional comparada com a ferramenta PRETEXT anterior. Essa melhoria permite que o PRETEXT II possa ser aplicado em situações que exijam o pré-processamento de grandes volumes de dados em um tempo computacional baixo. 
O PRETEXT II possibilita que futuros usuários possam explorar melhor as suas funcionalidades. A ferramenta conta agora com inúmeras novas facilidades tais como uma limpeza de dados mais apurada; a remoção de símbolos especiais indicados pelo usuário; a remoção de tags HTML; a geração de $n$-grama para qualquer valor de $n$; maiores facilidades para cortes por frequência de documentos; geração de tabelas transpostas, entre outros. Atualmente, existe a possibilidade de ativação e desativação da maioria das funcionalidades do PRETEXT II. Deve ser observado que a implementação modular do PRETEXT II permite também implementar novas medidas, normalizações ou outros algoritmos de stemming sem a necessidade de alteração do código existente. 


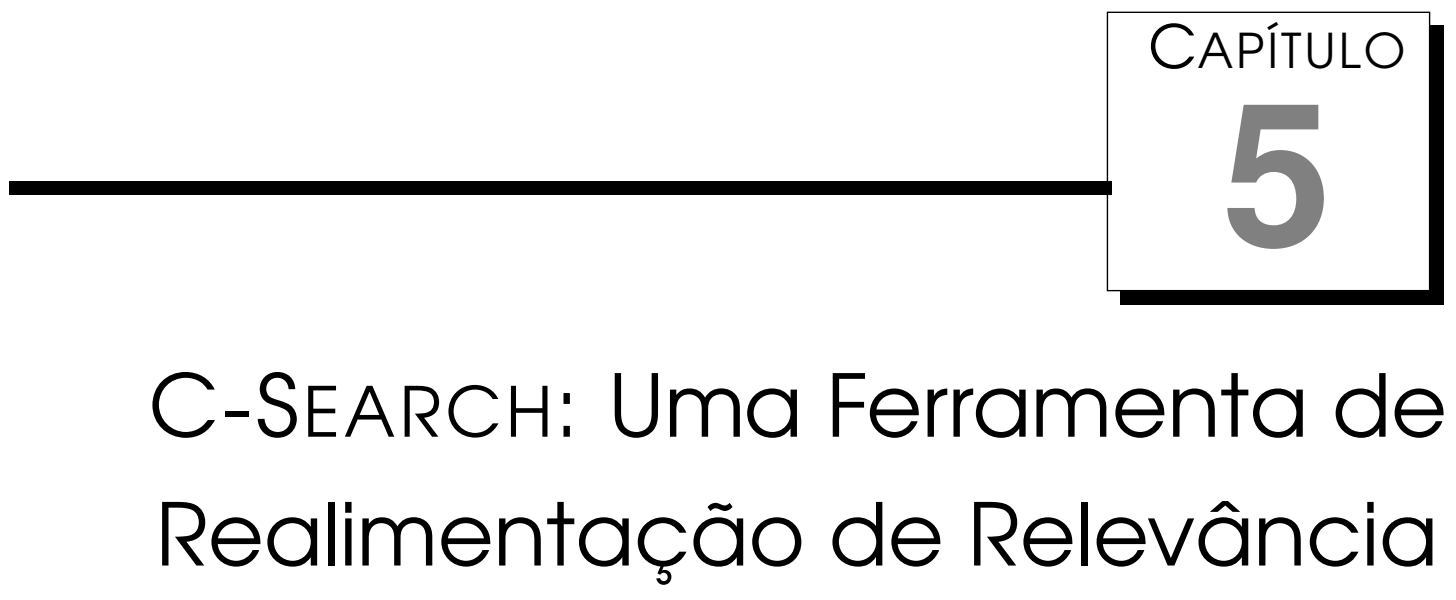

om o objetivo de avaliar a hipótese deste trabalho, foi implementada uma ferramenta de realimentação de relevância para reordenação dos

rankings de uma busca, denominada $\mathrm{C}-\mathrm{SEARCH}{ }^{1}$. Essa ferramenta reorganiza os resultados de uma busca na $W E B$ visando personalizar o resultado final a partir dos interesses do usuário, utilizando-se do processo de aprendizado de máquina parcialmente supervisionado multidescrição. Neste capítulo é apresentado a ferramenta C-SEARCH, bem como uma explicação de seu funcionameto.

\subsection{Visão Geral da Ferramenta}

Na Figura 5.1 é mostrada a visão geral da ferramenta. A partir de uma pesquisa realizada pelo usuário $(I)$, o motor de busca $(I I)$ retorna os sites que contêm os resultados iniciais dessa busca $(I I I)$. Esses três passos são realizados comumente no dia a dia da maioria dos usuários da Internet ao fazer uma pesquisa em um sistema de busca qualquer. Analizando esses resultados iniciais, o usuário deve rotular alguns poucos exemplos (sites) como relevantes ou irrelevantes utilizando somente sua opinião pessoal quanto à relevância do tema que está procurando $(I V)$. Com essa informação, o sistema C-SEARCH gera duas visões $V_{1}$ e $V_{2}$ a partir dos resultados $(V)$, as quais são processadas pela ferramenta PRETexT II (VI) para a criação das duas tabelas

${ }^{1}$ http://sistemas.labic.icmc.usp.br:8088/realimentar/ 
atributo-valor correspondentes $(V I I)$. Essas tabelas são então utilizadas pelo CO-TRAINING (VIII) para gerar novos rankings para os sites da pesquisa inicial, obtendo então o resultado final $(I X)$, em que esses sites são mostrados ao usuário na ordem de relevância encontrada pelo C-SEARCH. Os passos $I V$ à $I X$ representam a realimentação de relevância realizada pela ferramenta C-SEARCH.

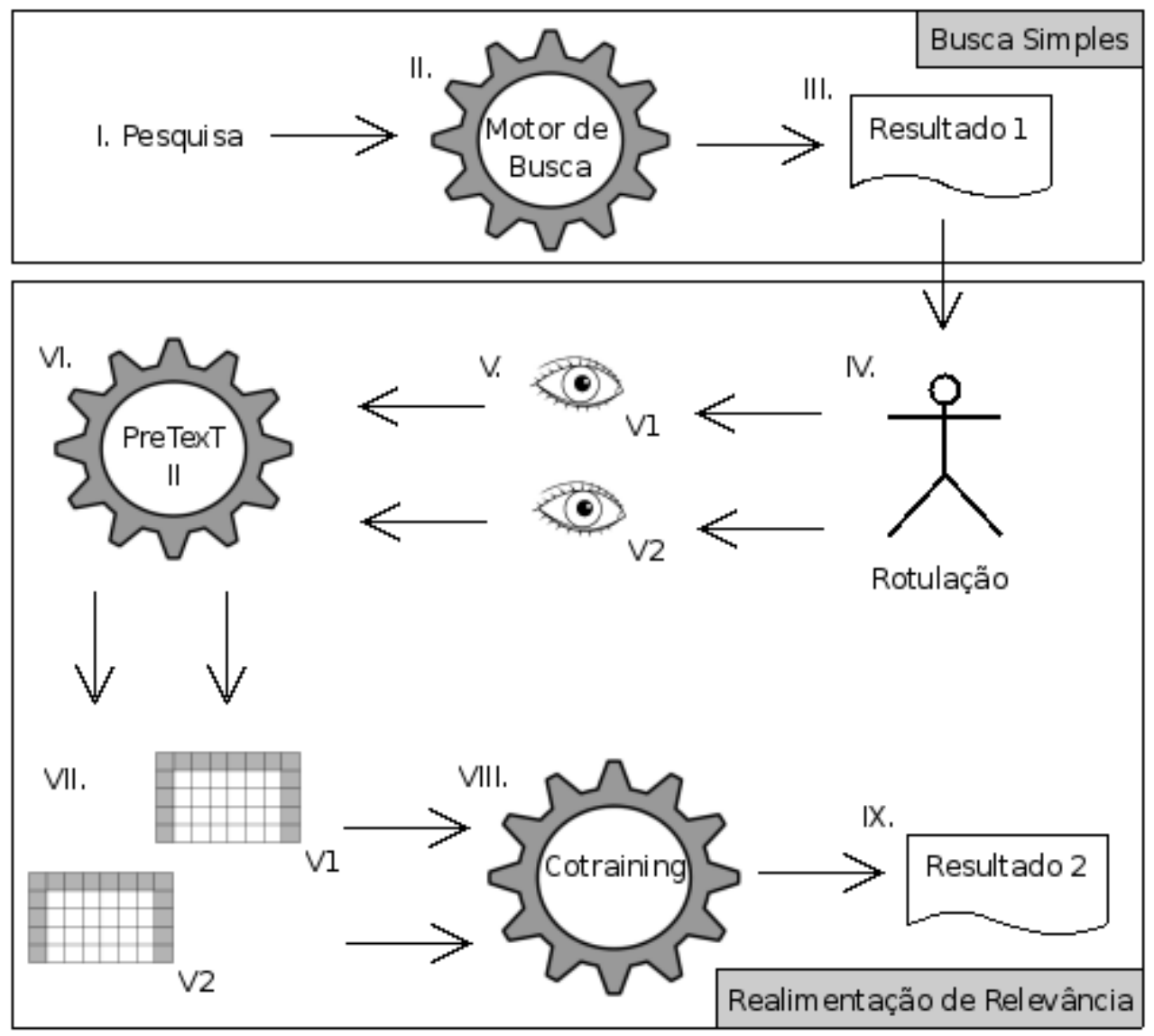

Figura 5.1: Visão geral da ferramenta C-SEARCH

Em outras palavras, a partir de uma busca realizada pelo Yahoo! Search $A P I^{2}$, e poucos sites indicados pelo usuário como relevantes ou irrelevantes, o C-SEARCH realiza o processo descrito para reordenar o resultado da busca de maneira que os resultados mais relevantes segundo as preferências do usuário devem aparecer antes dos resultados que são considerados irrelevantes, dessa maneira personalizando o sistema de busca.

Nas próximas seções são explicados em maiores detalhes o uso dos componentes do C-SEARCH. 


\subsection{Motor de Busca}

Para realizar a primeira busca - Busca Simples na Figura 5.1 - para execução deste trabalho, foi necessária a utilização de um motor de busca externo, a partir de um serviço fornecido por algum sistema de busca já existente. Foram estudadas as possibilidades de utilização do motor de busca do Google e do Yahoo!, por serem atualmente os motores de busca mais utilizados na Internet. Ambos oferecem $\mathrm{APIs}^{3}$ para a utilização de seus motores de busca fora de seus próprios sistemas $W E B$, o que permite, entre outros, personalizar os resultados da busca levando em conta as preferências do usuárioprogramador.

Deve ser observado que no passado o Google oferecia uma API que devolvia buscas na $W E B$ em formato estruturado em arquivos XML. Porém, essa API foi descontinuada alguns anos atrás, e não são mais liberadas chaves para sua utilização. Para substituir essa primeira API do Google, foi criado a Google AJAX Search $A P I^{4}$, uma nova API para utilização de seu motor de busca no site do usuário, com algumas personalizações de como a busca deve ser filtrada. Essa API não se mostrou apropriada para os propósitos deste trabalho por não retornar um formato estruturado. Assim, o sistema de busca do Google, apesar de ser a nossa primeira opção, teve que ser deixado de lado.

Por outro lado, o Yahoo! oferece a Yahoo! Search API, uma API de busca na qual o resultado é retornado em um formato estruturado, podendo ser XML, JASON, ou PHP. Essa API, apesar de algumas limitações, fornece as facilidades necessárias para a realização deste trabalho. Uma das limitações está relacionada a máxima quantidade de sites retornados na busca, que é de cem sites. Entretanto, o Yahoo! Search API oferece uma vasta gama de opções de busca que podem ser configuradas de modo a personalizar ao máximo o tipo de busca desejada. A partir da criação de uma chave de utilização chamada appid, o usuário pode realizar 5.000 buscas por IP por dia, ainda que somente para sistemas sem uso comercial.

\subsection{CO-TRAINING E PRETEXT II}

O Discover (Prati, 2003) é um framework, criado no LABIC, que integra diversos algoritmos de aprendizado de máquina existentes na literatura. Esse framework é implementado com o paradigma de orientação a objetos e com-

\footnotetext{
${ }^{3}$ API, de Application Programming Interface (ou Interface de Programação de Aplicativos), são rotinas pré-estabelecidas para utilização de um software na qual o usuário-programador não precisa saber o funcionamento interno da aplicação, e somente interessa o que é retornado como resultado.

${ }^{4}$ http://code.google.com/intl/pt-BR/apis/ajaxsearch/
} 
posto de classes para facilitar seu uso. Neste trabalho foi utilizada a implementação do algoritmo CO-TRAINING realizada por Matsubara (2004), disponível no Discover, utilizando o algoritmo Naive Baiyes como algoritmo base. Na implementação de Matsubara (2004), a função melhores/2 implementada, Seção $2.3 \mathrm{pg}$. 12, somente rotula um exemplo se ele for rotulado por $h_{D_{1}} \mathrm{e}$ $h_{D_{2}}$ com a mesma classe na visão correspondente. Deve ser observado que o grau de confiança para rotular exemplos é um parametro dessa função. Nos experimentos realizados neste trabalho foram utilizados diversos valores de confiança.

Um ponto importante a ser ressaltado quanto a função melhores/2 proposta por Matsubara (2004) é que, durante a etapa de treinamento, o COTRAINING não rotulará exemplos (ou pontos) de contenção, i.e. exemplos que são rotulados por $h_{D_{1}}$ e $h_{D_{2}}$ com classes diferentes.

Recapitulando, após serem recuperados os sites pelo Yahoo! Search API e o usuário informar os sites relevantes ou irrelevantes correspondentes à sua consulta - etapas $I I I$ e $I V$ respectivamente na Figura 5.1 - cada site é descrito pelas duas seguintes visões - etapa $V$ na Figura 5.1:

1. título do site (title); e

2. descrição do site (summary),

para a utilização do algoritmo CO-TRAINING. Ambas visões são submetidas a um pré-processamento, realizado pela ferramenta PRETEXT II - etapa VI na Figura 5.1 -, com o objetivo de transformar a informação textual dessas visões para o formato tabela atributo-valor - etapa VII na Figura 5.1 apropriado para o algoritmo base utilizado pelo CO-TRAINING - etapa VIII na Figura 5.1.

\subsection{Processo de Execução}

O processo de execução da ferramenta C-SEARCH é descrito a seguir considerando esse processo na perspectiva do usuário e no seu funcionamento interno.

\subsection{Perspectiva do Usuário}

O usuário encontra um sistema de busca similar aos sistemas atuais do mercado, no qual pode ser realizada uma busca em português, inglês ou espanhol, digitando uma ou mais palavras no campo de busca e ativando a opção "Pesquisar". Como resultado, serão retornados de zero a cem (0 a 100) sites relacionados a essa busca e o usuário pode, então, indicar dentre os resultados os sites que considera relevantes ou irrelevantes de acordo com sua 
opinião pessoal. Resultados da busca que não sejam indicados como relevantes ou irrelevantes pelo usuário são considerados exemplos não rotulados, os quais serão rotulados pelo sistema utilizando o CO-TRAINING. A Figura 5.2 mostra o visual do sistema C-SEARCH.

Deve ser observado que é mandatório que o usuário indique quantidades similares de sites relevantes e irrelevantes, com a diferença máxima de um site. Também é mandatório que seja indicado no mínimo um site relevante e um irrelevante. Após esse processo, o usuário deve ativar a opção "Realimentar" e o sistema C-SEARCH internamente reordena todas os sites e retorna a resposta ao usuário. O usuário tem ainda a opção de alterar entre dois tipos de ranking, como explicado a seguir.

\subsubsection{Funcionamento Interno}

Após o usuário digitar a busca desejada, o C-SEARCH verifica no cache do sistema se o arquivo correspondente a essa busca já existe e, caso exista, verifica se foi modificado nas últimas 2 horas. Caso o arquivo cache não exista, ou, se existir, não foi modificado nas últimas 2 horas, o C-SEARCH faz uma requisição ao Yahoo! Search API que retorna o resultado da busca em formato XML, e o sistema armazena esse resultado em seu cache. Esse processo de backup das buscas em forma de cache propicia ao C-SEARCH realizar buscas mais rápidas, uma vez que não é necessário sempre consultar a API, e também garante que o sistema vai demorar mais para utilizar as 5.000 buscas máximas que a API oferece por dia.

Com o resultado carregado no sistema, ele é formatado e exibido na tela do usuário para que possa ser feita a seleção de sites relevantes e irrelevantes. São exibidos sempre grupos de 10 resultados (sites) com no máximo 10 grupos (telas), sendo possível selecionar qualquer resultado como relevante e irrelevante independente do grupo em que se encontra. Por exemplo, o usuário pode indicar o primeiro resultado, que estará no primeiro grupo, como relevante e o vigésimo quinto resultado, que estará no terceiro grupo, como irrelevante.

Ao ativar a opção "Realimentar", o sistema verifica se foram indicados ao menos um resultado como relevante e um como irrelevante, e verifica se os resultados indicados têm números iguais de relevantes e irrelevantes com a diferença máxima de um. Após essas verificações, é dado início o processo de aprendizado semissupervisionado.

Inicialmente, como já mencionado, o sistema cria dois conjuntos de documentos texto, um para o título dos sites e outro para a descrição dos sites. Cada site é armazenado em um arquivo diferente, que tem seu equivalente nos dois conjuntos de documentos. Esse processo é realizado para facilitar a utilização da ferramenta PRETEXT II para a criação das tabelas atributo-valor 


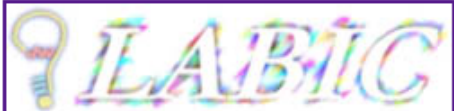

caneca

Português $:$ Pesquisar

Resultados 1 - 10 de 100 (Gerado em 0.0299 segundos)

Relevantes: 2

Irrelevantes: 2

Realimentar Limpar

1 - .:: Caneca.Com :.:Canecas personalizadas. Canecas plásticas ...

Relevante Caneca.com - Canecas Personalizadas ... Quem somos. www.caneca.com.br uma empresa do Grupo BB,

Indiferente especializada na produção de canecas ...

- Irrelevante http://www.caneca.com.br/

2 - Caneca - Wikipédia, a enciclopédia livre

Relevante Caneca. Origem: Wikipédia, a enciclopédia livre. Ir para: navegação, pesquisa ... Frei Caneca, religioso e político

- Indiferente brasileiro; Célio Caneca, lutador e mestre ...

Irrelevante http://pt.wikipedia.org/wiki/Caneca

3 - Caneca \& Cia

Relevante Kel às 11:59 AM || Encha a caneca | ou se preferir, aqui []. sexta-feira, 8 de abril de 2005 ... 05:01 PM || Encha Indiferente a caneca | ou se preferir, aqui []. quinta ...

- Irrelevante http://kel.blogbrasil.com/

4 - Acessórios: Canecas: - Linux Mall

Relevante Caneca Debian, R\$ 14.90. Caneca Double Space (Branca), R\$ 14.90 ... Caneca Hacked by Linux c/ Tux (Preta),

- Indiferente R\$14.90. Caneca Infectious Liquid, $200 \mathrm{ml}$ (Inox), R\$ $19.90 \ldots$

Orrelevante http://www.linuxmall.com.br/?category=canecas

5 - Caneca, Mug - Compare todas as ofertas com Twenga

Relevante Compare todas as ofertas de Caneca, Mug entre milhares de lojas e compre pelo melhor preço Caneca, Mug

- Indiferente ... para Camping > CANECA EXPONENT MONTAIN - COLEMAN" ...

Orrelevante http://www.twenga.com.br/dir-Casa,Louca,Caneca

6 - Frei Caneca - Wikipédia, a enciclopédia livre

- Relevante Frei Caneca apoiou a formação da primeira Junta Governativa de Pernambuco, ... Em 1824 Frei Caneca se

Indiferente tornou um dos conselheiros de Manuel de Carvalho Pais de ...

OIrrelevante http://pt.wikipedia.org/wiki/Frei_Caneca

7 - Shopping Frei Caneca

Relevante

Indiferente Mostra relação de lojas e programação das salas de cinema do Unibanco Arteplex.

Orrelevante

8 - Bolo de Caneca - Receita de Bolo de Caneca| Resumo do Dia

Relevante A Receita de Bolo de Caneca passou a interessar muitas pessoas após ser exibida no domingo (02/11/08) no

- Indiferente quadro 1001 Dicas do programa Tudo é Possível, de

OIrrelevante http://resumododia.com/bolo-de-caneca-receita-de-bolo-de-caneca/

9 - Caneca Slackware

Relevante Fãs do Slackware, com vocês a. caneca mais esperada de todos os tempos! Mostre aos seus amigos através

- Indiferente de 3 palavras por que vale a pena usar o...

Orrelevante http://www.linuxmall.com.br/index.php?product_id=3107\&fil=linuxclube.com

10 - Bolo na Caneca - Receitas de Bolo na Caneca

Relevante o bolo de caneca deixou muitas pessoas curiosas após ter sua receita divulgada no domingo (02/11/200) no

- Indiferente programa Tudo é Possível no quadro 1001 Dicas da

OIrrelevante http://www.mundodastribos.com/bolo-na-caneca-receitas-de-bolo-na-caneca.html

$$
1 \underline{2} \underline{3} \underline{4} \underline{5} \underline{6} \underline{7} \quad \underline{8} \underline{9} \underline{10}
$$

Figura 5.2: O sistema C-SEARCH

correspondentes. Cada um dos dois conjuntos de documentos é utilizado no PRETEXT II separadamente. Deve ser observado que ambos os conjuntos têm a configuração básica do PRETexT II para limpeza de números, tags HTML, 
símbolos não alpha-numéricos, stoplists em português e inglês e stemming na língua selecionada na busca, podendo ser português, inglês ou espanhol.

Para o conjunto de documentos correspondente aos títulos dos sites, os atributos são definidos utilizando um-grama conjuntamente com bi-grama. Isso deve-se ao fato de que os títulos são normalmente compostos por poucas palavras e espera-se que o uso conjunto de um-grama e bi-grama incrementem a quantidade de informação contida nesses títulos. Por outro lado, no conjunto de documentos da descrição dos sites é utilizado somente um-grama. Para ambos os conjuntos é realizado o corte por frequência de palavras da seguinte maneira:

1. São desconsiderados os atributos cuja frequência no conjunto de documentos seja menor ou igual a 2; e

2. São desconsiderados os atributos que aparecem somente em até 2 documentos, bem como os que aparecem em mais de 80 documentos.

Esses cortes foram decididos empiricamente a partir da analise dos resultados de alguns experimentos.

Após a execução do PRETEXT II, tem-se as duas tabelas atributo-valor, cuja estrutura de dados é adaptada para a estrutura utilizada no sistema Discover. Cada tabela representa uma descrição dos dados, e existem tuplas equivalentes em ambas as tabelas. Essas tabelas, então, são utilizadas pelo algoritmo CO-TRAINING, o qual foi adaptado para realizar a rotulação em três etapas que servem aos propósitos deste trabalho, descritas a seguir.

O CO-TRAINING é executado em três etapas com configurações diferentes para que seja classificado o maior número possivel de sites. O objetivo da primeira etapa é manter balanceada a classificação dos sites, pois o número de sites inicialmente classificados pelo usuário pode representar somente $2 \%$ do conjunto de sites. Nessa etapa somente são classificados sites nos quais $h_{D_{1}}$ e $h_{D_{2}}$ coincidem na classificação com um grau de confiança maior que 0.55 , visando incrementar o pequeno número de sites classificados. Para manter o balanceamento, o CO-TRAINING força para que seja rotulado sempre um site de cada classe. Ou seja, caso não haja um site com o grau de confiança maior que 0.55 em uma das classes, não será rotulado também o site da outra classe, e o CO-TRAINING executará a próxima iteração.

Foi observado que nesta etapa, em conjuntos de sites nos quais o algoritmo consegue encontrar facilmente padrões que distinguem claramente sites relevantes de irrelevantes, é classificada grande parte dos sites. Na realidade, esta primeira etapa do CO-TRAINING é importante no caso de não existir padrões que distinguem claramente entre as duas classes. Nesses casos, foi observado que esta primeira classificação é muito importante para controlar o balanceamento na rotulação dos sites. 
Na segunda etapa do CO-TRAINING, a restrição de classificar um site de cada classe é retirada, sendo possível classificar até 2 sites de cada classe em cada iteração, i.e. zero, um ou dois sites de cada classe são classificados. Nesta etapa, o limiar de classificação sobe para 0.60 de confiança. Essa é a principal etapa de classificação, na qual a maior parte do conjunto de sites deve ser classificado.

Quando é encerrada a segunda etapa, algumas vezes ficam para trás alguns bons exemplos que poderiam ser classificados mas não foram por causa do limite de 2 sites por classe. Assim, é realizada a terceira etapa, com apenas uma iteração, na qual todos os sites com mais de 0.70 de confiança são classificados de uma só vez. É importante lembrar que a cada iteração de cada etapa, os sites já rotulados são utilizados para melhorar o classificador na próxima iteração.

Com os dois conjuntos rotulados, é executada uma última vez o algoritmo Naive Bayes em cada visão dos dados, para a geração de um ranking de classificação, para que seja decidida a ordem em que serão mostrados os sites para o usuário. Deve ser observado que cada visão dos dados tem seu próprio ranking, os quais são comparados para obter o ranking final utilizando duas abordagens diferentes.

A primeira abordagem, denominada Rank 1, consiste em calcular o ranking final multiplicando o grau de confiança das duas descrições e ordenado esses rankings de forma decrescente. Considere que o Naive Bayes retorna os valores $\left(p_{i}^{D_{1}}, n_{i}^{D_{1}}\right)$ para a classificação do exemplo $\mathbf{x}_{i}^{D_{1}}$ e $\left(p_{i}^{D_{2}}, n_{i}^{D_{2}}\right)$ para a sua classificação na outra visão $\mathbf{x}_{i}^{D_{2}}$, onde $p_{i}$ é um valor entre 0 e 1 referente ao grau de confiança de que o exemplo seja positivo (relevante) e $n_{i}$ também é um valor entre 0 e 1 referente ao grau de confiança de que o exemplo seja negativo (irrelevante) e $p_{i}+n_{i}=1$. O Rank 1 é calculado como $p_{i}^{D_{1}} \times p_{i}^{D_{2}}$. Por exemplo, dado que Naive Bayes retorna os valores $(0.85,0.15)$ na classificação de um site na primeira visão $D_{1}$ e $(0.93,0.07)$ na segunda visão $D_{2}$, então o Rank 1 para esse site seria $0.85 \times 0.93=0.7905$.

A segunda abordagem, denominada Rank 2, considera a soma do rank que o site é classificado em cada visão e ordenado de forma crescente, ou seja um site classificado em $3^{\circ}$ lugar em uma visão e $7^{\circ}$ lugar em outra visão teria o Rank 2 dado por $3+7=10$.

Utilizando esse novo ranking, os sites são reordenados e exibidos na tela para o usuário, com a opção de alterar entre o Rank 1 e Rank 2, sendo Rank 1 o default. A escolha do Rank 1 como default não leva em consideração uma qualidade superior de um rank em detrimento do outro, essa escolha foi feita de modo aleatório.

Entre uma fase do processo e outra, para integrar todos esses sistemas, as 
vezes se torna necessário que os dados sejam tratados para serem lidos por sistemas diferentes. Para auxiliar neste processo de integração das ferramentas foram criados alguns scripts em Perl, PHP e JavaScript.

\subsection{Exemplo de Execução}

Para ilustrar é mostrada uma execução da ferramenta C-SEARCH, com o resultado da busca utilizando a palavra chave caneca, considerando que o objetivo do usuário é achar referências sobre Frei Caneca que viveu no século XVI, e que por ser um personagem históricamente importante, atualmente existem ruas e shoppings com seu nome. Assim, na busca inicial, são retornados sites relevantes ao usuário relacionados ao personagem histórico Frei Caneca, shopping, ruas, concessionárias com seu nome, bem como vários sites irrelevantes sobre vendas de canecas - Figura 5.2.

Foram indicados pelo usuário dois sites relevantes que tratava do Frei Caneca e dois sites irrelevantes consistindo de propagandas e vendas de canecas. Após a realimentação de relevância o sistema retornou o novo ranking mostrado na Figura 5.3.

Pode ser observado que depois da realimentação sete dos dez primeiros sites atendem as preferências do usuário, enquanto antes da realimentação somente três sites atendiam a consulta do usuário - Figura 5.2. Observe que esses sete sites estavam em $23^{\circ}, 84^{\circ}, 29^{\circ}, 71^{\circ}, 79^{\circ}, 12^{\circ}$ e $6^{\circ}$ no ranking original do Yahoo!, se tornaram $3^{\circ}, 4^{\circ}, 5^{\circ}, 6^{\circ}, 7^{\circ}, 9^{\circ}$ e $10^{\circ}$ no Rank 1 do C-SEARCH, respectivamente. Na Figura 5.4 é mostrado o resultado obtido após ativar a opção "Mudar Ranking" que mostra os sites relevantes utilizando o Rank 2 do C-SEARCH. Para esta execução o Rank 2 obteve resultados semelhantes ao Rank 1 se considerados somente os dez primeiros sites. Visto que os sites $23^{\circ}, 12^{\circ}, 84^{\circ}, 71^{\circ}, 69^{\circ}, 29^{\circ}$ e $79^{\circ}$ do ranking original do Yahoo!, se tornaram as $2^{\circ}, 4^{\circ}, 5^{\circ}, 6^{\circ}, 7^{\circ}, 8^{\circ}$ e $10^{\circ}$ no Rank 2 do C-SEARCH, respectivamente. Pode-se notar também que os sites retornados pelo Rank 1 e o Rank 2 possuem seis sites relevantes semelhantes, e somente um site relevante diferente, porém em posições diferentes dentre os 10 primeiros de seus rankings.

\subsection{Considerações Finais}

Neste capítulo foi apresentado o $\mathrm{C}$-SEARCH, uma ferramenta de realimentação de relevância que permite aos usuários personalizar sua busca a partir da indicação de sua opinião quanto a relevância de poucos dos sites retornados. Após obter essas indicações, o C-SEARCH reordena os sites tal que sites com maior relevância para o usuário sejam posicionados à frente dos sites não 


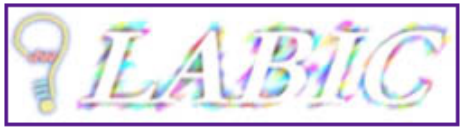

caneca

Mudar Ranking

Resultados 1 - 10 de 100 (Gerado em 0.0165 segundos)

1 -- 10 - Bolo na Caneca - Receitas de Bolo na Caneca

relevant O bolo de caneca deixou muitas pessoas curiosas após ter sua receita divulgada no domingo (02/11/200) no

$\begin{array}{ll}\text { Nota: } 0.999976 & \text { programa Tudo é Possível no quadro } 1001 \text { Dicas da } \\ \text { http://www.mundodastribos.com/bolo-na-caneca-receitas-de-bolo-na-caneca.html }\end{array}$

2 -- 8 - Bolo de Caneca - Receita de Bolo de Caneca | Resumo do Dia

relevant A Receita de Bolo de Caneca passou a interessar muitas pessoas após ser exibida no domingo (02/11/08) no Nota: 0.999940 quadro 1001 Dicas do programa Tudo é Possível, de

Nota: 0.999940 http://resumododia.com/bolo-de-caneca-receita-de-bolo-de-caneca/

\section{3 -- 23 - Cadastre-se para receber informações da Ford - Frei Caneca}

relevant Faça o cadastro na Concessionária Frei Caneca para receber informações, notícias e promoções da Nota: 0.999590 concessionária Ford mais próxima de você.

Nota: 0.999590 http://www.freicaneca.com.br/institucional/geral/cadastreSe.asp

\section{4 -- 84 - rraurl.com :: cena | Rua Frei Caneca: ser ou não ser gay \\ relevant É a rua Frei Caneca e sempre será, onde todos terão o direito a trafegar, ... A Frei Caneca é conhecida no Nota: 0.999494 mundo inteiro como rua gay", diz, lembrando ... \\ Nota: 0.999494 http://rraurl.uol.com.br/cena/5574/Rua_Frei_Caneca_ser_ou_nao_ser_gay}

\section{5 -- 29 - FREI CANECA E A CONFEDERAÇÃO DO EQUADOR Frei Wilmar Santin, O. Carm.}

relevant citar Frei Caneca com certa frequência; 2) A partir de 1981 a Prefeitura Municipal de ... Recife tem feito uma homenagem a Frei Caneca em frente ao seu busto ...

Nota: 0.999404 homenagem a Frei Caneca em frente ao seu busto

6 -- 71 - Centro de Convenções Frei Caneca

relevant $\quad \ldots 18$ operações, o Teatro Shopping Frei Caneca, nove salas de cinema do Unibanco ... Chagas, o Centro de relevant 0 Convenções Frei Caneca tem uma das agendas mais disputadas ...

Nota: 0.999186 http://Www.freicanecashopping.com.br/convencoes/Institucional.asp

7 -- 79 - A Idéia do Pacto Social e o Constitucionalismo em Frei Caneca

relevant citações de Frei Caneca aqui feitas são extraídas de Antonio joaquim de Mello, ... A IDÉIA DO PACTO SOCIAL E relevant 0 CONSTITUCIONALISMO EM FREI CANECA

Nota: 0.998341 http://www.iea.usp.br/iea/textos/bernardesfreicaneca.pdf

8 -- 40 - Bolo na caneca - receita divertida

relevant Então lá vamos nós com a exótica receita do Bolo de caneca! ... Coloque o ovo na caneca e bata bem com garfo. ... A caneca deve ter capacidade de $300 \mathrm{ml}$. - A ...

Nota: 0.998209 http://www.gazetta.com.br/blog/bolo-na-caneca-receita-divertida/

9 -- 12 - Concessionária Frei Caneca - Carros novos, usados e serviços Ford...

relevant Conheça a rede de concessionárias Ford Frei Caneca de São Paulo. ... Cliente Frei Caneca pode agendar a Nota: 0.997992 revisão de seu automóvel pela internet. ...

10 -- 6 - Frei Caneca - Wikipédia, a enciclopédia livre

relevant Frei Caneca apoiou a formação da primeira Junta Governativa de Pernambuco, ... Em 1824 Frei Caneca se Nota: 0.997956 tornou um dos conselheiros de Manuel de Carvalho Pais de ...

Nota: $0.997956 \begin{aligned} & \text { tornou um dos conselheiros de Manue } \\ & \text { http://pt.wikipedia.org/wiki/Frei_Caneca }\end{aligned}$

\section{$1 \underline{2} \underline{3} \underline{4} \underline{5} \underline{6} \underline{7} \quad \underline{8} \quad \underline{9} \quad \underline{10}$}

Figura 5.3: O Rank 1 da realimentação do C-SEARCH

relevantes. A ferramenta utiliza para o seu funcionamento, a Yahoo! Search API, o PRETEXT II e a implementação do CO-TRAINING no Discover. O design do C-SEARCH foi inspirado nos sites de buscas mais populares do mercado para que seja simples e intuitivo de ser utilizado. O sistema se encontra disponível para utilização no endereço http://sistemas.labic.icmc.usp.br: 8088 /realimentar/. 


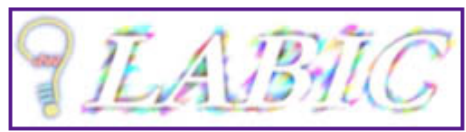

Resultados 1 - 10 de 100 (Gerado em $\mathbf{0 . 0 3 1 3}$ segundos)

1 -- 10 - Bolo na Caneca - Receitas de Bolo na Caneca

relevant o bolo de caneca deixou muitas pessoas curiosas após ter sua receita divulgada no domingo (02/11/200) no Nota: 3.5 programa Tudo é Possível no quadro 1001 Dicas da

Nota: 3.5 http://www.mundodastribos.com/bolo-na-caneca-receitas-de-bolo-na-caneca.html

2 -- 23 - Cadastre-se para receber informações da Ford - Frei Caneca

relevant Faça o cadastro na Concessionária Frei Caneca para receber informações, notícias e promoções da concessionária Nota: 5.0 Ford mais próxima de você.

Nota: 5.0 http://www.freicaneca.com.br/institucional/geral/cadastrese.asp

3 -- 8 - Bolo de Caneca - Receita de Bolo de Caneca | Resumo do Dia

relevant A Receita de Bolo de Caneca passou a interessar muitas pessoas após ser exibida no domingo (02/11/08) no Nota: 6.5 quadro 1001 Dicas do programa Tudo é Possível, de

Nota: 6.5 http://resumododia.com/bolo-de-caneca-receita-de-bolo-de-caneca/

4 -- 12 - Concessionária Frei Caneca - Carros novos, usados e serviços Ford ...

relevant Conheça a rede de concessionárias Ford Frei Caneca de São Paulo. ... Cliente Frei Caneca pode agendar a revisão Nota: 7.0 de seu automóvel pela internet. ...

Nota: 7.0 http://www.freicaneca.com.br/

5 -- 84 - rraurl.com :: cena | Rua Frei Caneca: ser ou não ser gay

relevant É a rua Frei Caneca e sempre será, onde todos terão o direito a trafegar, ... A Frei Caneca é conhecida no mundo relevant inteiro como rua gay", diz, lembrando...

Nota: 8.0 http://rraurl.uol.com.br/cena/5574/Rua_Frei_Caneca_ser_ou_nao_ser_gay

6 -- 71 - Centro de Convenções Frei Caneca

relevant ... 18 operações, o Teatro Shopping Frei Caneca, nove salas de cinema do Unibanco ... Chagas, o Centro de relevant Convenções Frei Caneca tem uma das agendas mais disputadas ...

Nota: 10.5 http://www.freicanecashopping.com.br/convencoes/Institucional.asp

7 -- 69 - FREI CANECA E A CONFEDERAÇ̃̃O DO EQUADOR

relevant "É Frei Joaquim do Amor Divino e Caneca, um erudito na accepção ampla do vocábulo. ... Num segundo capítulo

$\begin{array}{ll}\text { Nelevant } & \text { diremos quem foi Frei Caneca.... } \\ \text { http://br.geocities.com/wilmarsantin/Frei_Caneca.htm }\end{array}$

8 -- 29 - FREI CANECA E A CONFEDERAÇÃO DO EQUADOR Frei Wilmar Santin, O. Carm.

relevant citar Frei Caneca com certa frequência; 2) A partir de 1981 a Prefeitura Municipal de ... Recife tem feito uma Nota: 12.0 homenagem a Frei Caneca em frente ao seu busto ...

http://br.geocities.com/wilmarsantin/Frei_Caneca.pdf

9 -- 40 - Bolo na caneca - receita divertida

relevant Então lá vamos nós com a exótica receita do Bolo de caneca! ... Coloque o ovo na caneca e bata bem com garfo. Nota: 13.0 ... A caneca deve ter capacidade de 300 ml. - A ...

http://www.gazetta.com.br/blog/bolo-na-caneca-receita-divertida/

10 -- 79 - A Idéia do Pacto Social e o Constitucionalismo em Frei Caneca

relevant citações de Frei Caneca aqui feitas são extraídas de Antonio joaquim de Mello, ... A IDÉIA DO PACTO SOCIAL E O Nota: 13.0 CONSTITUCIONALISMO EM FREI CANECA ...

Nota: 13.0 http://www.iea.usp.br/iea/textos/bernardesfreicaneca.pdf

$1 \underline{2} \underline{3} \underline{4} \underline{5} \quad \underline{6} \underline{7} \quad \underline{8} \quad \underline{9} \quad \underline{10}$

Figura 5.4: O Rank 2 da realimentação do C-SEARCH 


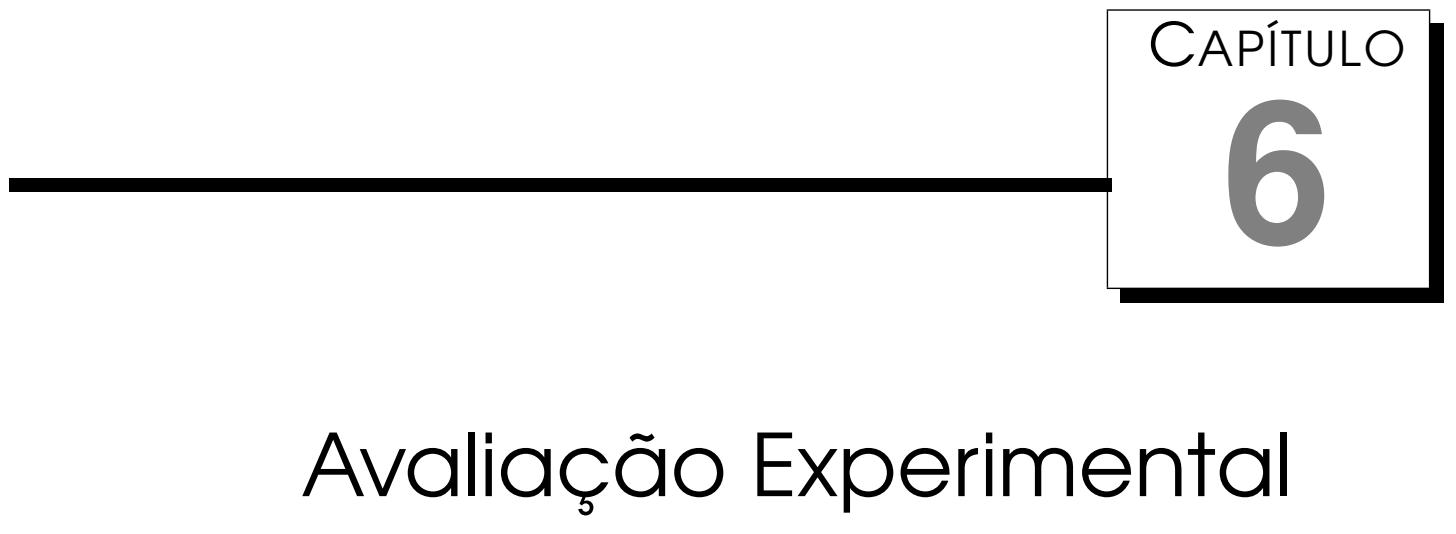

Avaliação Experimental

omo mencionado na Seção 3.3, são várias as medidas propostas para avaliar um sistema de recuperação de informação. Dentre essas medidas, a precisão e o recall são amplamente usadas pela comunidade. Entretanto, essas medidas consideram, entre outras, a qualidade de documentos relevantes recuperados e a quantidade de documentos relevantes no conjunto de documentos.

No caso do C-SEARCH, um sistema de realimentação de relevância, a relevância dos sites retornados após uma consulta depende exclusivamente da opinião do usuário, visto que usuários diferentes, ainda que realizando buscas semelhantes, podem estar procurando por informações diferentes.

Neste capítulo é descrita a avaliação realizada do C-SEARCH considerando os resultados das consultas realizadas por diferentes usuários-voluntários. Nessas consultas, foi solicitado aos usuários indicar um número variado e pequeno de sites relevantes ou irrelevantes para executar o C-SEARCH, utilizando sempre a mesma consulta. Além disso, o usuário deve também informar todos os sites relevantes dessa consulta dentre os 100 sites retornados inicialmente pelo Yahoo!. Com essas informações, o C-SEARCH é avaliado considerando as curvas dos gráficos recall-precisão, as quais provêem uma caracterização da performance relativa e absoluta do sistema. 


\subsection{Construção dos Testes com Voluntários}

Foi solicitado a um grupo de voluntários realizar uma consulta genérica no buscador C-SEARCH ${ }^{1}$, de forma que como resultado sejam retornados 100 (cem) WEB sites. A partir dos WEB sites retornados, o voluntário deve indicar os sites como relevantes ou irrelevantes conforme sua opinião pessoal. A indicação desses $W E B$ sites pode ser em qualquer um dos dez grupos de WEB sites retornados.

Foi solicitado a cada voluntário realizar, para a mesma consulta genérica, os três testes descritos a seguir:

1. (a) Realizar uma busca;

(b) Indicar dois $W E B$ sites relevantes e dois $W E B$ sites irrelevantes (2x2);

(c) Ativar a opção "Realimentar"; e

(d) Esperar pelos resultados.

2. (a) Realizar a mesma busca feita anteriormente;

(b) Indicar três $W E B$ sites relevantes e três $W E B$ sites irrelevantes (3x3);

(c) Ativar a opção "Realimentar"; e

(d) Esperar pelos resultados.

3. (a) Realizar novamente a mesma busca;

(b) Indicar três $W E B$ sites relevantes e dois $W E B$ sites irrelevantes, ou dois $W E B$ sites relevantes e três $W E B$ sites irrelevantes $(2 \times 3)$;

(c) Ativar a opção "Realimentar"; e

(d) Esperar pelos resultados.

Finalizados os três testes, o voluntário deve acessar o endereço para classificação manual dos sites ${ }^{2}$, no qual encontra-se o resultado completo da consulta genérica realizada e indicar dentre os 100 WEB sites retornados, todos os relevantes conforme sua opinião pessoal.

Com essas informações e os resultados dos três testes solicitados, os quais também ficam armazenados para análise posterior, é possivel construir as curvas recall-precisão para caracterizar a performance do C-SEARCH.

O grupo de voluntários consistiu de 23 usuários que atuam em áreas diferentes, e com conhecimentos variados de computação. Dentre esses testes, somente 18 puderam ser aproveitados, pois alguns usuários realizaram o teste de maneira errônea, impossibilitando a utilização dos resultados.

\footnotetext{
${ }^{1}$ http://sistemas.labic.icmc.usp.br:8088/realimentar/

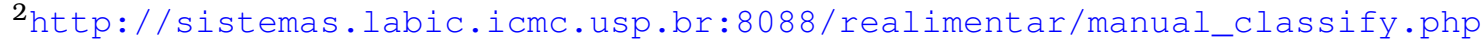




\subsection{Interpretação dos Gráficos Recall-Precisão}

Em recuperação de informação, o máximo valor de precisão, 1.0 (100\%), indica que todos os documentos recuperados na busca são relevantes, independentemente do número de documentos recuperados, i.e. não fornece informação se um, dois ou todos os documentos relevantes foram recuperados. Por outro lado, o máximo valor do recall, 1.0 (100\%), indica que todos os documentos relevantes foram recuperados, mas não fornece informação sobre quantos documentos irrelevantes foram também recuperados na busca.

Frequentemente, há uma relação inversa entre precisão e recall, no qual é possivel incrementar uma delas ao custo de decrementar a outra. Assim, ambas medidas não são utilizadas isoladamente, mas são comparadas uma com a outra para um valor fixo de uma delas. Isto é facilmente visualizado nas curvas recall-precisão, ou podem ser combinadas com uma única medida como a medida $F$.

Neste trabalho usaremos as curvas recall-precisão para avaliar os resultados. Nessas curvas, o resultado ótimo seria representado por uma linha reta com precisão de $100 \%$.

Neste capítulo são descritos em maiores detalhes alguns dos resultados obtidos nesses 18 testes. Os resultados correspondentes a totalidade dos testes realizados encontram-se em Soares (2009).

A partir dos resultados gerados pelas buscas e pelas realimentações realizadas, foram gerados dois tipos de gráficos recall-precisão para cada realimentação:

- o gráfico recall-precision; e

- o gráfico recall-precision-individual

Ambos os gráficos representam os mesmos dados, porém de pontos de vista diferentes. Enquanto o recall-precision agrupa os resultados em grupos de dez, o recall-precision-individual mostra os resultados individualmente. Ambos os gráficos contêm três curvas descritas a seguir:

Normal: representa o resultado de recall-precisão do Yahoo! Search API;

Rank 1: representa o resultado do Rank 1 do C-SEARCH; e

Rank 2: representa o resultado do $\mathbf{R a n k} 2$ do C-SEARCH.

Também, a ordem na leitura dos pontos dessas curvas é importante, pois indicam o número de resultados analizados nos gráficos recall-precision e recall-precision-individual. No gráfico recall-precision, o primeiro 
ponto indica o recall e precisão dos 10 primeiros sites mostrados em tela pelo sistema C-SEARCH. O segundo ponto indica o recall e precisão dos 20 primeiros sites, ou seja, os 10 anteriores mais os próximos 10, e assim por diante, até que seja alcançado o recall de 100\%. Já no gráfico recall-precision-individual o primeiro ponto indica o recall e precisão do primeiro site, o segundo ponto representa o recall e precisão dos 2 primeiros sites, o terceiro ponto representa o recall e precisão dos 3 primeiros sites e assim por diante, até que seja alcançado o recall de $100 \%^{3}$.

Para a avaliação do desempenho dos rankings dos sites, são utilizados três critérios de comparação descritos a seguir:

Critério 1: leva em conta se a curva de um ranking está acima da curva de outro ranking, ou seja, tem a precisão superior em toda, ou a maior parte da curva. Assim, em casos em que as curvas estão próximas, não se pode considerar uma melhor que a outra.

Critério 2: leva em conta o número de pontos existentes na curva. Um número menor de pontos indica que o ranking posicionou todos os sites relevantes dentre os primeiros do ranking, deixando somente sites irrelevantes no final do ranking.

Critério 3: leva em conta somente os primeiros pontos das curvas no gráfico. Deve ser observado que no caso do gráfico recall-precision, no qual o primeiro ponto corresponde a recuperação dos 10 primeiros sites, se a precisão do primeiro ponto da curva for maior, significa que o usuário obteve mais resultados relevantes logo no primeiro conjunto de 10 sites mostrados na tela, de modo que o usuário não necessitaria procurar por mais resultados em outras telas.

\subsection{Descrição dos Resultados}

Na Tabela 6.1 encontram-se as 18 consultas genéricas realizadas pelos voluntários ${ }^{4}$ o número de sites relevantes totais, dentre os 100 sites retornados pela busca, indicados pelos respectivos usuários, assim como os sites relevantes dentre os 10 primeiros sites, e os sites relevantes dentre os 20 primeiros sites retornados pelo Yahoo! Search API.

\footnotetext{
${ }^{3} \mathrm{Em}$ alguns casos o recall de $100 \%$ pode não ser atingido devido ao fato do site retornado pelo Yahoo! Search API conter somente uma descrição dos dados.

${ }^{4}$ Algumas palavras-chaves digitadas contêm erros de grafia digitados pelos voluntários, mas esses erros foram mantidos neste trabalho, pois tais erros podem interferir no resultado das buscas. Também maiúsculas e minúsculas foram mantidas exatamente como digitadas pelos voluntários.
} 


\begin{tabular}{l||l|c|c|c}
\hline \hline \multicolumn{1}{c||}{ Usuário } & Consulta & \multicolumn{3}{c}{ Relevantes } \\
\cline { 3 - 5 } & & Totais & Primeiros 10 & Primeiros 20 \\
\hline \hline 01 & caneca & 17 & 3 & 4 \\
02 & cotinga & 26 & 2 & 6 \\
03 & Direito Processual do Trabalho & 27 & 3 & 8 \\
04 & maquinas finita & 9 & 7 & 7 \\
05 & proficiencia ingles & 24 & 5 & 8 \\
06 & sarmiento & 17 & 3 & 4 \\
\hline \hline 07 & aprender chinês & 29 & 7 & 11 \\
08 & mercado de derivativos & 93 & 10 & 19 \\
09 & Nero & 9 & 2 & 2 \\
\hline \hline 10 & Álcman & 38 & 6 & 13 \\
11 & Complexo MHC & 46 & 7 & 13 \\
12 & esporte & 8 & 3 & 5 \\
13 & fender & 38 & 6 & 7 \\
14 & freesbe & 16 & 4 & 10 \\
15 & machine learning evaluation & 27 & 5 & 7 \\
16 & segunda guerra mundial & 30 & 7 & 9 \\
17 & Thomas Mann & 21 & 8 & 12 \\
18 & títulos palmeiras & \multicolumn{3}{c}{} \\
\hline \hline
\end{tabular}

Tabela 6.1: Consultas e números total e parcial de sites relevantes marcados pelo usuário por consulta.

Nesta seção são mostrados alguns dos resultados obtidos nesses 18 experimentos, os quais foram separados em três grupos:

1. Resultados Positivos;

2. Resultados Neutros; e

3. Resultados Negativos.

A totalidade dos resultados obtidos nesses experimentos encontram-se em Soares (2009).

\subsubsection{Resultados Positivos}

Os resultados considerados positivos são aqueles nos quais o sistema CSEARCH obteve resultados melhores que os retornados pelo Yahoo! em pelo menos dois dos três critérios de comparação e em pelo menos duas das três realimentações. Foram obtidos resultados positivos nas seguintes buscas: caneca, cotinga, Direito Processual do Trabalho, maquinas finita, proficiencia ingles e sarmiento, realizadas pelos usuários 1 a 6 - Tabela 6.1 .

Os dois melhores resultados desse grupo foram obtidos a partir das buscas caneca e sarmiento. Isso deve-se ao fato de que ambas palavras recuperam sites cujo conteúdo é irrelevante para a intenção da consulta do usuário, tal que esse conteúdo fica bem diferenciado do conteúdo dos sites indicados como relevantes. No caso de sarmiento, o usuário pretendia buscar por 
informações relacionadas a um famoso personagem, Domingo Faustino Sarmiento, que foi presidente da República Argentina no período de 1868 a 1874, e destacou-se pela sua atuação na área de educação, duplicando o número de escolas públicas na Argentina e construindo quase 100 bibliotecas públicas nesse país. Devido à importância histórica de Sarmiento, nessa consulta são também recuperados sites relacionados a hotéis, ruas e outros estabelecimentos diversos que tem esse nome, mas que o usuário não considera relevantes.

A situação é semelhante na busca por caneca, na qual a intenção do usuário foi procurar informações relacionadas ao Frei Caneca ${ }^{5}$, que foi um religioso e político brasileiro com destacada atuação em vários movimentos revolucionários tais como a Revolução Pernambucana (1817) e a Confederação do Equador (1824). Semelhante ao caso anterior, existem inúmeros estabelecimentos e ruas com seu nome, mas, diferentemente do caso anterior, o usuário também está interessado nessas informações. Além disso, caneca é o nome de um utensílio doméstico muito popular, que foge aos interesses do usuário.

A seguir são mostrados os gráficos recall-precisão dos resultados obtidos pelas consultas sarmiento, maquinas finita e cotinga.

Na Figura 6.1 são mostrados os resultados correspondentes à consulta sarmiento. Na primeira coluna - Figuras 6.1(a), 6.1(c) e 6.1(e), coluna Gos gráficos recall-precision, i.e. cada um dos pontos da curva representa múltiplos de 10 sites recuperados, e na segunda coluna - Figuras 6.1(b), 6.1(d) e 6.1(f), coluna I - os gráficos recall-precision-individual, para os três testes realizados. Como pode ser observado, o C-SEARCH obteve resultados melhores que o Yahoo! em todos as 3 realimentações e em todos os critérios de comparação. Em especial na realimentação $3 \times 3$, em que o usuário indicou 3 sites relevantes e 3 sites irrelevantes, ilustrado nas Figuras 6.1(c) e 6.1(d), o C-SEARCH teve 90\% de precisão logo no primeiro grupo de resultados, o que poderia deixar o usuário satisfeito com a consulta. A busca por caneca, obteve resultados semelhantes.

A busca por maquinas finita obteve resultados interessantes. Foi observado que grande parte dos sites retornados pelo Yahoo! Search API não tratavam do assunto em questão, já que eram sites sobre máquinas agrícolas, máquinas de papel, máquinas de café, etc. Somente nove resultados dentre os 100 são sites sobre Máquinas de Estados Finitos, que era o objetivo do usuário. Apesar do Yahoo! conseguir retornar mais sites relevantes no primeiro grupo de dez sites em todas as três realimentações, o C-SEARCH conseguiu retornar todos os sites relevantes dentre os primeiros 20 a 40 exibidos para o usuário, enquanto o Yahoo! necessitou de 90 sites para exibir todos os relevantes para este usuário, como pode ser observado na Figura 6.2. A concentração dos si-

\footnotetext{
${ }^{5}$ Nome popular de Joaquim da Silva Rabelo (1779 - 1825), ordenando em 1801 com o nome oficial de Frei Joaquim do Amor Divino Rabelo
} 
G

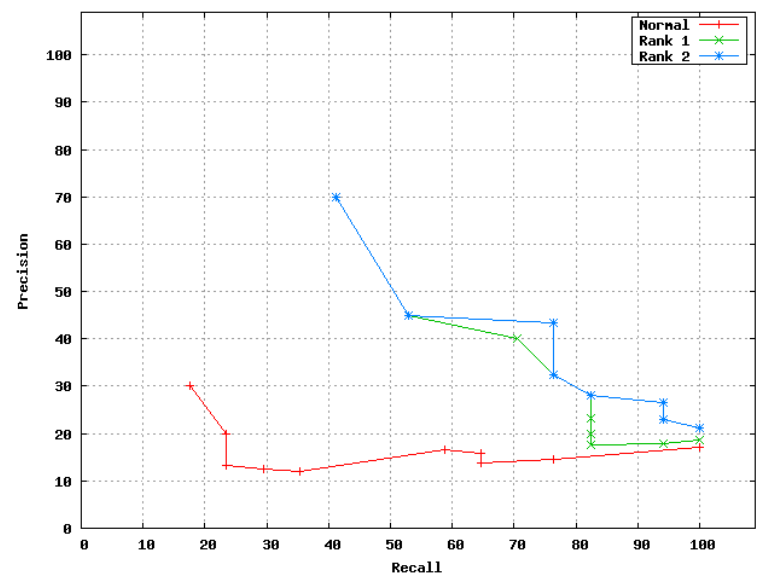

(a)

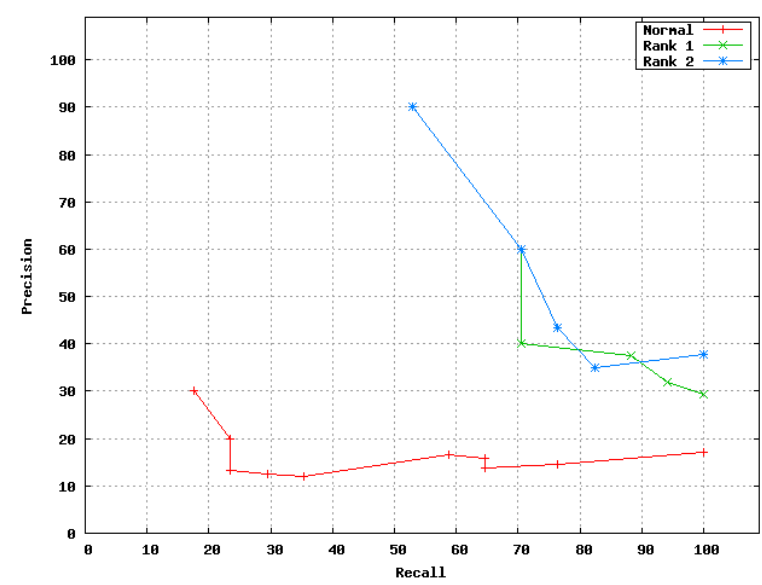

(c)

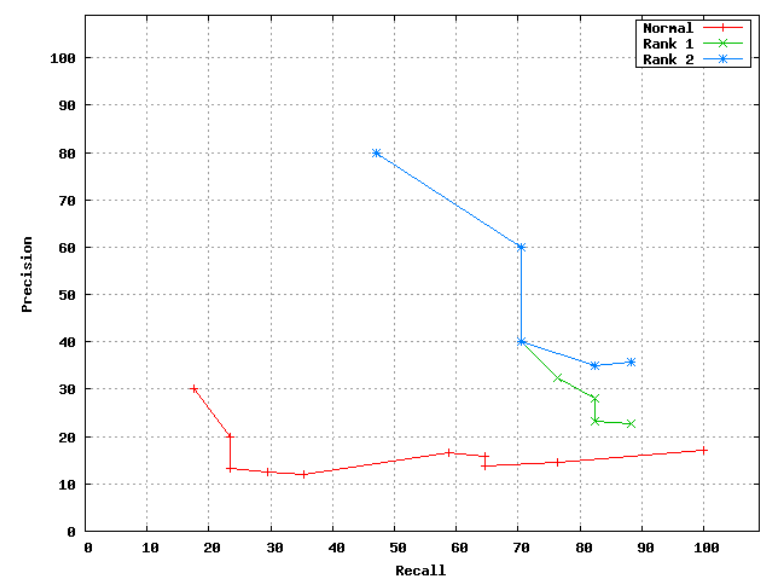

(e)
I

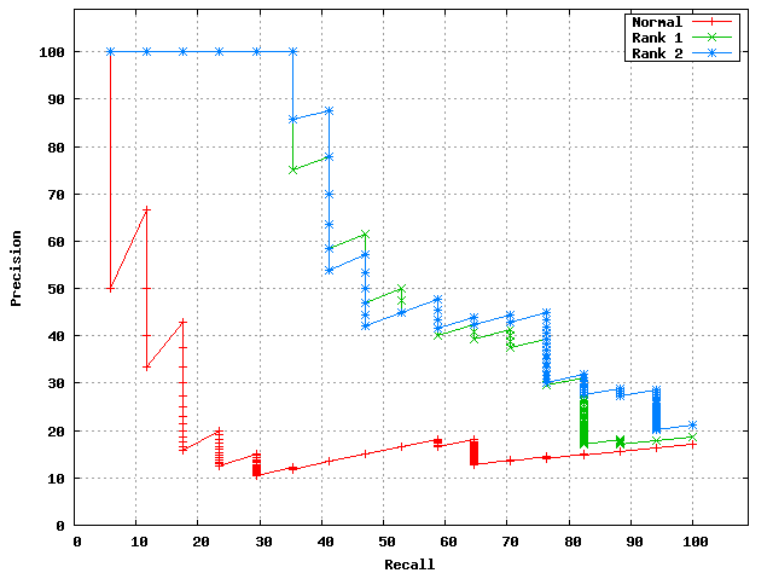

(b)

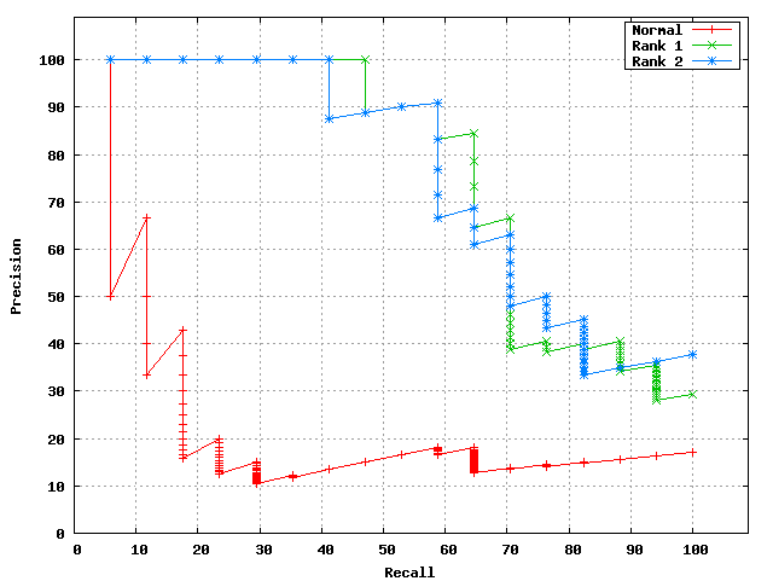

(d)

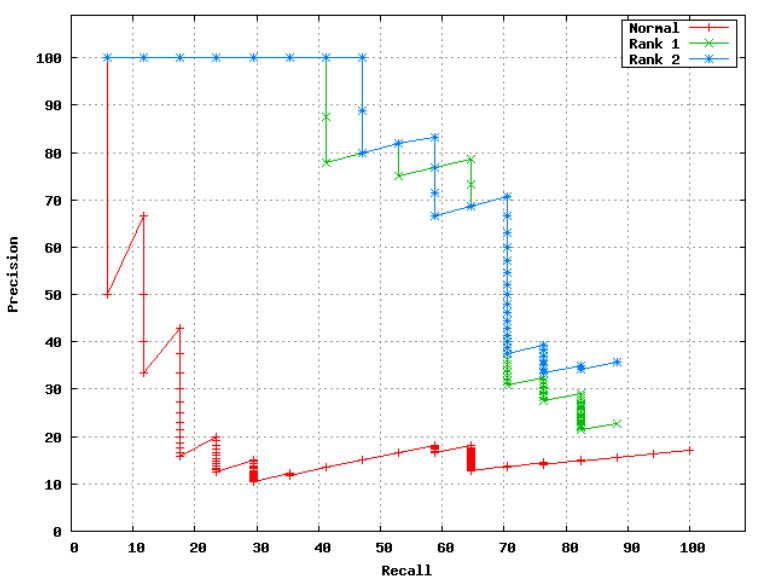

(f)

Figura 6.1: Gráficos recall-precisão da consulta sarmiento: (a) 2x2 por grupos (b) $2 \times 2$ individual (c) $3 \times 3$ por grupos (d) $3 \times 3$ individual (e) $2 \times 3$ por grupos (f) $2 \times 3$ individual

tes relevantes entre os primeiros resultados facilita muito o processo de busca do usuário. Nas Figuras 6.2(a), 6.2(c) e 6.2(e), pode-se observar que o Rank 1 retornou todos os sites relevantes dentre os 20 primeiros, enquanto que $o$ 
Rank 2 necessitou de 30 a 40 sites para exibir todos os relevantes.

G

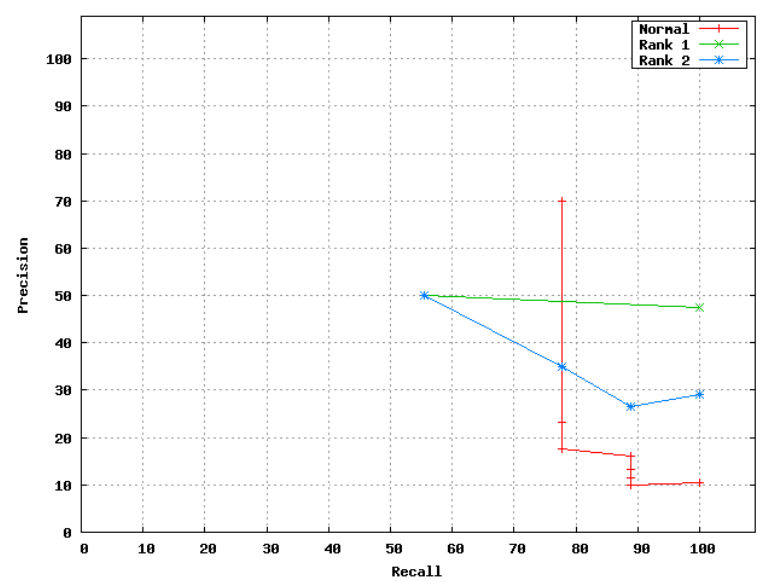

(a)

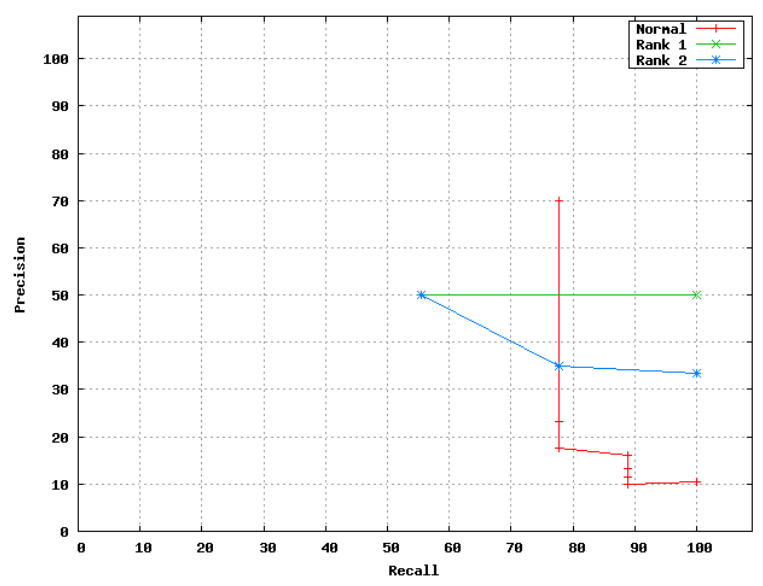

(c)

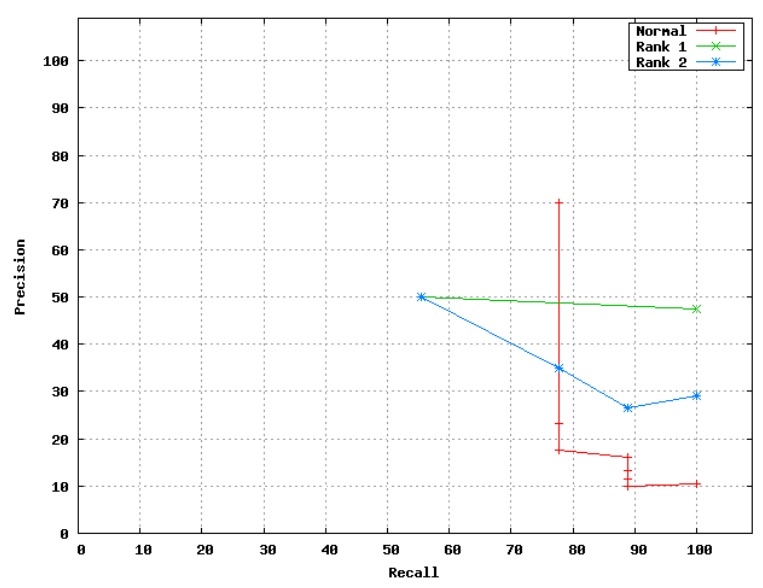

(e)
I

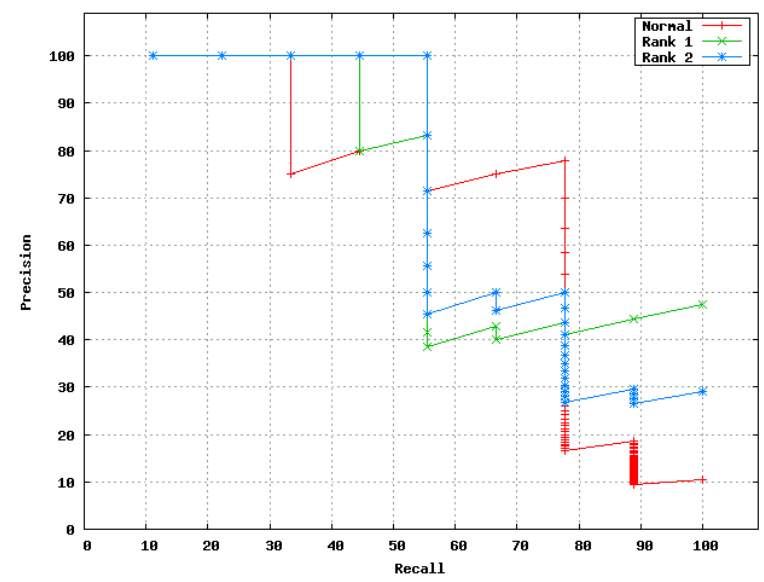

(b)

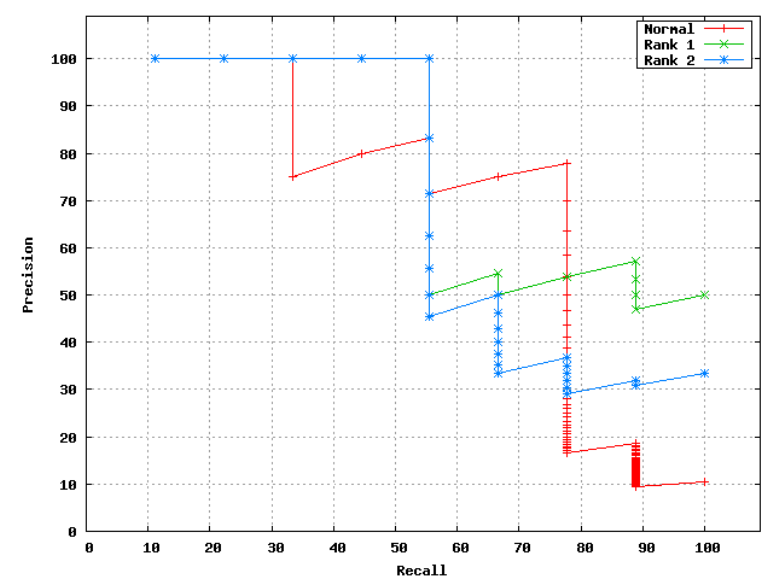

(d)

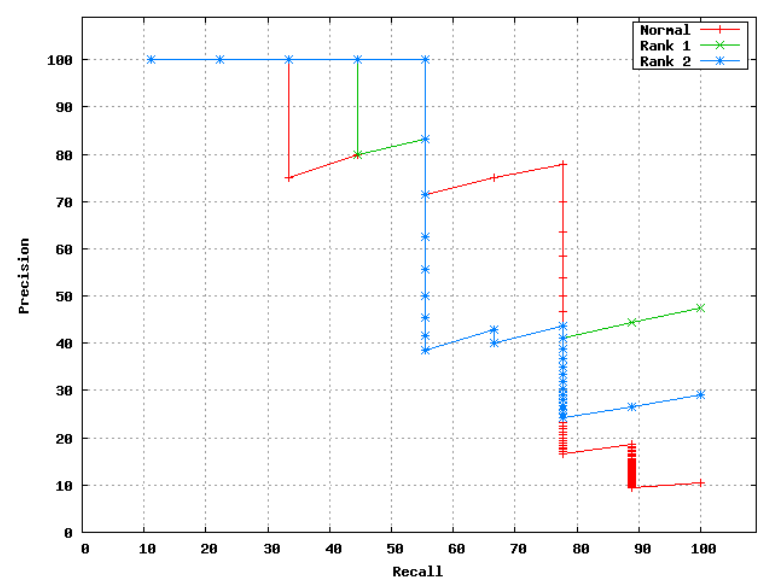

(f)

Figura 6.2: Gráficos recall-precisão da consulta maquinas finita: (a) 2x2 por grupos (b) $2 \times 2$ individual (c) $3 \times 3$ por grupos (d) $3 \times 3$ individual (e) $2 \times 3$ por grupos (f) $2 \times 3$ individual

Também obtiveram resultados interessantes a busca por cotinga, um gênero de aves com penagem azul. O usuário desejava informações mais cien- 
tíficas sobre esta ave, e não eram interessantes informações mais didáticas sobre a ave, assim como nomes de hotéis e outros estabelecimentos. Nessa busca, as realimentações 2x2 e 3x3 tiveram resultados muito bons, e a realimentação 2x3, por conta do desbalanceamento das classes (Matsubara et al., 2006), degradou o modelo criando rankings muito piores que os retornados pelo Yahoo! como visto na Figura 6.3.

Nesse exemplo, pode-se notar que uma quantidade maior de sites rotulados pode fornecer um resultado muito superior, como pode ser visto comparando a Figura 6.3(a), onde tem-se somente quatro sites rotulados, com a Figura 6.3(c), onde tem-se 6 sites rotulados. Pode ser observado também na Figura 6.3(e) que, para esta consulta, o desbalanceamento, mesmo que somente de um site, degrada o modelo.

\subsubsection{Resultados Neutros}

Os resultados considerados neutros são aqueles nos quais o sistema CSEARCH obteve resultados iguais ou com pouca diferença dos resultados retornados pelo Yahoo!. Uma vez que o sistema C-SEARCH é um sistema que envolve um tempo de execução adicional, resultados neutros podem até ser considerados negativos, pois foi utilizado um tempo computacional adicional para obter resultados não muito diferentes dos resultados apresentados pelo Yahoo!. Foram obtidos resultados neutros nas seguintes buscas: aprender chinês, mercado de derivativos e Nero, realizadas pelos usuários 7 a 9 Tabela 6.1.

As buscas por mercado de derivativos e Nero tiveram resultados muito semelhantes. No caso de mercado de derivativos a grande maioria dos 100 resultados retornados foram relevantes, e no caso de Nero, Nero Claudius Cæsar Augustus Germanicus, o quinto imperador romano, a grande maioria foram sites irrelevantes sobre Nero, um software de gravação de CDs e DVDs muito popular. Nesses dois casos, o C-SEARCH não foi capaz de melhorar o ranking dos sites, que se mantiveram semelhantes ao ranking do Yahoo!.

Na Figura 6.4 pode ser observado o comportamento do C-SEARCH quando o conjunto de sites analisados contem uma minoria de elementos de uma classe e uma grande maioria de outra classe, como ocorre na consulta por mercado de derivativos. Apesar do Yahoo! ter melhores resultados no inicio da realimentação 3x3, como é mostrado na Figura 6.4(c), não se pode dizer que o $\mathrm{C}$-SEARCH obteve resultados negativos nesse caso. Porém, como foi utilizado um tempo computacional extra para retornar um resultado similar, não se justificaria a utilização do C-SEARCH. 
G

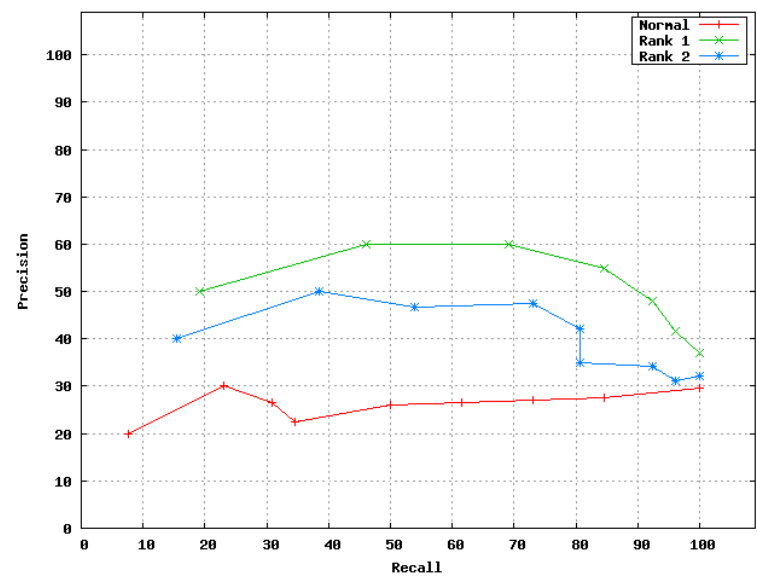

(a)

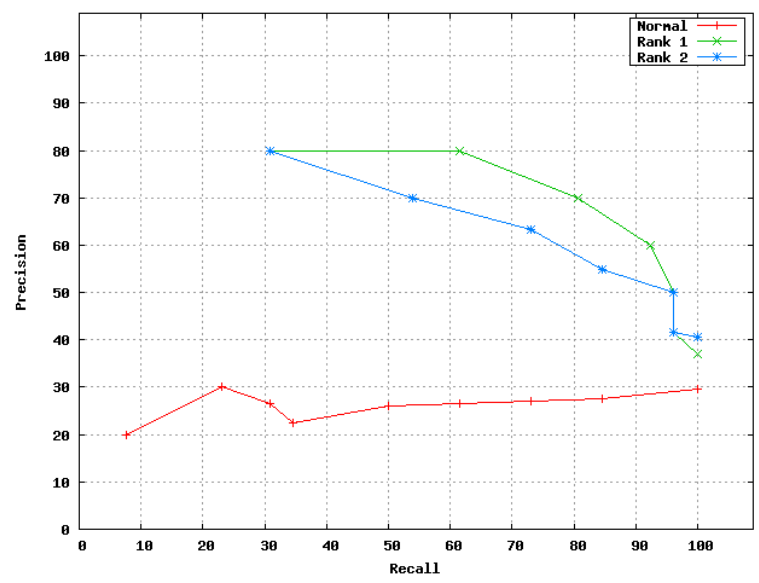

(c)

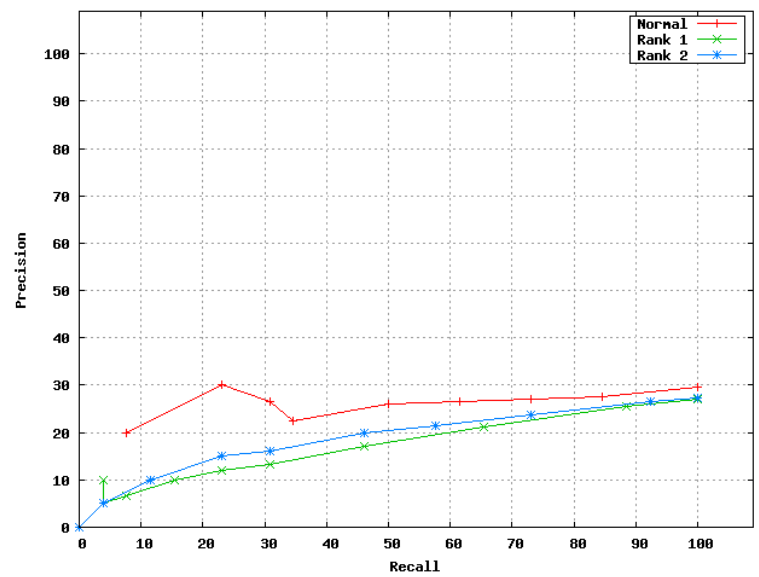

(e)

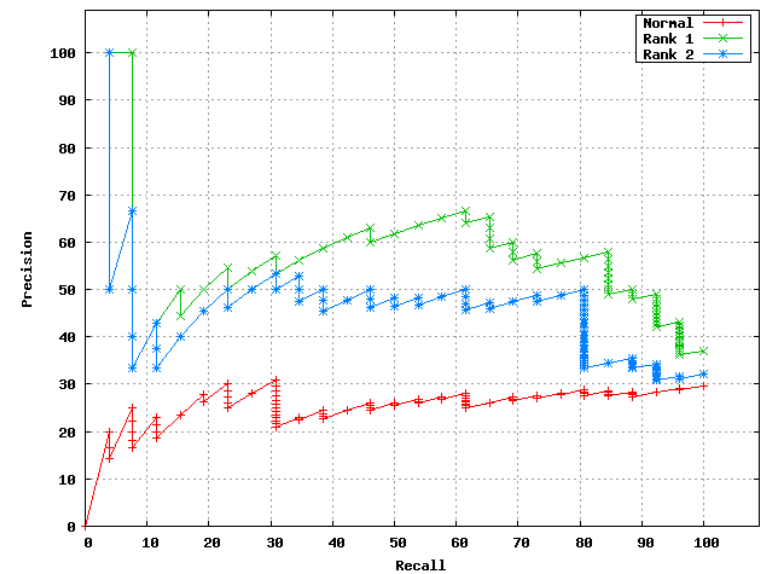

(b)

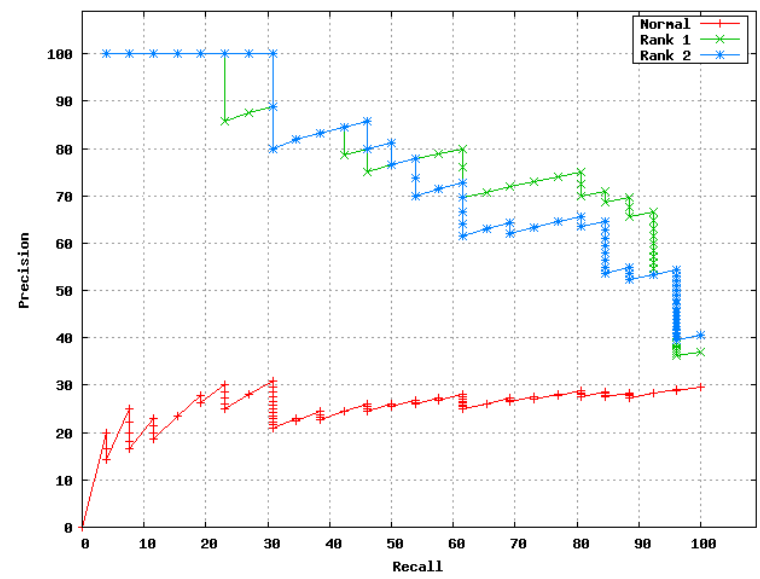

(d)

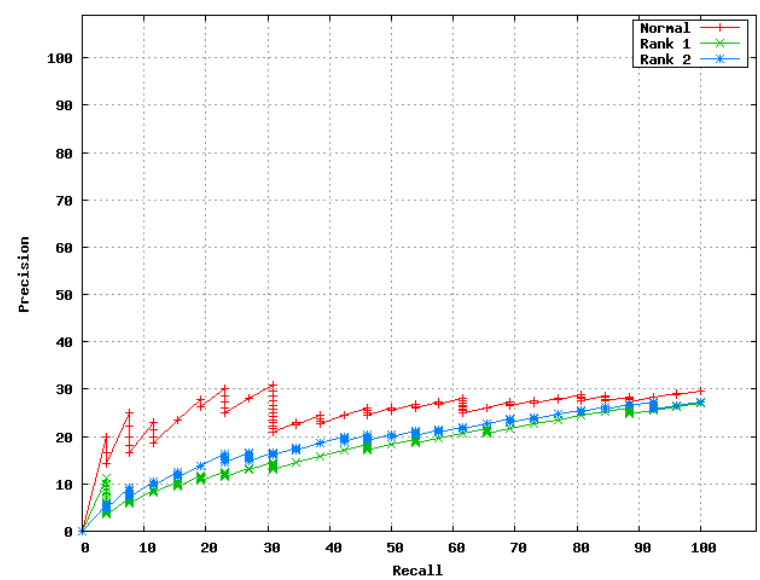

(f)

Figura 6.3: Gráficos recall-precisão da consulta cotinga: (a) 2x2 por grupos (b) $2 \times 2$ individual (c) $3 \times 3$ por grupos (d) $3 \times 3$ individual (e) $2 \times 3$ por grupos (f) $2 \times 3$ individual

\subsubsection{Resultados Negativos}

Os resultados considerados negativos são aqueles nos quais o sistema CSEARCH obteve resultados piores que os resultados retornados pelo Yahoo!. 
G

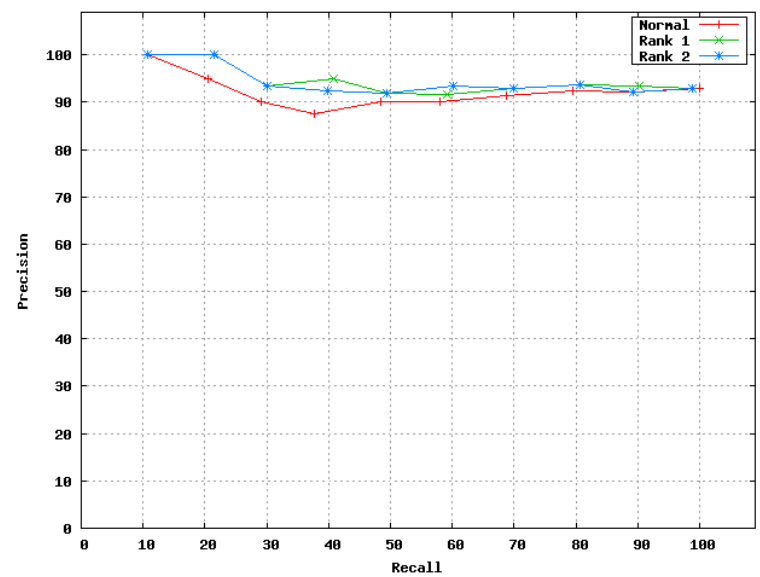

(a)

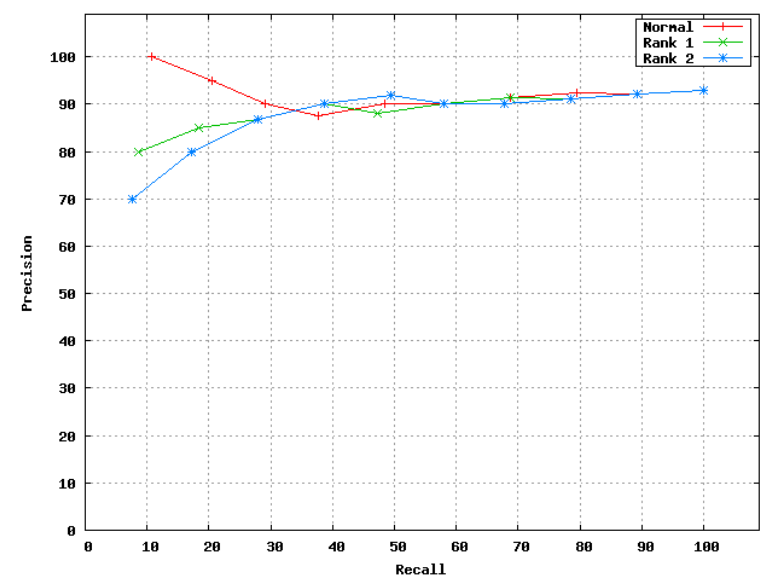

(c)

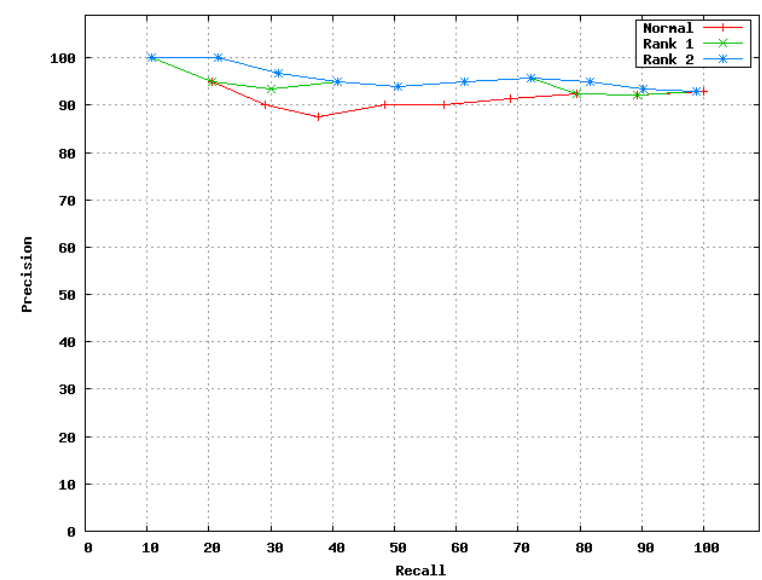

(e)
I

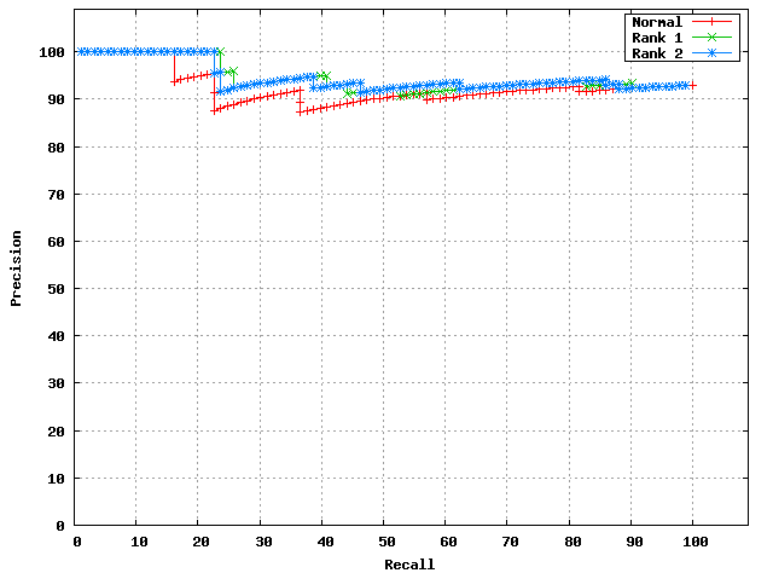

(b)

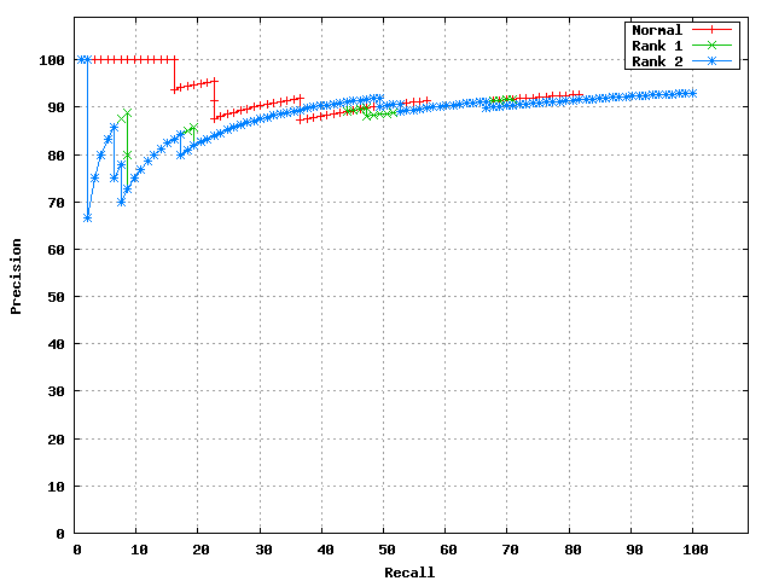

(d)

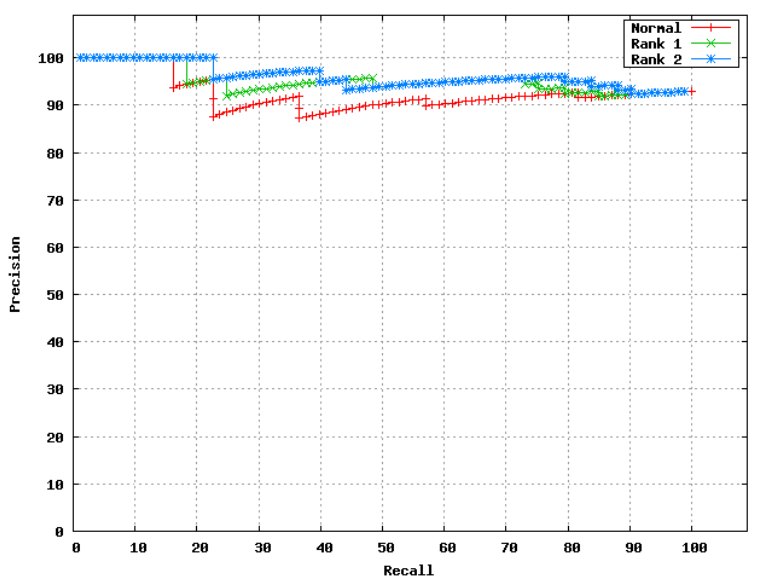

(f)

Figura 6.4: Gráficos recall-precisão da consulta mercado de derivativos: (a) $2 \times 2$ por grupos (b) $2 \times 2$ individual (c) $3 \times 3$ por grupos (d) $3 \times 3$ individual (e) $2 \times 3$ por grupos (f) $2 \times 3$ individual

Foram obtidos resultados negativos nas seguintes buscas: Álcman, Complexo MHC, esporte, fender, freesbe, machine learning evaluation, segunda guerra mundial, thomas mannetítulos palmeiras, realizadas pelos usuá- 
rios 10 a 18 - Tabela 6.1 .

Alguns dos resultados negativos obtiveram resultados parciais positivos, dependendo da seleção de sites relevantes e irrelevantes, como é o caso de Complexo MHC, freesbe e segunda guerra mundial. Como pode ser visto na Figura 6.5(c), ao serem indicados três sites relevantes e três irrelevantes (3x3), a consulta por Complexo MHC obteve resultados melhores que o Yahoo! tanto no Rank 1 quanto no Rank 2 do C-SEARCH.

Pode-se notar também que na realimentação 2x3, ao desbalancear o conjunto de sites rotulados, o resultado obteve piores resultados, como mostra a Figura 6.5(e). A consulta por Complexo $\mathrm{MHC}^{6}$ retornou inúmeros sites da área de biológicas a qual somente um especialista no domínio poderia indicar a relevância e irrelevância, porém para um leigo no assunto, todos os 100 resultados aparentam ser similares. Dessa forma o C-SEARCH também não foi capaz de distinguir com exatidão as classes e os resultados para essa busca foram negativos.

Os piores resultados foram obtidos pelas consultas thomas mann e títulos palmeiras, para os quais o Yahoo! obtem bons resultados e o C-SEARCH somente desorganiza os resultados do Yahoo!, como pode ser visto na busca por títulos palmeiras na Figura 6.6. Dentre os sites retornados, muitos deles são sites de notícias ou de fã clubes do time de futebol Palmeiras, com relação aos campeonatos ganhos, que era o objetivo do usuário. Porém, existem também inúmeros sites sobre noticias do Palmeiras disputando o título, ou tentando alcançar a vitória do título, que eram sites irrelevantes para o usuário. A grande maioria das páginas retornadas falam de futebol, e tem palavras características deste esporte, sem muita diferença entre páginas relevantes e irrelevantes. Por este motivo, o C-SEARCH não foi capaz de obter resultados satisfatórios nessa consulta.

\subsection{Considerações Finais}

A ferramenta C-SEARCH, construída para reordenar o ranking dos sites retornados pelo Yahoo!, obteve bons resultados em consultas genéricas nas quais os sites considerados relevantes e os sites considerados irrelevantes contêm grande quantidade de informações diferentes. Nos casos nos quais os textos dos sites relevantes e irrelevantes são muito similares, o C-SEARCH não conseguiu obter bons resultados. Dessa forma, o C-SEARCH poderia ser usado de forma eficaz para eliminar sites completamente contrários aos interesses do usuário. Entretanto, sites com informações irrelevantes porém muito próximas, devem ser ignorados pelo usuário no momento de sua busca.

\footnotetext{
${ }^{6} \mathrm{O}$ complexo principal de histocompatibilidade ou MHC (do inglês major histocompatibility complex) é uma grande região genômica encontrada na maioria dos vertebrados.
} 
G

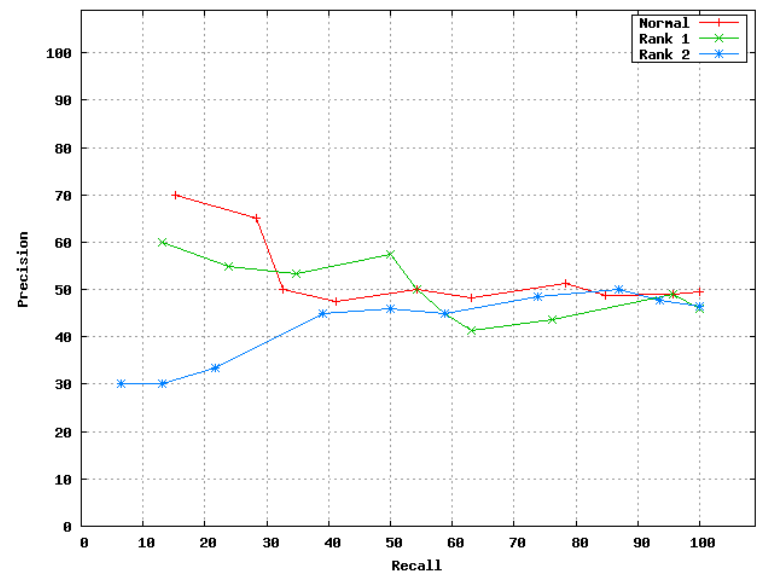

(a)

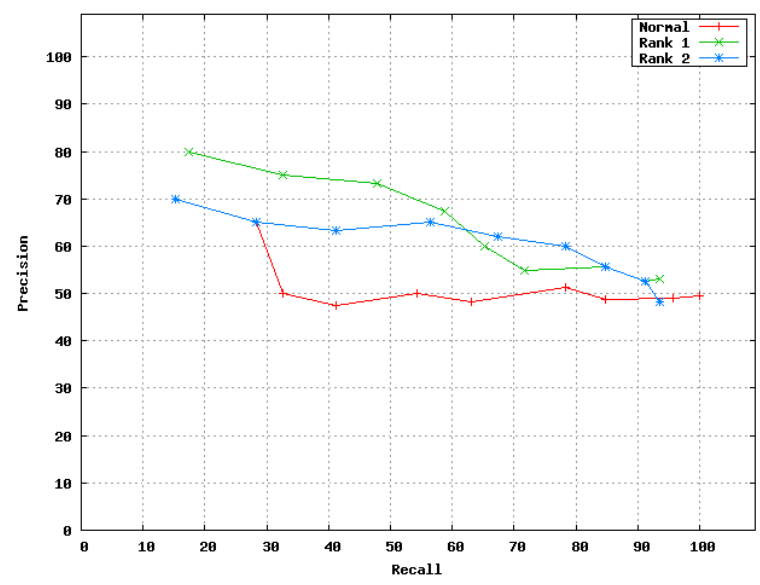

(c)

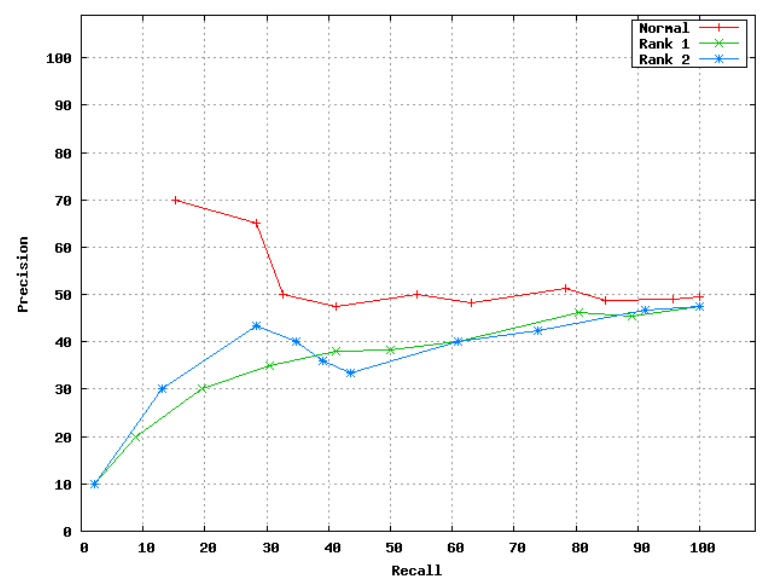

(e)

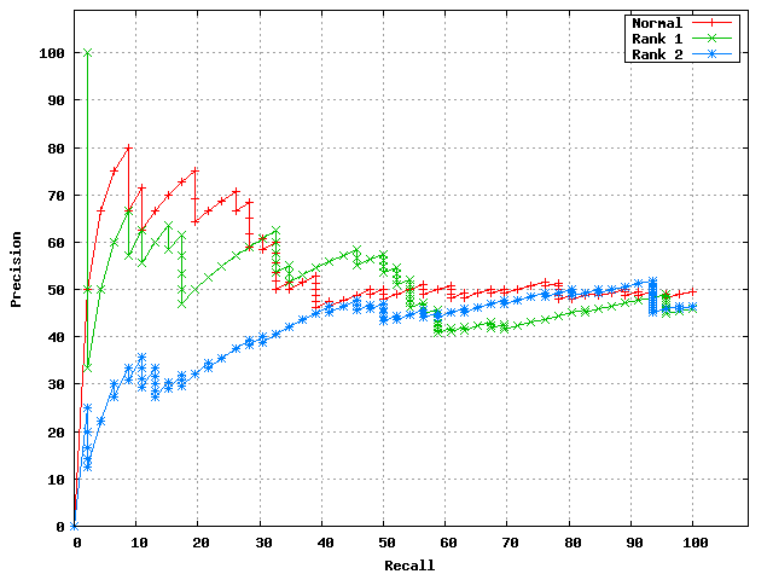

(b)

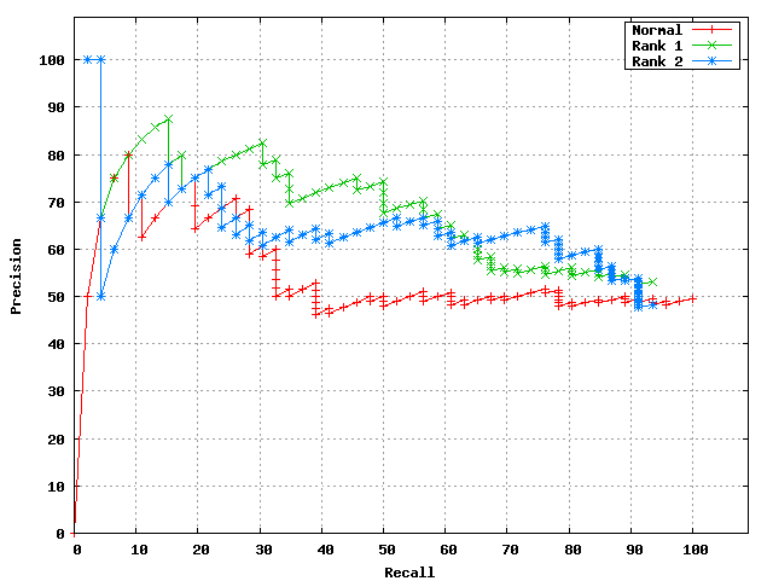

(d)

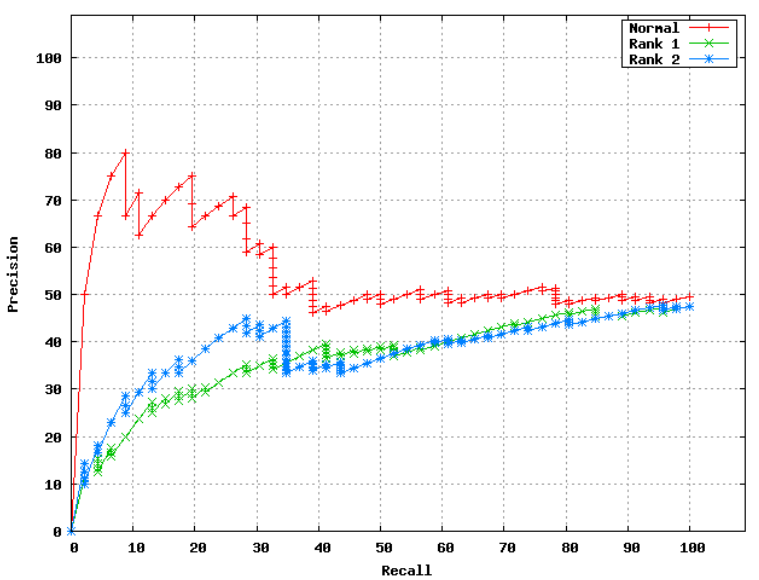

(f)

Figura 6.5: Gráficos recall-precisão da consulta Complexo MHC: (a) 2x2 por grupos (b) $2 \times 2$ individual (c) $3 \times 3$ por grupos (d) $3 \times 3$ individual (e) $2 \times 3$ por grupos (f) $2 \times 3$ individual

Foi observado também que o desbalanceamento das classes pode ser prejudicial ao aprendizado, e o sistema, em alguns casos, consegue obter melhores resultados quando o número de páginas rotuladas é maior. 
G

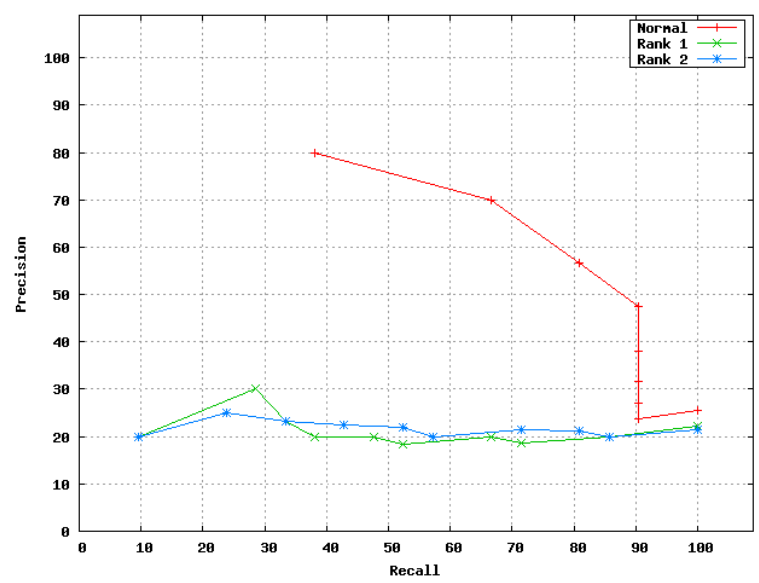

(a)

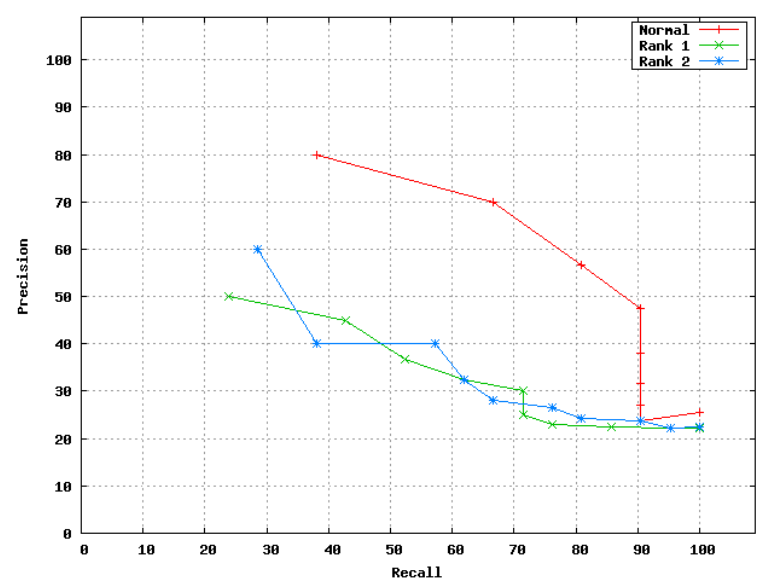

(c)

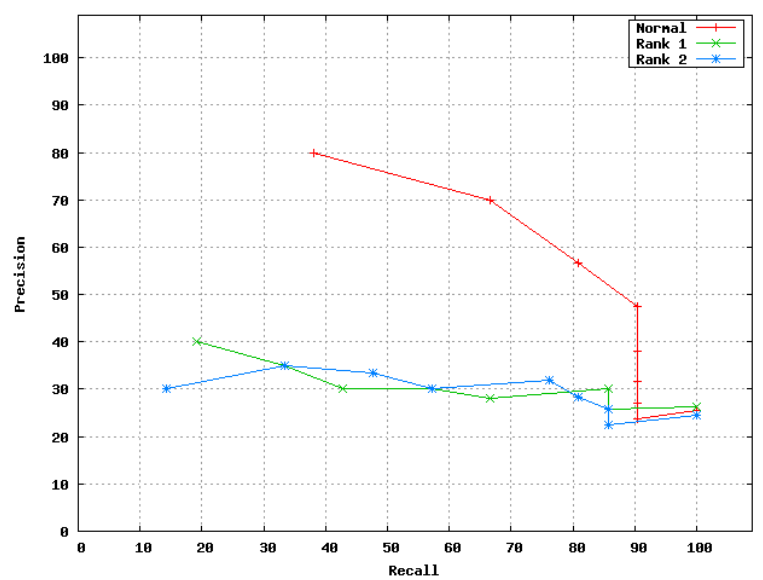

(e)

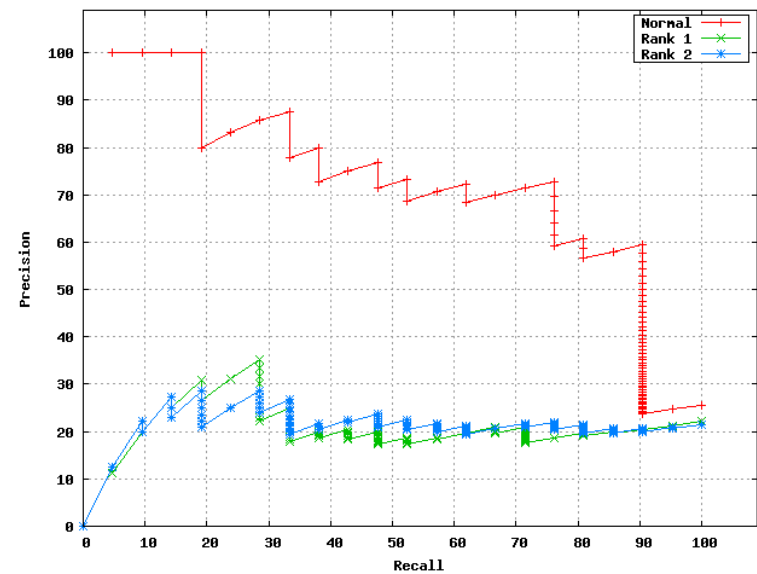

(b)

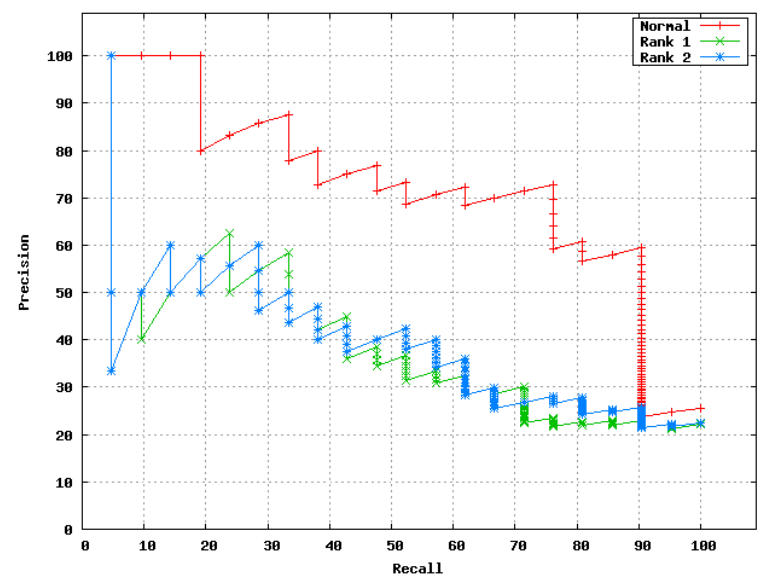

(d)

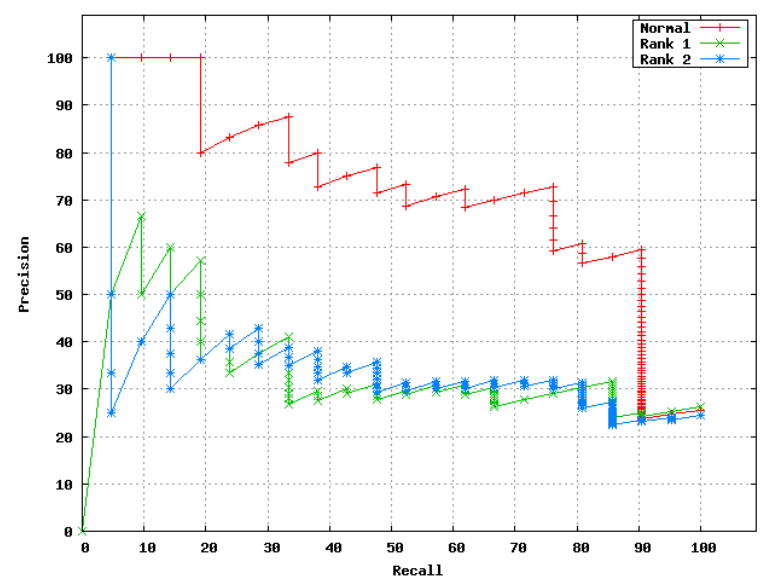

(f)

Figura 6.6: Gráficos recall-precisão da consulta títulos palmeiras: (a) 2x2 por grupos (b) $2 \times 2$ individual (c) $3 \times 3$ por grupos (d) $3 \times 3$ individual (e) 2x3 por grupos (f) 2x3 individual

Deve ser observado também que na avaliação experimental realizada com 18 usuários, a realimentação de relevância foi utilizada independentemente dos resultados obtidos pelo motor de busca inicial. Nesse caso, dos 18 testes 
realizados $6(33.3 \%)$ foram positivos, $3(16,7 \%)$ neutros e $9(50.0 \%)$ negativos. Porém, em uma aplicação real, caso o resultado de uma busca simples seja satisfatório, dificilmente o usuário utilizaria uma ferramenta para melhorar a busca. Considerando que a obtenção de mais da metade de sites relevantes no primeiro grupo de dez sites retornados pelo buscador é satisfatório (Primeiros 10 > 5 na Tabela 6.1) então, provavelmente, somente 9 dos testes realizados o usuário ativaria a opção de realimentação de relevância, com os seguintes resultados: $5(55.6 \%)$ positivos, $1(11.1 \%)$ neutro e $3(33.3 \%)$ negativos. 


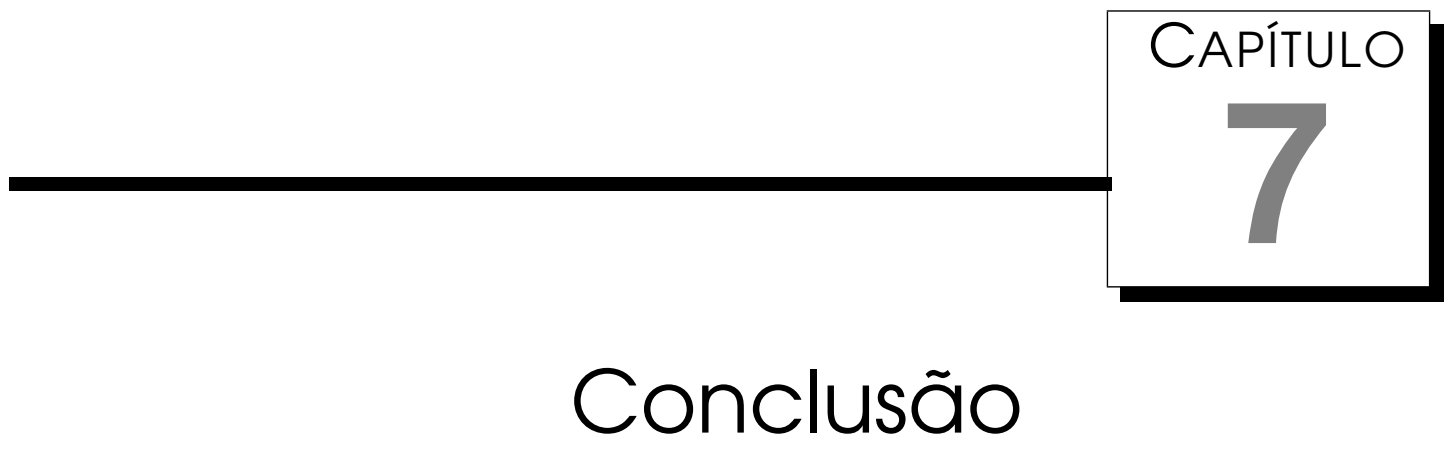

$\mathcal{E}$ stamos na era da informação, e o maior maneira de compartilhar e disseminar essa informação é por meio da Internet. A Internet possui milhões de sites dos mais diversos tópicos e cresce de maneira descontrolada. Para oferecer e organizar essa informação de maneira simples para o usuário existem diversos motores de busca na $W E B$, que tem suas bases na recuperação de informação. Porém, ainda não é uma tarefa simples realizar uma busca na Internet, pois normalmente depende da escolha de palavras-chaves que caracterizem a busca desejada. Muitas vezes essas palavras-chaves não são suficientes para encontrar os sites desejados pelo usuário, pois usuários com interesses diferentes podem digitar palavras-chaves semelhantes com objetivos de buscas diferentes.

A hipótese levantada neste trabalho tem a ver com a possibilidade de criar um filtro de realimentação de relevância utilizando aprendizado de máquina parcialmente supervisionado multidescrição, o qual pudesse reorganizar melhor os resultados de uma busca a partir de indicações do usuário quanto a relevância ou não de um número pequeno de sites.

Neste trabalho foi projetado e implementado um filtro de realimentação de relevância utilizando aprendizado parcialmente supervisionado multidescrição, chamado C-SEARCH, de modo a verificar a hipótese proposta. O CSEARCH foi criado integrando diversas outras ferramentas com funções distintas, tais como:

- o PRETEXT II, utilizado para pré-processamento de textos na tarefa de mineração de textos, o qual foi remodelado a partir da ferramenta PRETEXT objetivando um melhor desempenho computacional, além de mais 
funcionalidades e facilidades para realizar esse processo;

- o algoritmo de aprendizado parcialmente supervisionado multidescrição CO-TRAINING do Discover, o qual foi adaptado para realizar o aprendizado em três etapas que serviram ao propósito deste trabalho; e

- o Yahoo! Search API, como motor de busca para a recuperação inicial dos sites.

O C-SEARCH foi avaliado e comparado ao desempenho do site de buscas Yahoo! a partir de consultas genéricas realizadas por usuários-voluntários que foram responsáveis pelas consultas realizadas e pela classificação manual dos sites retornados na busca como sites relevantes ou irrelevantes, considerando suas opiniões pessoais na busca realizada.

Foi observado que nos casos em que o conjunto de sites relevantes e irrelevantes têm diferenças bem definidas após o pré-processamento dos dados, no qual o site não estruturado é transformado em um formato estruturado, i.e. tabela atributo-valor, para que seja possível a utilização do algoritmo de aprendizado, o C-SEARCH obteve bons resultados na reordenação dos rankings das consultas. Entretanto, devido ao baixo número de sites que devem ser rotulados pelo usuário como relevantes ou irrelevantes, máximo de $6 \%$ nos experimentos realizados neste trabalho, é importante que esses poucos sites sejam "fortemente" relevantes ou "fortemente" irrelevantes. Porém, foi observado que após indicar um, dois ou até no máximo três sites relevantes, o usuário é menos cuidadoso na indicação dos sites a serem rotulados como irrelevantes. Em outras palavras, não há a preocupação em distinguir sites pouco relevantes de sites muito (fortemente) irrelevantes. Como a qualidade dos poucos exemplos rotulados é um fator importante para o algoritmo de aprendizado parcialmente supervisionado obter bons resultados, a realimentação de relevância realizada com usuários que têm esse comportamento fica prejudicada.

Foi observado que o C-SEARCH obtem bons resultados principalmente em pesquisas ambíguas que retornam sites fortemente irrelevantes, e nas quais o usuário não encontra na primeira busca no Yahoo! muitos sites relevantes no primeiro grupo de 10 sites. Acreditamos que nesses casos, como o usuário deve analisar um número maior de sites procurando os sites relevantes para rotular, encontra mais sites fortemente irrelevantes durante a sua procura pelos relevantes. Dessas maneira, o problema descrito previamente quanto ao usuário não distinguir bem sites pouco relevantes de fortemente irrelevantes é aliviada.

Pesquisas com muitos sites relevantes ou muitos irrelevantes, normalmente não obtem melhora nos resultados, a não ser que as informações con- 
tidas nos sites tenham diferenças muito marcantes. Outra observação tem a ver com casos nos quais os sites relevantes e irrelevantes contêm muita informação similar e relacionada, para os quais o C-SEARCH não obteve resultados satisfatórios. O que acontece nessa situação é que os sites não são fortemente irrelevantes ou relevantes, assim, eles não apresentam diferenças marcantes independentemente do que o usuário indicar.

Durante os testes com os usuários, foi solicitado a realização da realimentação de relevância independente do resultado inicial retornado pelo Yahoo! Search API. fazendo então que o C-SEARCH obtivesse $33.3 \%$ de resultados positivos. Porém, alguns dos resultados iniciais poderiam já ser considerados satisfatórios considerando que, por exemplo, a obtenção de mais da metade de sites relevantes no primeiro grupo de dez sites retornados pelo buscador é um resultado satisfatório. Neste caso, somente 9 das 18 realimentações realizadas - Tabela 6.1, página 53 - seriam consideradas necessárias, e o C-SEARCH passaria a apresentar $55.6 \%$ de resultados positivos.

Considerando os resultados das consultas analisadas, os mesmos podem ser considerados promissores. Entretanto são resultados iniciais. Assim, um número maior de consultas deverá ser analisada futuramente para chegar a resultados mais conclusivos. Como trabalhos futuros, pretendemos realizar mais experimentos com usuários-voluntários, mas alertando aos usuários para rotular, sempre que possivel, sites fortemente irrelevantes, com o objetivo de comprovar as considerações apresentadas quando ao comportamento do C-SEARCH.

Outro aspecto do C-SEARCH a ser considerado no futuro, está relacionado a otimização da implementação realizada, pois resultados de busca na WEB devem ser apresentadas rapidamente ao usuário. Na implementação atual, após ativar a opção "Realimentar" o sistema demora de 10 a 15 segundos para retornar os novos rankings dos sites. Esse tempo deve ser diminuído consideravelmente na versão melhorada.

Finalmente, ainda que realizado como um trabalho em paralelo, mas muito importante para o desenvolvimento deste trabalho, deve ser ressaltada a otimização e as novas funcionalidades implementadas na atual ferramenta de pré-processamento de textos PRETEXT II, que substitui a ferramenta anterior PRETEXT. A ferramenta está disponível para download no site http: //www.icmc.usp.br/ caneca/pretext.htm e já tem sido e está sendo utilizada em pesquisas em mineração de textos por alunos de mestrado e doutorado tanto do ICMC-USP quanto de outras instituições de pesquisa. Vários desses usuários já expressaram sua satisfação com a nova ferramenta PRETEXT II, e sugeriram a implementação de mais funcionalidades que serão incorporadas futuramente. 


\section{Referências Bibliográficas}

Baeza-Yates, R. A. \& B. A. Ribeiro-Neto (1999). Modern Information Retrieval. ACM Press / Addison-Wesley. Citado na página 15.

Batista, G. E. A. P. A. (2003). Pré-processamento de dados em aprendizado de máquina supervisionado. Tese de Doutorado, ICMC-USP. http://www . teses.usp.br/teses/disponiveis/55/55134/tde-06102003-160219/.

Citado na página 34.

Blum, A. \& T. Mitchell (1998). Combining labeled and unlabeled data with COTRAINING. In Proceedings of the 11th Annual Conference on Computational Learning Theory (COLT), New York, USA, pp. 92-100. ACM Press. Citado nas páginas 7,8 , e 12 .

Chapelle, O., B. Schölkopf, \& A. Zien (2006). Semi-Supervised Learning. Cambridge, MA: MIT Press. Citado na página 6.

Collins, M. \& Y. Singer (1999). Unsupervised models for named entity classification. In Proceedings of the Joint SIGDAT Conference on Empirical Methods in Natural Language Processing and Very Large Corpora, pp. 100-110. Citado na página 8.

Deng, L., X. Chai, Q. Tan, W. Ng, \& D.-L. Lee (2004). Spying out real user preferences for metasearch engine personalization. In Proceedings of the 6th WebKDD workshop: Webmining and Web Usage Analysis, pp. 22-25. http: //www.cs.ust.hk/ wilfred/paper/webkdd04.pdf. Citado nas páginas 2 e 18 .

dos Santos, M. A. M. R. (2002). Extraindo regras de associação a partir de textos. Dissertação de Mestrado, PUC-PR, Curitiba. http://www.ppgia. pucpr.br/teses/DissertacaoPPGIa-MariaRoveredo-062002.pdf. Citado na página 16. 
Hastie, T. \& R. Tibshirani (1998). Classification by pairwise coupling. In M. I. Jordan, M. J. Kearns, \& S. A. Solla (Eds.), Advances in Neural Information Processing Systems, Volume 10. MIT Press. Citado nas páginas 29 e 30.

Hotho, A., A. Nürnberger, \& G. Paaß (2005, MAY). A brief survey of text mining. LDV Forum - GLDV Journal for Computational Linguistics and Language Technology 20(1), 19-62. Citado na página 23.

Jones, K. S. (1972). A statistical interpretation of term specificity and its application in retrieval. Journal of Documentation 28, 11-21. Citado na página 26.

Jones, R. (2005). Learning to extract entities from labeled and unlabeled text. Tese de Doutorado, Carnegie Mellon University. http://www. lti.cs.cmu. edu/Research/Thesis/RosieJones2005.pdf. Citado na página 12.

Keerthi, S., S. Shevade, C. Bhattacharyya, \& K. Murthy (2001). Improvements to Platt's SMO algorithm for SVM classifier design. Neural Computation 13(3), 637-649. Citado nas páginas 29 e 30.

Kiritchenko, S. \& S. Matwin (2001). Email classification with CO-TRAINING. In Conference of the Centre for Advanced Studies on Collaborative research, pp. 192-201. IBM Press. Citado na página 9.

Luhn, H. P. (1958). The automatic creation of literature abstracts. IBM Journal of Research and Development 2(2), 159-165. Citado na página 24.

Maeireizo, B., D. Litman, \& R. Hwa (2004). CO-TRAINING for predicting emotions with spoken dialogue data. In The Companion Volume to the Proceedings of 42nd Annual Meeting of the Association for Computational Linguistics (ACL), Barcelona, Spain, pp. 202-205. Association for Computational Linguistics. Citado na página 9.

Manning, C. D. \& H. Schütze (Eds.) (1999). Foundations of Statistical Natural Language Processing. Cambridge, Massachusetts: MIT Press. Citado na página 16.

Matsubara, E. T. (2004). O algoritmo de aprendizado semi-supervisionado CO-TRAINING e sua aplicação na rotulação de documentos. Dissertação de Mestrado, ICMC-USP, São Carlos, SP. http: / / www.teses.usp.br/teses / disponiveis/55/55134/tde-19082004-092311/. Citado nas páginas 10 e 40 .

Matsubara, E. T., C. A. Martins, \& M. C. Monard (2003). PreTexT: Uma ferramenta para pré-processamento de textos utilizando a abordagem bag-ofwords. Technical Report 209, ICMC-USP. ftp://ftp.icmc.sc.usp.br/ 
pub/BIBLIOTECA/rel_tec/RT_209.pdf. Citado nas páginas 23, 24, 25, e 29.

Matsubara, E. T., M. C. Monard, \& G. E. Batista (2005). Utilizando algoritmos de aprendizado semi-supervisionados multi-visão como rotuladores de texto. In Anais do Workshop em Tecnologia da Informação de da Linguagem Humana (TIL2005), pp. 2108-2117. Citado na página 9.

Matsubara, E. T., M. C. Monard, \& R. C. Prati (2006). On the class distribution labelling step sensitivity of CO-TRAINING. In IFIP AI '06: Artificial Intelligence in Theory and Practice, pp. 199-208. Citado na página 57.

Mitchell, T. M. (1997). Machine Learning. McGraw-Hill. Citado nas páginas 5 e 11 .

Muslea, I., S. Minton, \& C. A. Knoblock (2000). Selective sampling with redundant views. In Proceedings of the 17th National Conference on Artificial Intelligence and Twelfth Conference on Innovative Applications of Artificial Intelligence, pp. 621-626. AAAI Press / The MIT Press. http://www.isi .edu/ integration/papers/muslea00-aaai.pdf. Citado na página 12.

Muslea, I., S. Minton, \& C. A. Knoblock (2002). Active + semi-supervised learning $=$ robust multi-view learning. In ICML 2002: Proceedings of the 19th International Conference on Machine Learning, Sydney, Australia, pp. 435-442. Morgan Kaufmann. http: / / www. fetch.com/resources / muslea-minton-knoblock_ICML2002.pdf. Citado nas páginas 8 e 12 .

Muslea, I. A. (2002). Active Learning With Multiple Views. Tese de Doutorado, University Southerm California. http://www.isi.edu/integration/ papers/muslea02-thesis.pdf. Citado nas páginas 7 e 8.

Nigam, K., A. K. McCallum, S. Thrun, \& T. M. Mitchell (2000). Text classification from labeled and unlabeled documents using EM. Machine Learning 39(2/3), 103-134. http: / /www.kamalnigam.com/papers / emcat-mlj99.pdf. Citado nas páginas 6 e 12 .

Orengo, V. M. \& C. R. Huyck (2001). A stemming algorithmm for the portuguese language. In String Processing and Information Retrieval Symposium (SPIRE), pp. 186-193. Citado nas páginas 29, 30, e 31.

Porter, M. F. (1980). An algorithm for suffix stripping. Program 14(3), 130137. http://tartarus.org/ martin/Porterstemmer/def.txt. Citado na página 17 . 
Porter, M. F. (2001). Snowball: A language for stemming algorithms. http: //snowball.tartarus.org/texts/introduction.html. Citado na página 17.

Porter, M. F. (2006). An algorithm for suffix stripping. Program: electronic library and information systems 4O(3), 211-218. Citado na página 17.

Prati, R. C. (2003). O framework de integração do sistema Discover. Dissertação de Mestrado, ICMC-USP. http://www.teses.usp.br/teses/ disponiveis/55/55134/tde-20082003-152116/. Citado nas páginas 30, 34 , e 39.

Quinlan, J. R. (1993). C4.5: Programs for machine Learning. Morgan Kaufmann. Citado nas páginas 29 e 30.

Rezende, S. O., J. B. Pugliesi, E. A. Melanda, \& M. F. Paula (2003). Mineração de Textos (1 ed.), Volume 1 of 1, Chapter 13, pp. 337-370. São Paulo, Brasil: Editora Manole. Citado na página 23.

Riloff, E., J. Wiebe, \& T. Wilson (2003). Learning subjective nouns using extraction pattern bootstrapping. In Proceedings of the 7th Conference on Natural Language Learning (CoNLL), pp. 25-32. Citado na página 7.

Robertson, S. (2004). Understanding inverse document frequency: On theoretical arguments for idf. Journal of Documentation 60(5), 503-520. Citado na página 26.

Rosenberg, C., M. Hebert, \& H. Schneiderman (2005). Semi-supervised SELFTRAINING of object detection models. In Proceedings of the 7th IEEE Workshop on Applications of Computer Vision / IEEE Workshop on Motion and Video Computing (WACV/MOTION), pp. 29-36. Citado na página 7.

Ruthven, I. \& M. Lalmas (2003). A survey on the use of relevance feedback for information access systems. The Knowledge Engineering Review 18(2), 95-145. http://inex.is.informatik.uni-duisburg.de: 2004 /pdf/ker_ruthven_lalmas.pdf. Citado na página 18.

Schwartz, R., T. Christiansen, \& L. W. Pyle (1997). Learning Perl. California. Citado na página 23.

Sebastiani, F. (2002). Machine learning in automated text categorization. ACM Comput. Surv. 34(1), 1-47. Citado na página 25.

Soares, M. V. B. (2009). Documento interno - Avaliação experimental do sistema C-SEARCH. http://labic.icmc.usp.br/resultados/caneca. Citado nas páginas 51 e 53. 
Soares, M. V. B., R. C. Prati, \& M. C. Monard (2008a). Melhorando o desempenho computacional e a geração de atributos na ferramenta de préprocessamento de textos PRETExT. In N. P. Kuri \& P. C. L. Segantine (Eds.), Iniciação Científica e Tecnológica: o jovem pesquisador em ação, São Carlos. Citado nas páginas 23 e 27.

Soares, M. V. B., R. C. Prati, \& M. C. Monard (2008b). Melhorias do algoritmo de Stemming do Porter para o português. In II Workshop on Computational Intelligence, Salvador. International Joint Conference SBIA, SBRN, JRI. Citado nas páginas 23, 28, 30, e 31 .

Soares, M. V. B., R. C. Prati, \& M. C. Monard (2008c). PreTexT II: Descrição da reestruturação da ferramenta de pré-processamento de textos. Technical Report 333, ICMC-USP. http://www. icmc.usp.br/ biblio/BIBLIOTECA/ rel_tec/RT_333.pdf. Citado na página 23.

Soares, M. V. B., R. C. Prati, \& M. C. Monard (2009). Melhorias do algoritmo de Stemming do Porter para o português. IEEE América Latina. In print. Citado nas páginas 23 e 28.

Weiss, S. M., N. Indurkhya, \& T. Zhang (2005). Text Mining : Predictive Methods for Analyzing Unstructured Information. Nova Iorque, EUA: Springer. Citado na página 23.

Witten, I. H. \& E. Frank (2005). Data Mining: Practical Machine Learning Tools and Techniques (2 ed.). Morgan Kaufmann. Citado na página 30.

Zipf, G. (1949). Human Behaviour and the Principle of Least Effort. AddisonWesley. Citado na página 24. 